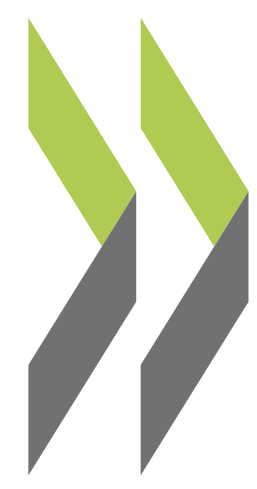

OECD Local Economic and Employment Development (LEED) Papers 2012/01

\title{
Enabling Local Green
}

Growth: Addressing Climate Change Effects on Employment and Local

\section{Gabriela Miranda, Graham Larcombe} Development 


\title{
Enabling Local Green Growth
}

\author{
Addressing Climate \\ Change Effects on \\ Employment and \\ Local Development
}

GREEN GROWTH STRATEGY

STRATÉGIE POUR UNE CROISSANCE VERTE

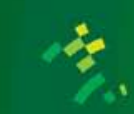
\&

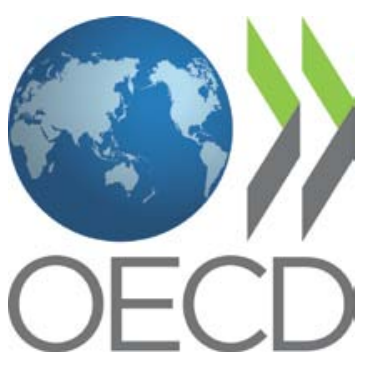



A REPORT BY THE OECD

LOCAL ECONOMIC AND EMPLOYMENT DEVELOPMENT (LEED) PROGRAMME

ENABLING LOCAL GREEN GROWTH:

ADDRESSING CLIMATE CHANGE EFFECTS ON EMPLOYMENT AND

LOCAL DEVELOPMENT

2012 


\section{ORGANISATION FOR ECONOMIC CO-OPERATION AND DEVELOPMENT}

The OECD is a unique forum where governments work together to address the economic, social and environmental challenges of globalisation. The OECD is also at the forefront of efforts to understand and to help governments respond to new developments and concerns, such as corporate governance, the information economy and the challenges of an ageing population. The Organisation provides a setting where governments can compare policy experiences, seek answers to common problems, identify good practice and work to co-ordinate domestic and international policies.

The OECD member countries are: Australia, Austria, Belgium, Canada, Chile, the Czech Republic, Denmark, Estonia, Finland, France, Germany, Greece, Hungary, Iceland, Ireland, Israel, Italy, Japan, Korea, Luxembourg, Mexico, the Netherlands, New Zealand, Norway, Poland, Portugal, the Slovak Republic, Slovenia, Spain, Sweden, Switzerland, Turkey, the United Kingdom and the United States. The European Commission takes part in the work of the OECD.

This work is published on the responsibility of the Secretary-General of the OECD. The opinions expressed and arguments employed herein do not necessarily reflect the official views of the Organisation or of the governments of its member countries. This document and any map included herein are without prejudice to the status of or sovereignty over any territory, to the delimitation of international frontiers and boundaries and to the name of any territory, city or area.

You can copy, download or print OECD content for your own use, and you can include excerpts from OECD publications, databases and multimedia products in your own documents, presentations, blogs, websites and teaching materials, provided that suitable acknowledgment of OECD as source and copyright owner is given. All requests for public or commercial use and translation rights should be submitted to rights@oecd.org. Requests for permission to photocopy portions of this material for public or commercial use shall be addressed directly to the Copyright Clearance Center (CCC) at info@copyright.com or the Centre français d'exploitation du droit de copie (CFC) contact@cfcopies.com. 


\section{FOREWORD}

At the OECD Ministerial Council Meeting in June 2009, Ministers acknowledged that green and growth go hand-in-hand and adopted the Declaration on Green Growth. On this occasion, Ministers asked the OECD to develop a Green Growth Strategy to provide guidance and recommendations on the programmes and initiatives required to facilitate the transition to a green economy. In developing this strategy, the OECD Local Economic and Employment Development (LEED) Programme proposed the project 'Climate Change, Employment and Local Development' to examine the impacts of climate change on labour markets and local development, as well as to assist participants in managing the transition to a low-carbon economy.

Most national and local governments have made ambitious commitments to mitigate climate change and to adapt the new environmental and regulatory conditions, while combating unemployment. This project has offered a unique opportunity to participant cities and regions to assess the potential of job creation and local development while moving to a greener economy. The project has assisted participants in identifying their challenges and barriers hindering green growth, while finding ways to exploit the opportunities and prepare the labour markets to the new context.

This project has brought to light the importance of pursuing an economic strategy with a flexible approach to labour market, environment and economic policies, while ensuring their coordination. The findings also highlight the necessity to build capacities on local economic and environmental policies to effectively support job creation in the transition to a green economy. The LEED Programme contributes to these, and hence continues to be a relevant source of knowledge and expertise for member countries.

This work stream is led by Gabriela Miranda, LEED Policy Analyst who also prepared this report with inputs from other experts. The main findings and recommendations have fed into the OECD Green Growth Strategy launched at the 2011 OECD Ministerial Council Meeting. The project has benefitted from the participation of Extremadura (Spain), London (UK), Podlaskie and Pomorskie (Poland) and Sydney (Australia). It has also received financial support from the European Commission, DG Employment, Social Affairs and Equal Opportunity.

I believe that the identification of best practices and the benchmark of approaches offer an invaluable opportunity to improve policies and programmes across the OECD. I am sure that the content of this report will contribute to making a fairer, cleaner and stronger economy of our member countries.

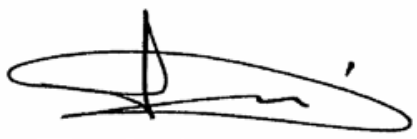

Sergio Arzeni

Director, OECD Centre for Entrepreneurship Head, OECD LEED Programme 


\section{ACKNOWLEDGEMENTS}

The project on Climate Change, Employment and Local Development has been undertaken by the Local Economic and Employment Development (LEED) Programme of the Organisation for Economic Co-operation and Development (OECD). This project and work stream was led by Ms Gabriela Miranda, policy analyst in the OECD LEED Programme.

The OECD is grateful to all participant regions in this project: Extremadura (Spain), London (UK), Podlaskie and Pomorskie (Poland) and Sydney (Australia). The regions of Trento (Italy) and Styria (Austria) hosted interesting field visits which allowed the possibility to identify other approaches and good practices. The European Commission, DG Employment, Social Affairs and Equal Opportunity, provided a financial contribution towards this project. The work would not have been possible without the engagement and continuous support of the various stakeholders in each of the participating cities and regions.

Additional thanks go to the various experts that shared their knowledge and contributed with chapters for the country reports, including: Mr. Hyoung-Woo Chung, Policy Analyst at the OECD Employment Analysis and Policy Division, Prof. David Gibbs, Department of Geography, University of Hull, UK; Mr. Richard Howard, Analyst of DTZ Consulting in the UK; Ms Lisa Rustico, research fellow at the Department of Economics of the University of Modena and Reggio Emilia in Italy; Mr. Andy Westwood, chairman of the OECD Forum on Social Innovations; Ms Bettina Schaefer, founding member of Ecoinstitut Barcelona; Mr. Mads Greaker, Head of research for the Section for Economic Growth and Environmental Economics at the Research Department in Statistics Norway; Ms Cecilia Estolano, Senior Consultant in Green For All USA; Mr. Kris Krasnowski, Labour Market Analyst at the Greater London Authority; Prof. Paul Dalziel, Lincoln University New Zealand; Mr. Graham Larcombe, Director Strategic Economics Australia; Prof. Randall Eberts, President Upjohn Institute for Employment Research USA, Ms. Elvira González, Economist at the Tomillo Centre for Economic Studies; Ms. Vanessa Foo, Senior Analyst at The Economist Intelligence Unit; Prof. Przemyslaw Kulawczuk, University of Gdansk in Poland. Mr. Graham Todd, consultant, UK; Ms. Teresa Alvarado, consultant, USA; Ms. Gabriela PrataDias from CEEETA-ECO, Consultores em Energia, Lda in Portugal; Mr. Peter Garforth and Mr. Dale Medearis from Northern Virginia Regional Commission \& Garforth International USA; and Mr. Carlos Hinojosa, Technopolis France, also provided valuable contributions at different stages of the project.

Thanks are also due to OECD colleagues for their comments on a preliminary draft version. Dr. Cristina Martinez-Fernandez and Ms. Debra Mountford, OECD LEED policy analysts provided useful comments throughout the project. Mr. Damian Garnys, OECD research assistant, prepared the surveys and ran the platforms. Mr. Raffaele Trapasso, from the OECD Rural and Regional Development Unit, facilitated information from the project on "Renewable Energy as a Regional Development Policy for Rural Areas”. Ms. Céline Kauffmann, from the OECD Regulatory Policy Division provided useful material for the completion of this report. Valuable comments were received from Mr. Andrea Beltramello and Mr. Tomoo Machiba, from the OECD Structural Policy Division and Mr. Paul Swaim, from the OECD Employment Analysis and Policy Division.

Mr. Roland Schneider, Senior Policy Adviser of the Trade Union Advisory Committee (TUAC) to the OECD; Mr. Kees Van der Ree, Green Jobs Programme Co-ordinator at the International Labour 
Organisation (ILO); and Ms. Joanna Obarymska-Dzierzgwa and Mr. Przemyslaw Herman from the Ministry of Regional Development of Poland provided useful comments on the draft report.

This report was drafted and prepared by Ms. Gabriela Miranda, OECD LEED policy analyst, with inputs from Mr. Graham Larcombe, Strategic Economics Australia. Ms Michela Meghnagi, statistical analyst in the OECD LEED Programme, provided valuable contributions notably on the survey analysis. 



\section{TABLE OF CONTENTS}

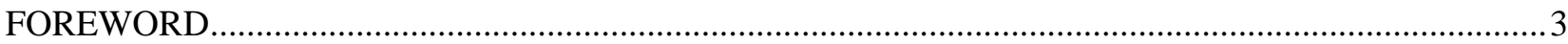

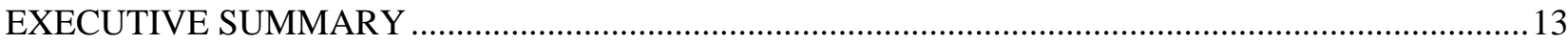

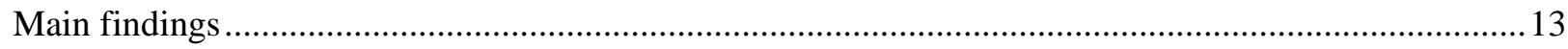

A framework for local sustainable economic development …...............................................................17

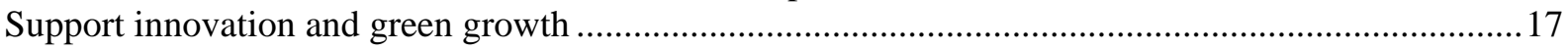

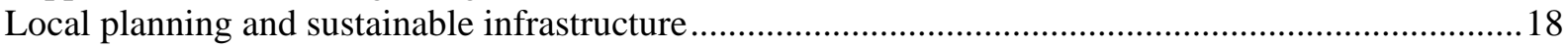

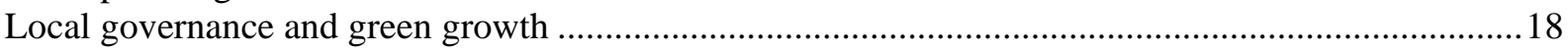

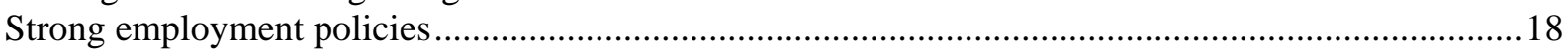

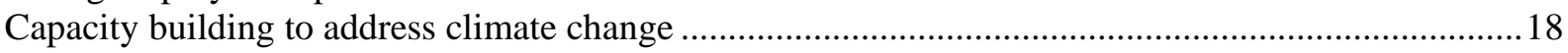

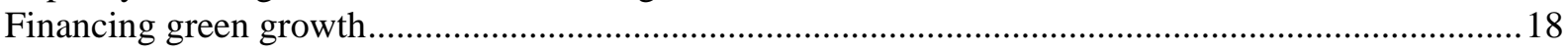

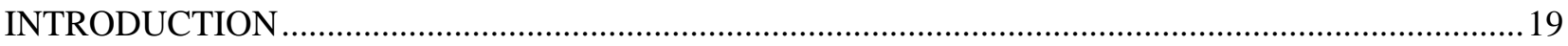

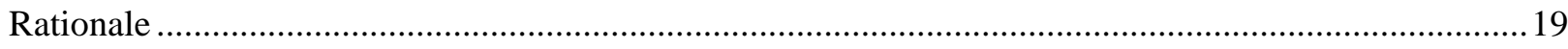

CHAPTER 1. THE LOCAL CONTEXT FOR ACTION ON CLIMATE CHANGE …............................23

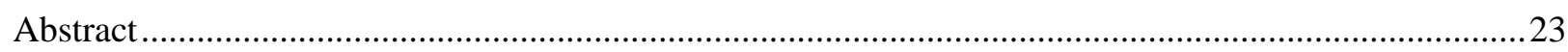

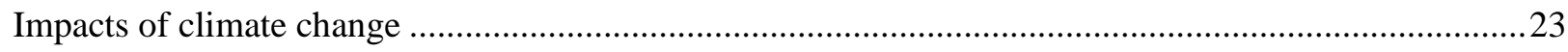

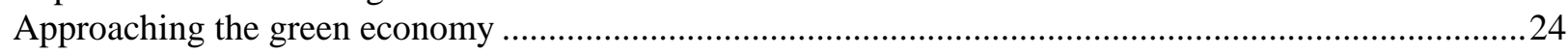

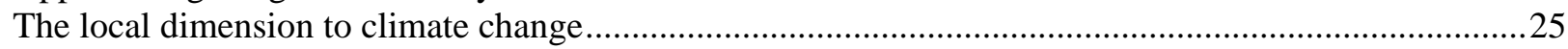

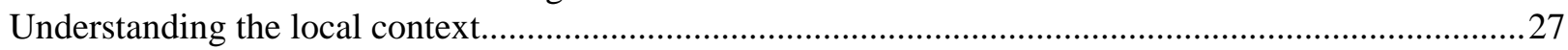

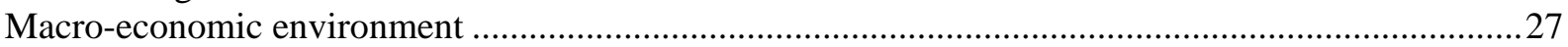

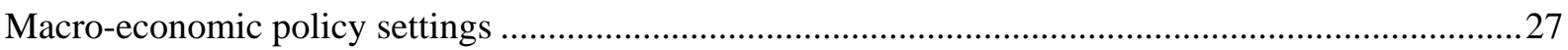

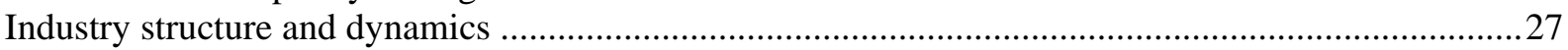

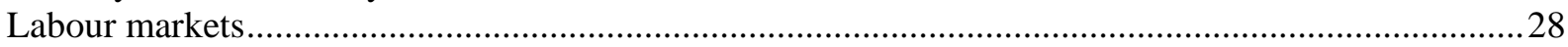

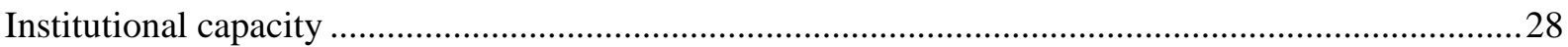

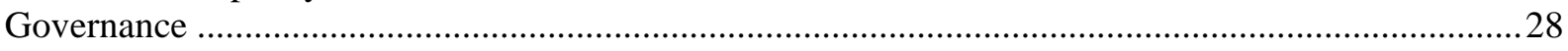

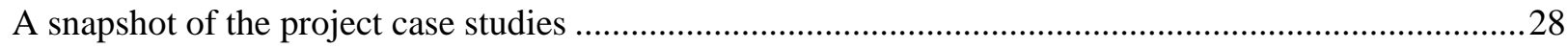

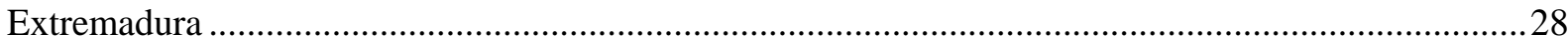

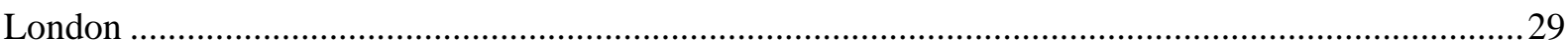

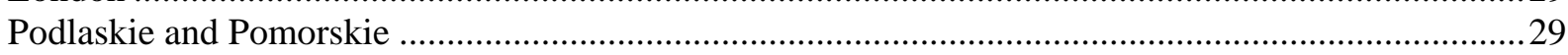

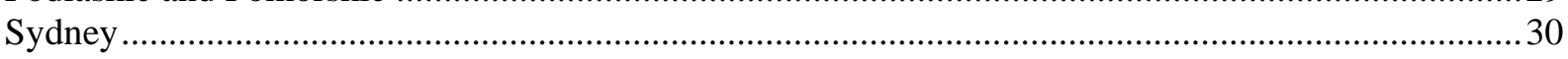

CHAPTER 2. LOCAL LABOUR MARKETS: GREENING JOBS AND SKILLS .................................33

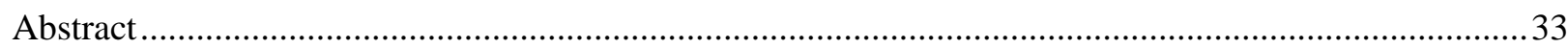

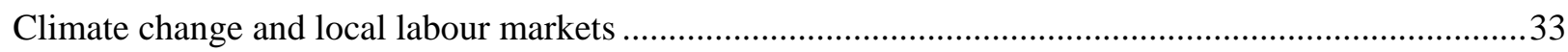

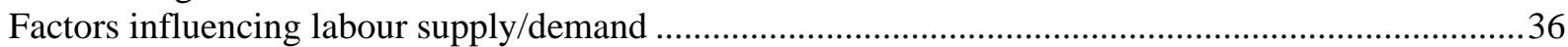

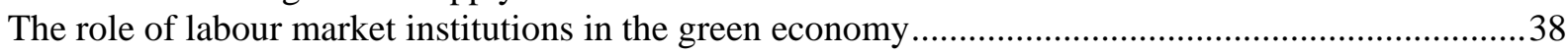

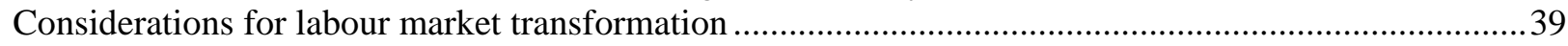

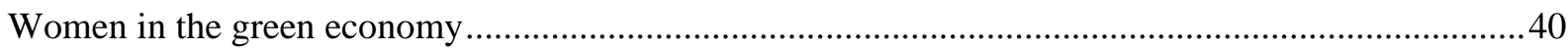

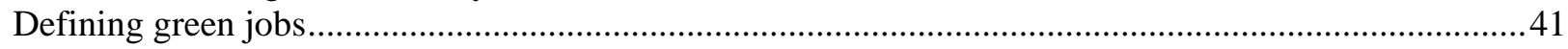

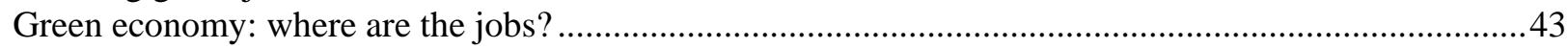

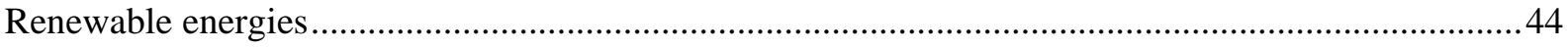

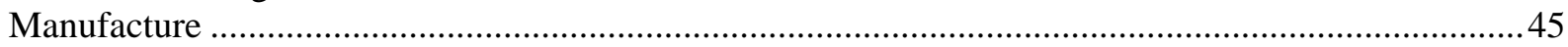




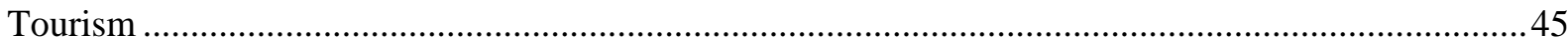

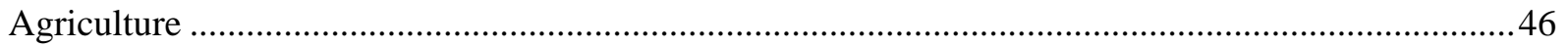

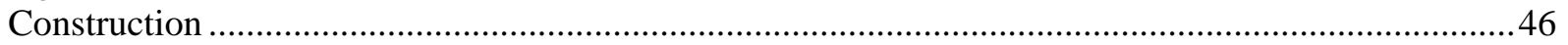

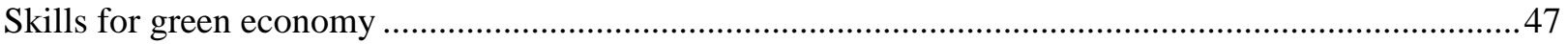

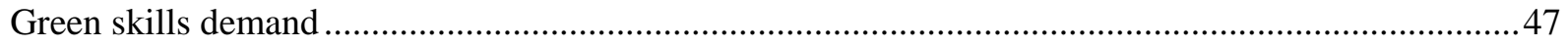

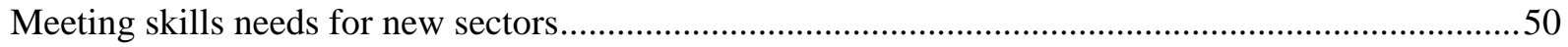

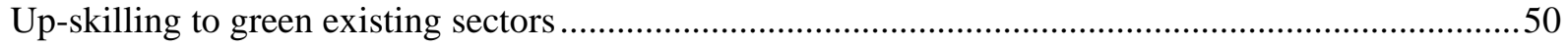

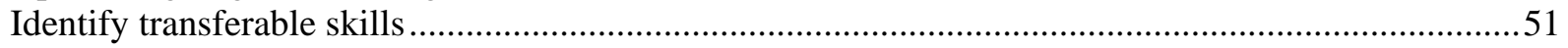

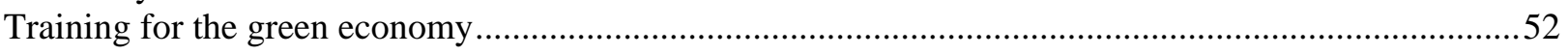

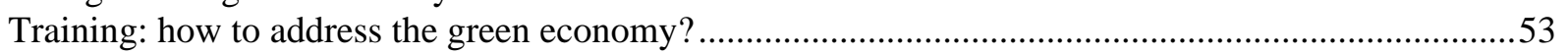

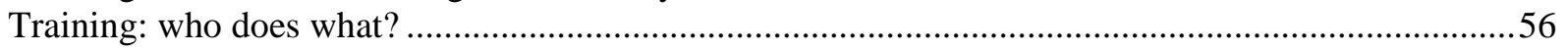

CHAPTER 3. INDUSTRY DYNAMICS AND THE GREEN ECONOMY .............................................61

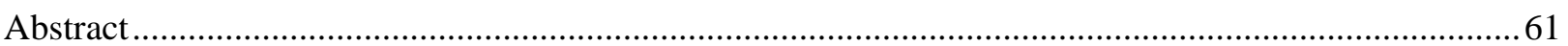

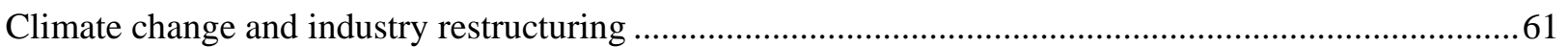

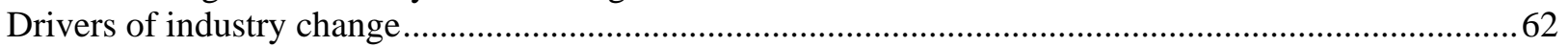

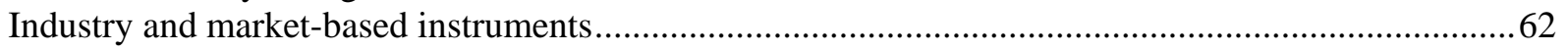

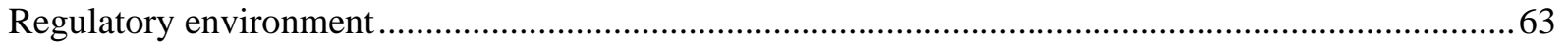

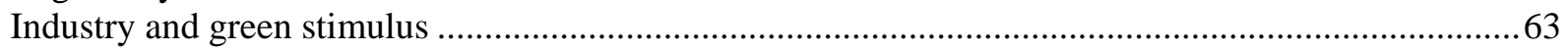

Household behaviour and consumer preferences .................................................................................64

Emerging industry models in response to climate change .....................................................................64

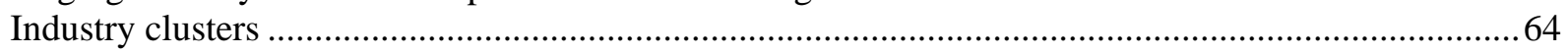

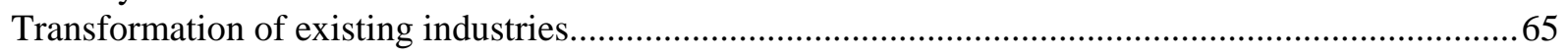

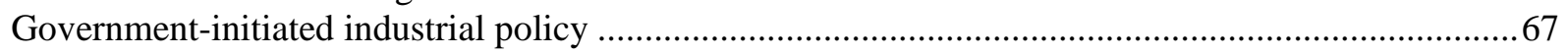

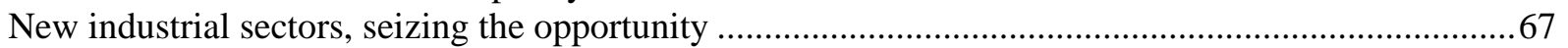

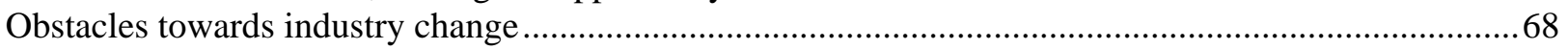

Lack of information regarding low-carbon economic opportunities......................................................68

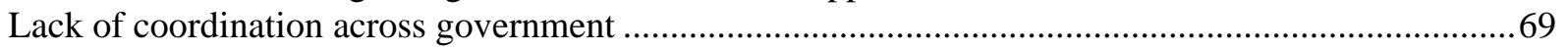

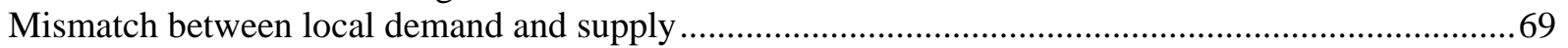

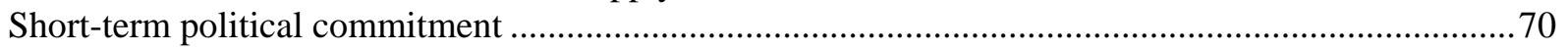

CHAPTER 4. THE ROLE OF PUBLIC SECTOR IN SUPPORTING LOCAL GREEN GROWTH .......73

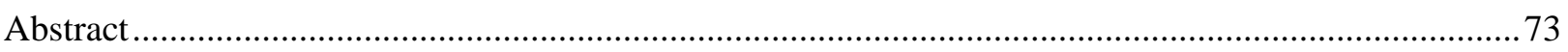

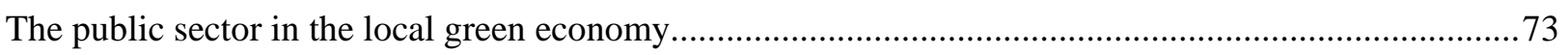

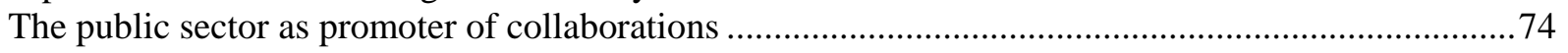

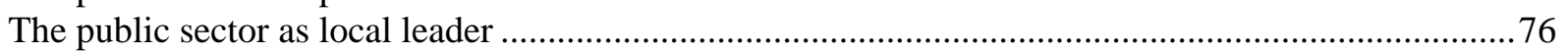

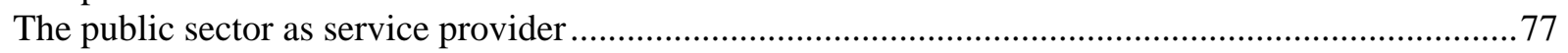

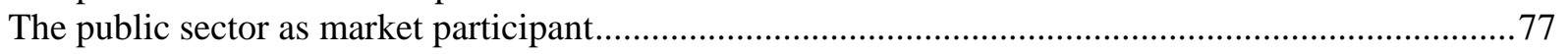

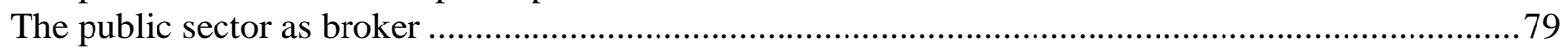

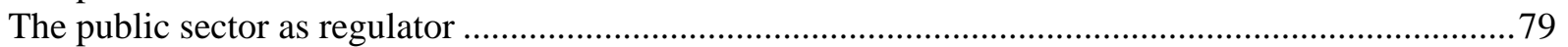

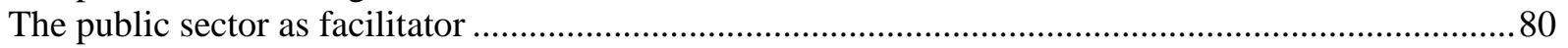

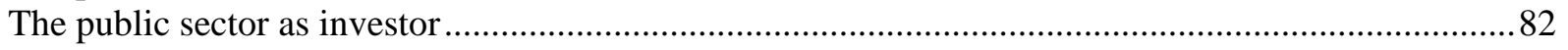

CHAPTER 5. ENABLING LOCAL GREEN GROWTH …....................................................................8 85

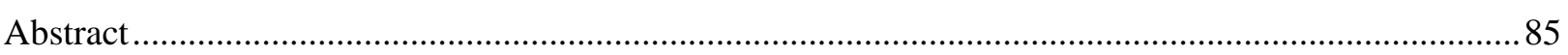

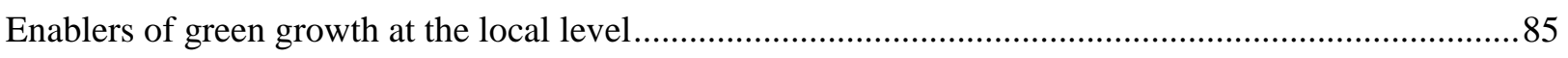

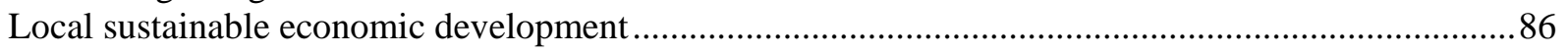

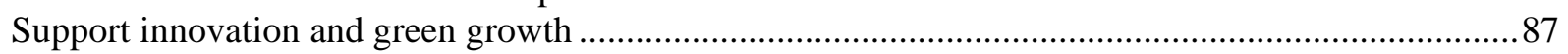

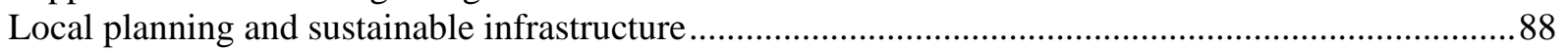

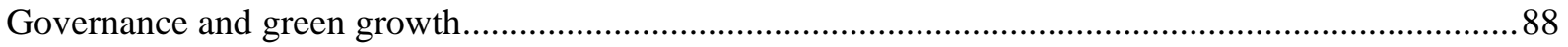

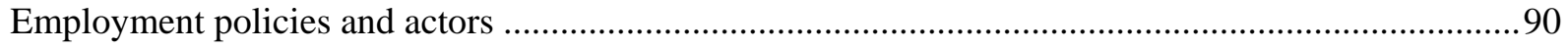




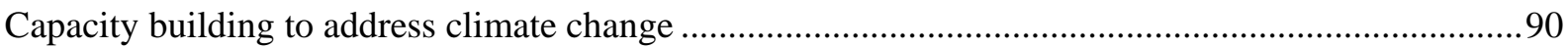

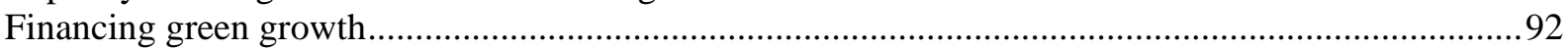

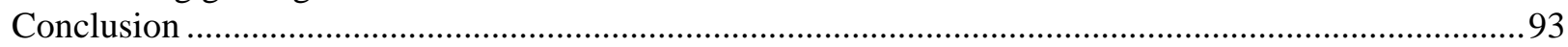

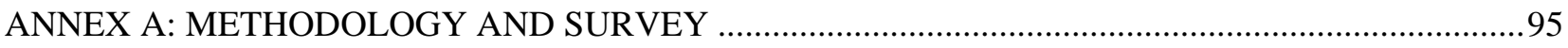

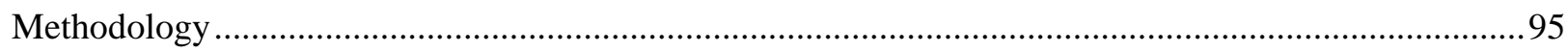

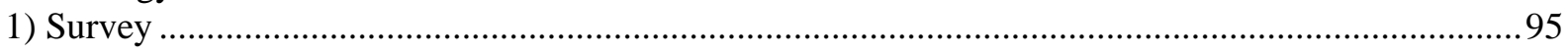

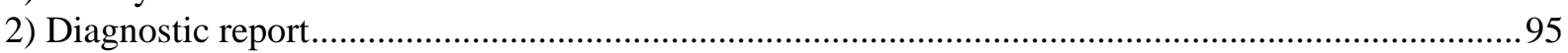

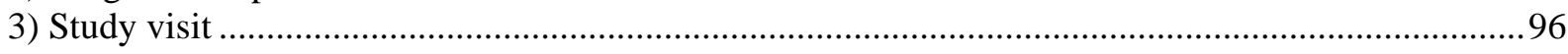

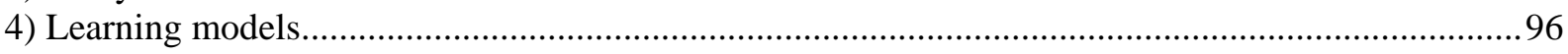

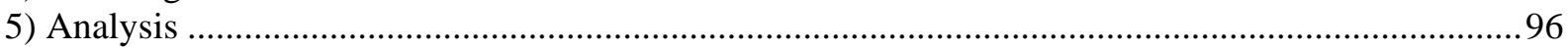

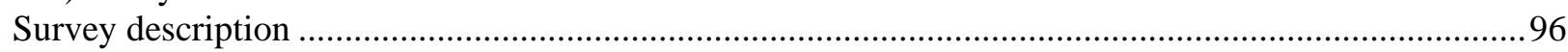

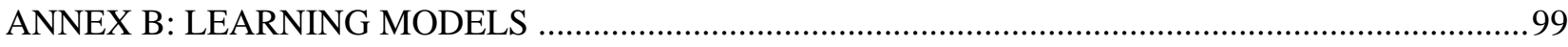

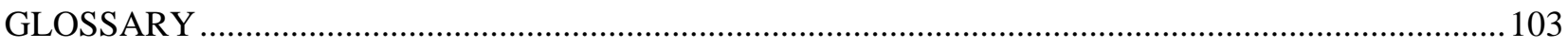

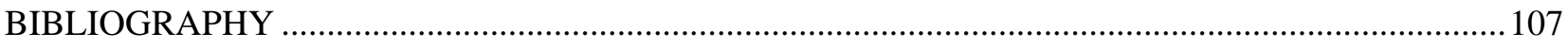

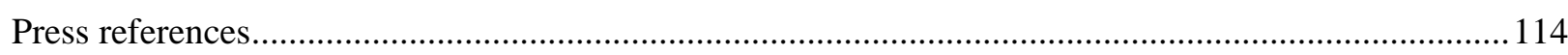

\section{Tables}

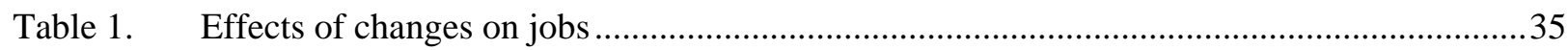

Table 2. Impact of climate change by sector in Extremadura ............................................................37

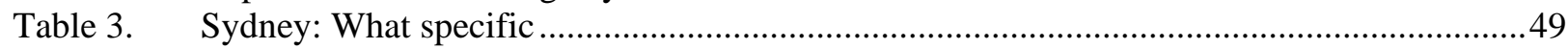

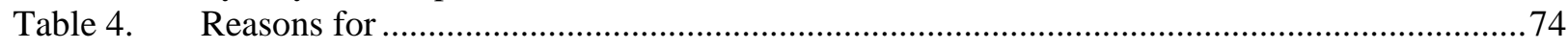

Table 5. Extremadura and Sydney: surveyed enterprises by sector .................................................97

Table 6. London: surveyed enterprises by sector ............................................................................97

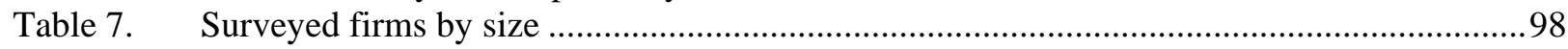

\section{Figures}

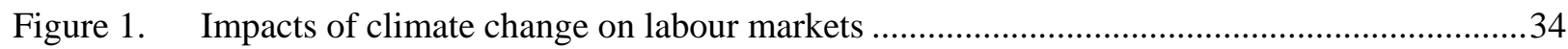

Figure 2. Extremadura and Sydney: What are the main reasons for the changes? ...............................36

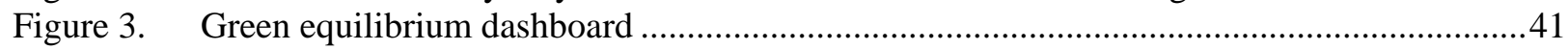

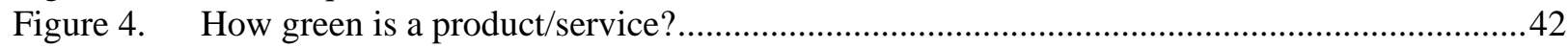

Figure 5. Representation of the green economy ..............................................................................4

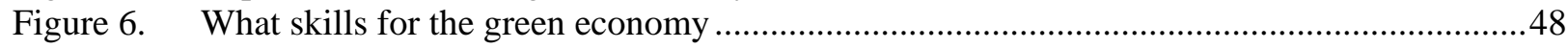

Figure 7. Sydney: What skills were needed in the new jobs? ............................................................49

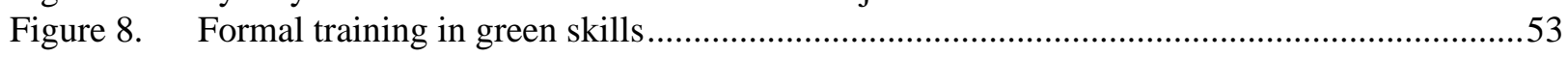

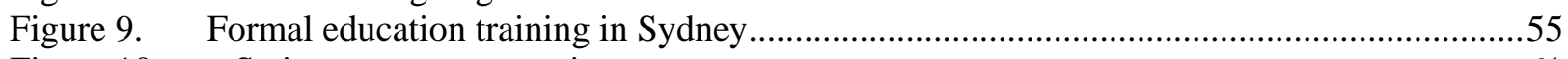

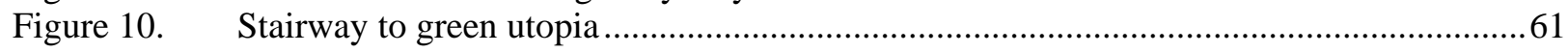

\section{Boxes}

Box 1. Local labour market institutions in the green economy …........................................................38

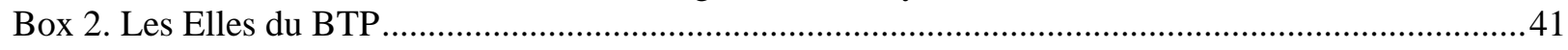

Box 3. Defining Green Jobs: The Case of London ................................................................................43 


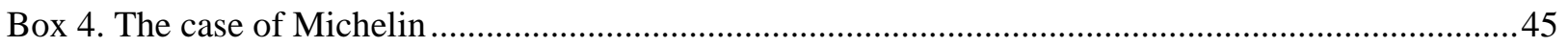

Box 5. South Styrian Cooperative for Energy Production, Mureck ............................................................46

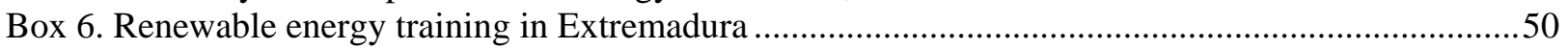

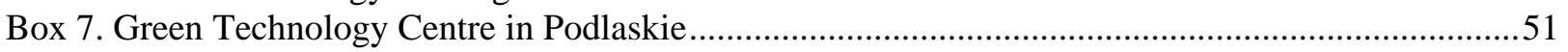

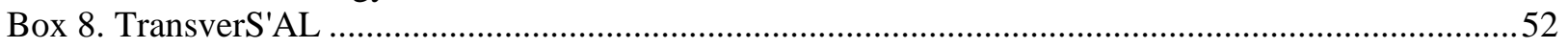

Box 9. Bartosz company: On-the-job training provision .......................................................................54

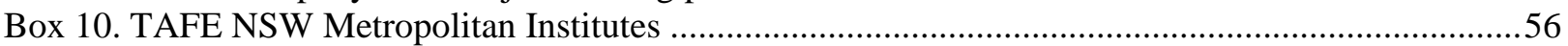

Box 11. Cooperatives as training providers: The case of Trento, Italy.................................................58

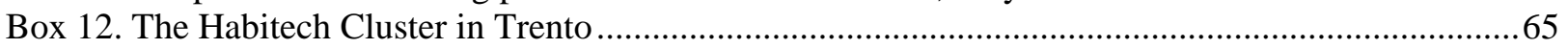

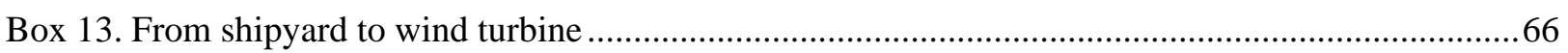

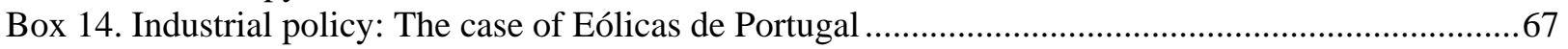

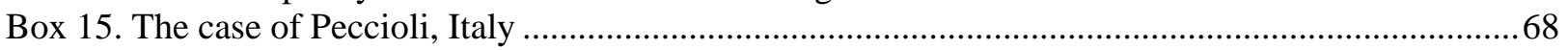

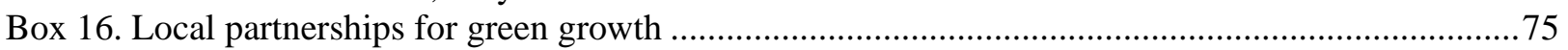

Box 17. Workforce Innovation in Regional Economic Development (WIRED) ...................................76

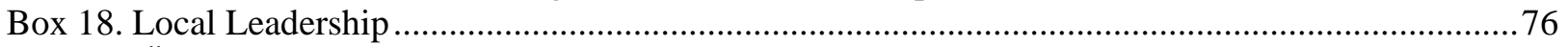

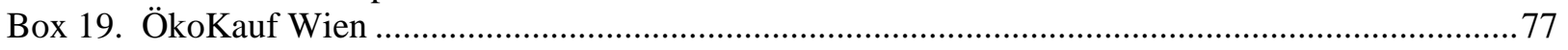

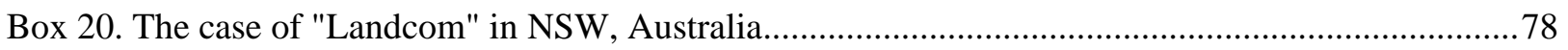

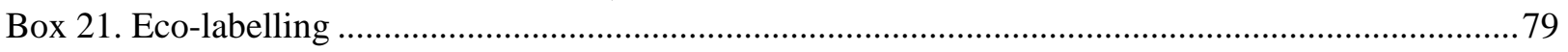

Box 22. Kristianstad: Using Biogas to Transform a Community ...........................................................8

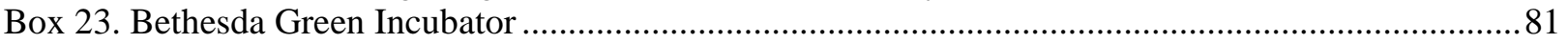

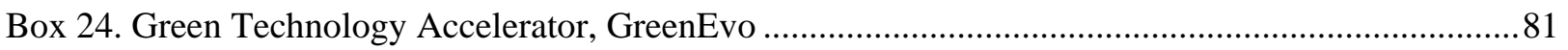

Box 25. Seven elements of an effective green growth strategy at local level..........................................86

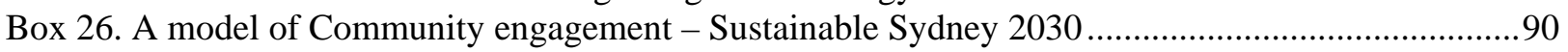

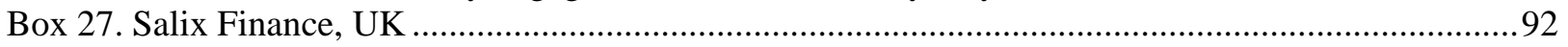





\section{EXECUTIVE SUMMARY}

This report is concerned with challenges and opportunities to grow local economic activity, employment and skills in response to climate change. Globally, there is a broad consensus that urgent action is required to reduce greenhouse gas emissions. More countries are establishing targets and programmes to reduce emissions and, increasingly countries are putting a price on carbon pollution. While at the macro level the implications of climate change are widely acknowledged and acted upon, it is at the local level that impacts need to be considered in detail. The barriers to the transition to a low-carbon economy are most acutely experienced at the local level.

Focusing on the local dimension, it is important to emphasise three distinctive features of this period. Firstly, the global community is working towards new policies and regulations to make the transition to a green economy. Irrespective of global and national policy frameworks, there is a great deal of momentum and local initiatives which need to be aligned with global and national frameworks. Secondly, the international community acknowledges that urgent action is required on climate change and that it is preferable to act sooner rather than later. The report emphasises that the transition to a green economy will take time, but cost effective options to reduce carbon pollution cannot be delayed. Thirdly, the transition to a low-carbon economy is taking place during a period of unprecedented economic turbulence, making it imperative to concentrate on initiatives that can strengthen economic and employment outcomes locally.

The report draws on analysis case study reports: Extremadura (Spain), London (United Kingdom), Podlaskie and Pomorskie (Poland) and Sydney (Australia). These case studies, and selective firm and institutional surveys, demonstrate specific challenges confronting very different types of locality. The report also draws on a number of learning models from public and private sectors in a number of countries. These learning models demonstrate innovative ways that local areas are integrating responses to climate change with new economic and employment opportunities. What role can public authorities play in the transition to a green economy? How can policies encourage business creation in green-related sectors? What are the obstacles facing skills provision for the green economy? How to approach job creation in the green economy? These and other questions are addressed in this report, and also provide a series of best practices that illustrate the various approaches suggested.

\section{Main findings}

Through the process of shifting economies from high carbon intensive to low-carbon activities some new jobs will be created, some jobs will be lost and many jobs will be restructured involving upgrading of existing skills. The aim is to support local areas, be they cities, rural areas or small communities, to manage the transition to a low-carbon economy by developing an appropriate set of initiatives that align them with global and national policies, whilst reinforcing their ability to coordinate and take action at the local level. By looking at case studies in four countries in some detail, and drawing on experiences in others, this report takes a "bottom-up" view of action on climate change.

Many terms associated with the green economy are used interchangeably - such as the greening economy, low-carbon economy, sustainable development and green growth. To date, there is not a consensus on what is meant by these different terms. This makes it difficult to identify programmes and projects, implement them and to measure outcomes. It also creates some confusion and policy incoherence. 
The report proposes that local areas need clarity about how they define these terms in order to ensure coherence in preparing, implementing and monitoring local green strategies.

Analysis of the impacts, challenges and opportunities associated with climate change at the local level and coordination of responses between governments, business, employment, educational and training agencies and households is critical if action on climate change is to be effective. The transition to a lowcarbon global economy requires concerted action at all levels. Local areas are comprised of distinct concentrations of industries, households and infrastructure networks and many are major greenhouse gas emission generators in their own right. The agglomeration of innovative capacity, business networks and skills in localities, particularly cities, are important foundations to generate and diffuse new technologies and practices. Changes in behaviour are increasingly driven, not just by prices, but also through interaction between firms, authorities, researchers, public sector agencies, and councils. This project also found that public policies are an important driver of change among businesses, and that the level of environmental awareness of the population has also an important effect on industry.

The transition to a low-carbon economy creates challenges for local labour markets. Business surveys undertaken for this project indicate that the number of direct jobs created is relatively small. But the implications across all industries may be profound. Many existing jobs will evolve into "greener" jobs as the requirements of the economy (and jobs) adjust to meet the changing consumer demand, government regulation and technological and market innovations. Many existing jobs and workplaces will begin to adapt to incorporate sustainability practices in the workplace. The skills the economy needs will change too, as green growth becomes the goal of governments. The cost of not making adjustments in industries and labour markets may also be significant, as the "green attributes" of products and services become an increasingly important factor in industry competition. It is important that local areas undertake concrete analysis and modelling of labour market changes.

A successful transition to a low-carbon economy requires close coordination of demand and supply for labour. Evidence from this project demonstrates that the most successful adjustments and transitions to a green economy have taken place in cities and regions where the labour market institutions are well aware of the challenges and opportunities of the green economy. The analysis of the various case study regions also concludes that the transition to a green economy requires strong institutional capacity and a robust system of labour market data collection and analysis. The project found that the quality of the jobs is enhanced when labour market institutions, the education and training system and the industry communicate regularly, as well as when social partners (notably trade unions) are involved in the process of transformation.

On the demand side, local firms need to be able to anticipate changes in demand associated with market forces and regulatory changes. They need to be adaptable and flexible to enable them to respond quickly to these changes. Trade unions and workers associations play an important role in supporting the anchorage of local jobs and training, and in facilitating industry information valuable for the local labour market. Similarly, the efficiency of local employment service providers is an important factor to ensure the transition, as these provide support for businesses in a locality, monitor their employment needs, and analyse the industry trends and business plans. The recognition of the skills available locally and the identification of transferrable skills from shrinking sectors to expanding sectors is also an important factor.

On the supply side, the quality of training and further education institutions, and their relationships with businesses and local public agencies, as well as the availability and long-term funding of programmes, are important factors in aligning supply with demand. In some cases, it may be easier to transform labour markets in good economic times, when unemployment is low and participation of different cohorts women, young people and older workers - is high. Similarly, industry dynamics are important. Some industries are restructuring themselves to shift resources out of mature or declining industries in order to 
focus on high growth "green" related sectors. For example, the report cites the case of how skilled automobile workers in Styria, Austria, became an important resource for emerging clean tech clusters.

The transition not only needs to be efficient, but it also needs to be seen to be fair. Many of the new jobs in the emerging green economy are traditional, male oriented jobs in construction and manufacturing. In addition, many emerging jobs are for high-skilled professionals, and in some localities, there is a concern that the loss of high paid jobs will not be replaced with jobs with commensurate skills and remuneration. Local strategies need to highlight how initiatives to strengthen the low-carbon economy will be broadly shared, paying special attention to expanding opportunities for women, younger people and lower skilled workers.

Skills are central to building local green economies, but this project did not identify any specific "green" skills. Most occupations in the public and private sector will have a shade of green to a certain extent. Surveys undertaken for the project suggest that the skills demanded by firms in the context of the transition to a greener economy will continue to be relatively generic including literacy, numeracy, team working, communication and problem solving. In emerging low-carbon sectors, more emphasis is put on more technical, trade and professional skills. These new "green skills" seem to be a mix of generic skills with a component of new specialised skills for specific sectors.

Training needs for the green economy are not very different from the needs in the traditional economy. One of the major challenges is to make "green" training available to SME's in ways that are relevant, flexible and affordable. In most countries, there continues to be a low level of demand in training for green skills due to limited availability of green training facilities and the difficulties in designing relevant curricula for businesses in their adjustment process. The report puts forward a number of possible solutions to improve green training. Firstly, the report finds that training institutions should concentrate on a solid basis of generic and core skills, combined with positive attitudes and add-on training in green skills. Secondly, the report suggests that a more structured system of linking employers, HEIs / VET institutions and labour market institutions with one another to identify skills gaps and develop skills development responses will support the transition. Thirdly, there needs to be more emphasis on greening the curricula across disciplines, rather than emphasising specialised courses. Finally, this project suggests that the recognition of informally acquired qualifications is an important way to up-skill the labour force and to respond rapidly to an emerging demand. This flexible approach would ease the transition to new or greener occupations.

The report looks at the implications of climate change policy on local industry. It identifies four key drivers that are impacting industry investment and employment decisions: (1) market-based policy instruments, (2) the regulatory environment, (3) green stimulus packages, and (4) household behaviour and consumer preferences.

A key theme of the report is integrating low-carbon initiatives with local economic development. Linking local carbon reduction, not only with the costs of abatement, but also through identifying and implementing new economic opportunities is central. Some localities aim to support early-mover enterprises that are seeking to enhance competitiveness in high growth green economy industries. Conversely, industries and local economies that do not invest in low-carbon technologies will be at risk of being locked out of low-carbon growth markets and may experience a reduced market share in traditional industries.

One of the central issues for localities is how to address barriers that impede engagement of local industries to the low-carbon economy. Many companies, particularly SMEs, do not have good information about the most efficient carbon abatement measures. Some companies lack good market intelligence about emerging opportunities. They often do not have the skills and internal resources to address emerging 
challenges, such as the implications of climate change policy, and will continue to engage in more carbon and energy intensive activities even if the life cycle costs of low-carbon technologies are lower. Some firms will not invest in low-carbon R\&D and innovation measures over concern that other companies will exploit the opportunities.

Given the barriers, regulations can establish favourable market conditions for rapid sustainability innovation. Regulations can spur innovation within localities, businesses and across supply chains, and increasingly push enterprises up the value-added chain. Evidence from this project confirms that the regulatory environment is also a driver of industry change. A successful transition to a low-carbon economy will therefore require a combination of market-based and regulatory policies to drive innovation and diffusion of low-carbon technologies, practices and processes. Low-carbon regulations need to be designed in a way that they complement market-based instruments and not compete with them.

The report outlines a number of learning models that aim to accelerate industry dynamics in different conditions. The learning models highlight the wide range of options available to localities. This includes identification and development of green industry clusters, transformation of existing industries towards the green economy, government-initiated industrial policy to facilitate technology transfer and industry spillovers, and growing new industrial sectors. In order to accelerate industry dynamics, the report outlines strategies that address obstacles towards industry change including overcoming lack of information regarding low-carbon economic opportunities, improving coordination across the public sector, aligning local demand and supply, and long-term political commitment.

To be effective, governments at all levels must have a clear and decisive strategy, and policies must be coordinated vertically and horizontally among all relevant government units. Markets are tightly integrated and extend beyond regional and national boundaries. Public policies have to be similarly integrated and coordinated. Local initiatives need to be aligned to national policies. Moreover, it is essential that the public sector aligns education, employment and economic development policies at regional levels to ensure that there is clarity in the vision and strategy in general. The importance of coherent, multi-level green governance is therefore a key element in maximising the potential of a local green strategy. The public sector has a key role to play in ensuring this national-local coordination and in removing policy barriers that hamper green growth.

The report outlines a typology of public sector roles. One key role for the public sector is to build and support local networks and partnerships. Through regional ministries and labour market institutions, the public sector can work to strengthen collaboration between businesses, trade unions, civil society, education institutions, economic development agencies and local authorities to ensure that public initiatives and programmes aimed at greening the economy are well defined, effectively implemented and meet the local needs.

The analysis highlights the importance of public sector leadership in supporting the development of green growth at the local level, including through pricing carbon pollution, regulations and support measures that underpin the transition. As shown in the cases of London and Sydney, successful local strategies require strong local leadership through raising awareness, setting targets and spearheading various initiatives. The public sector is an important service provider in its own right. Hence, strengthening the institutional capacity of local and regional authorities is essential to ensure a better definition, coordination and implementation of priority actions in relation to the green economy. The report cites the importance of public sector green procurement strategies to build market opportunities for local firms.

Finally, the report finds that eco-labelling is an important means of influencing household consumption. Increasingly local authorities are using eco-labelling to educate households about the advantages of purchasing green products. However, eco-labelling needs to have clear criteria and be 
evaluated regularly to ensure that the consumer understands the features and to avoid creating confusion. Similarly, local authorities are using green branding and positioning to support the green economy and drive industry change. Also, the public sector can take more direct measures to support the growth of the green economy through fostering green entrepreneurs and innovation and providing grants and subsidies to industries that are shifting towards low-carbon activities.

The report develops a framework to support localities to integrate economic development initiatives with environmental well-being. The starting point is to analyse the specific features and context of the locality in question. Local features include industry structure and dynamics, energy sources, energy consumption patterns, institutional capacity, skills and technological trajectories. The report aims to assist different types of localities strengthen their response to climate change, enhancing opportunities for green growth at the local level. It focuses on seven enablers of green growth at the local level:

\section{A framework for local sustainable economic development}

The report suggests that an effective green growth strategy be based on the following elements:

- Articulation of a clear vision for green growth.

- Identify potential local green clusters and implement strategies that build on local assets and encourage collaboration.

- Invest in green infrastructure and leverage public assets to build a green economy.

- Integrate demand-driven workforce development strategies with green economic development policies through meaningful partnerships.

- Foster creativity and innovation through collaborations among universities and research institutions, venture capital and other investors, industry innovators and government.

- Utilise the different roles of government - regulator, consumer, landowner, convenor and investor - to ensure they are aligned with green growth.

- Engage citizens, businesses and other stakeholders in developing green growth policies and maintaining their interest in assisting in the implementation and monitoring of such policies.

\section{Support innovation and green growth}

Innovation at the local level is central to combating climate change. To be effective, innovation initiatives in response to climate change will need to drive change across the whole economy. This will only occur if knowledge and learning about sustainable technologies and practices are diffused across the economy. For this to happen, there needs to be a focus on strengthening collaboration between firms, government, councils and households at the local level. The report emphasises the importance of incremental innovation at the local level that innovation across firms, particularly SMEs, and the workforce.

Local innovation associated with carbon reduction initiatives is likely to be most effective when it is tailored to meet emerging local demand whilst addressing local barriers to take-up low-carbon technologies. 


\section{Local planning and sustainable infrastructure}

Planning for climate change adaptation and mitigation is becoming an important issue. Understanding the geographical impacts of climate change on localities and preparing adaptation measures is a part of this. Cities and regions are places where much planning takes place. This includes land use planning, which sets out areas where jobs, housing, research and education facilities, and infrastructure will be located. Some localities are establishing low-carbon precincts or zones as in the case of London. These are geographical areas where a range of co-ordinated actions take place over a period of time with the objective of reducing carbon emissions. The report encourages localities to shift planning and infrastructure priorities from infrastructure that contributes to carbon intensive activities, either directly or indirectly, and towards an infrastructure that results in lower emissions such as public transport.

\section{Local governance and green growth}

Improving governance is an essential enabler of green growth. To be effective, governments at all levels will need to work towards policy alignment and coherence. Evidence gathered from this project suggests that there are three principles that should guide governance at the local level: strong leadership, building partnerships and community engagement.

\section{Strong employment policies}

The job effects of the transition to a green economy will depend on a variety of conditions. However, the effectiveness and quality of employment policies can contribute to ensuring that the transition runs smoothly, that the jobs created are fair, and that the green economy is inclusive. Labour market institutions, including trade unions, should be placed at the centre of the debates to define and implement strong employment policies.

\section{Capacity building to address climate change}

The transition to a low-carbon economy will require changes in the way individuals and organisations function. Attention needs to be given to finding cost-effective ways to support capacity building, not only to meet immediate priorities, but also to underpin longer term norms and values that will deliver lowcarbon growth.

\section{Financing green growth}

The transition to a low-carbon economy requires major investments in infrastructure, plant and equipment, technology and skilling people. The economic as well as environmental benefits are becoming clearer, but there are many financial barriers, many of them at the local level, that slow the transition. Evidence from this project confirms that one of the challenges at the local level is how to evaluate and assess the risks associated with emerging low-carbon technologies and projects. Finally, all localities need to strengthen entrepreneurial capabilities to identify projects, coordinate partners and to develop a business case to financial institutions to provide finance for these opportunities. 


\section{INTRODUCTION}

The OECD LEED project on "Climate Change, Employment and Local Development" focuses on the adjustments required to ensure labour markets comply with the demands of a greener economy (adaptation) as well as on the expansion of good quality green jobs as an opportunity to develop lowercarbon activities (mitigation). It aims at providing the support and advice that national and local actors need to maintain their employment levels while expanding into greener activities. The project also provides guidance on policy interventions and actions suitable to develop quality employment in the greener economy, with a multi-stakeholder approach.

The project methodology is described in Annex A. This report presents the analysis of the various case studies undertaken as part of this project ${ }^{1}$, and draws on the best practice models identified in other countries as part of the project (see Annex B). Although it is not possible to come to firm conclusions based on case studies of very different places, there are a number of common issues that these localities are dealing with that are relevant to other localities wanting to engage and encourage industries in pursuing opportunities in the low-carbon economy.

This report summarises the main analysis and draws recommendations from the four full case studies, supported by the surveys, as well as other learning models, case studies and workshops organised as part of this project.

\section{Rationale}

The OECD (2008c) carried out a projection to attempt to reflect how the future economy and environment might evolve in the absence of new policies or unforeseen disturbances regarding climate change. Although it is not a prediction of the future, the model showed that there will be a considerable change in the worldwide distribution of the labour force. While in real numbers the overall labour supply will increase, the OECD share will fall from 20\% in 2005 to 16\% in 2030. Whilst this is not exclusively a direct consequence of climate change, the figures do reflect the drop of the labour force share in the absence of policies to tackle climate change, which highlights that the challenge of job creation will remain at all levels.

Relying on the market to identify skills gaps and develop solutions to them is causing delays in the transition to a green economy. Governments at national and local levels should play a more active role in preparing the labour market and providing the skills needed to meet greener economic needs. Some efforts have been shown in this regard from central governments as the awareness on climate change has arisen.

As the OECD argues, the local level can provide a key contribution to the strategies for human resources development as these must be integrated and matched to the economic reality on the ground (OECD, 2008e). Hence, labour market institutions at the local level should be able to make decisions and provide strategic orientations in the implementation of public programmes and services, as they have a better knowledge of local business practices, local economic conditions, and industry developments. In partnership with other local stakeholders, labour market institutions could identify skills gaps and deficiencies in current and future green economic sectors, and use this as a basis for developing broad strategic skills and labour market orientations locally.

This report is concerned with the impacts of climate change on employment at the local level and with the challenges and opportunities to grow economic activity, employment and skills in response to climate 
change. The starting point is that in the process of shifting economies from high carbon intensive to lowcarbon activities some new jobs will be created, some jobs will be lost and many jobs will be restructured involving upgrading of existing skills. The findings seek to support local areas, be they cities, rural areas or small communities, to manage the transition to a low-carbon economy by developing an appropriate set of initiatives that align them with global and national policies, while reinforcing their ability to coordinate and take action at the local level.

The "local level" refers to all economic and governance units that operate at the sub-national level. Local areas encompass places where people live and where they work ranging from rural communities to metropolitan areas. The local level is the arena where different public and private agencies can develop meaningful relationships to take action in response to a range of challenges, including the globalisation of economies, the emergence of knowledge-based economies, and increasingly responding to environmental stress and adapting to climate change and implementing mitigation measures. At the local level, these subnational areas see opportunities to stimulate and restructure their economies by capitalizing on ecoinnovation, and new product and service development. By looking in some detail at the case studies of four countries, and drawing from the experiences of others, this report takes a "bottom-up" view of action on climate change. How are localities responding to the threat of climate change? How well are local initiatives aligned to global and national policy frameworks on climate change? How can local action on climate change maximise employment outcomes? How can government agencies better coordinate their responses on climate change?

It should be recognised that the transition to a low-carbon economy will not be costless. However, following the Stern report, the consensus amongst economists is that it will be less costly to take action in the short term rather than to delay action. Local areas are responding to climate change in an era of economic turbulence and uncertainty. Globally, governments are focused on the economic crisis and ways to restart economic growth during a period of high unemployment, low demand, high public and private debt, as well as financial fragility. One of the central challenges of the current crisis is how to integrate economic development with improved environmental outcomes. Following the onset of the global financial crisis, many governments focused on "green industries" and "green jobs" through support for activities and skills that encourage the transition towards a "greener future". Growing concern about the impacts of climate change is at the centre of this debate. It is increasingly apparent that a green economy will not suddenly appear. In parallel to other great transformations of the past 30 years, such as globalisation and the growth of knowledge-based economies, the transition to a low-carbon economy is a long-term process.

As discussed in the conceptual report of this project ${ }^{2}$, the need to match future skills needs with the demand for businesses to produce greener products and services will be a challenge for businesses and the labour market in general. Labour market institutions at the local level will bear the price of having to cope, on one side, with overarching regulations (e.g. national) that will impose restrictions in terms of production processes and economic activity, while seeking to implement incentives to modify consumer habits and therefore stimulate greener business activity on the other side. Three issues appeared to be essential to guarantee a smooth transition towards and adaptation to the green economy which are the core of this research.

Firstly, the transformation of jobs and the emerging skills requirements in the context of a greener economy will have to be identified and supported to achieve economic growth, by both firms and the labour market. Local authorities have an important role to play in assisting businesses in anticipating their skills needs and in putting in place the right programmes for workforce development in order to match human capital supply and demand in a given locality. A better understanding of the direct (i.e. market demand) and indirect (i.e. through regulations) impacts of climate change on existing job profiles and on 
the skills needs for new green activities is necessary so that labour market agents can define and implement the right policy mix to ensure the availability of a pertinent workforce.

Secondly, as businesses and other stakeholders face the challenges of complying with climate change stipulations and regulations, many economic opportunities may arise. If consumer habits are modified accordingly, the whole supply system (products and services) can expand significantly, resulting in the creation of jobs. With the right set of incentives and by showing the example, public authorities at the local level can stimulate the transformation of consumer habits to pull the demand of greener supplies and assist businesses in seizing the opportunities arising from a greener market.

Finally, there are various mechanisms and practices that could be used to facilitate transformation and adaptation of local labour markets to greener demands. As labour markets evolve, businesses and other stakeholders will have to adjust their production methods and outputs. Public authorities could play a key role in assisting economic agents to adapt their activities in order to maintain and create more and good quality jobs that are relevant to the current situation.

This project addressed the three issues above and examined the impacts of climate change (including through its effect on policy and regulations) on local labour markets, with a focus on the creation of green jobs and the development of a skilled workforce to meet the needs of the greener economy. In particular, the project identifies and assesses the:

1. impacts of climate change on job profiles and skills requirements on the work place;

2. challenges and opportunities arising for the work of public services and other stakeholders in the relevant policy areas, while meeting new demands and complying with regulations; and

3. mechanisms and practices used to facilitate transformation and adaptation of local labour markets to greener demands.

The project and this report are part of a series of activities produced in the context of the OECD Green Growth Strategy, which seeks to provide a framework to enable countries to pursue economic growth and development while combating climate change and preventing costly environmental degradation. The OECD Report Towards Green Growth defines green growth as "fostering economic growth and development, while ensuring that natural assets continue to provide the resources and environmental services on which our well-being relies”3. Towards Green Growth provides a framework to assist the governments of different countries to identify policies that can support the most efficient shift to green growth. Hence, the present report digs below this level. It looks at the barriers to change at the subnational level such as lack of integration between government agencies and their functional responsibilities, the inability and unwillingness of firms and households to respond quickly to price signals, lack of information, skills shortages and lack of innovative capacity in different localities. These barriers, and others, can only be addressed in a locality specific context.

This report is structured as follows. The first chapter builds the case for the analysis of the local level and the importance of considering externalities (macro-economic framework, regulations, etc) for action. Chapter 2 analyses the impact of climate change on labour markets and discusses the need for job, skills and training approaches to support the transition to a greener economy. The third chapter examines the responses of industry to climate change and identifies drivers of change and barriers hindering industrial transformation. Chapter 4 presents the role that public policy and authorities can play in facilitating the transition to a greener economy. The last chapter concludes with a set of strategic approaches to integrate sustainability into local economic development agendas. The Annex A provides an overview of the project methodology and the survey. Annex B presents a summary of the various learning models identified as 
part of this work. A glossary at the end clarifies the meaning of the terms more often utilised throughout this report.

\section{ENDNOTES}

Four full case studies: Extremadura (Spain), London (UK), Sydney (Australia), Podlaskie/Pomorskie (Poland). Capacity building seminar and study visit: Local strategies for greening jobs and skills (Trento, 9-11 June 2010). Study visit: Styria, Austria (11-13 October 2010). Seminar: Green growth - An opportunity for local development and employment (Paris, 8 December 2010).

Martinez-Fernandez C., Hinojosa C., Miranda G., Greening Jobs and Skills: Labour Market Implications of Addressing Climate Change, OECD Local Economic and Employment Development (LEED) Working Papers, No. 2010/02, OECD Publishing

OECD (2011), Towards Green Growth - a summary for policy makers 


\title{
CHAPTER 1.
}

\section{THE LOCAL CONTEXT FOR ACTION ON CLIMATE CHANGE}

\begin{abstract}
The chapter defines the low-carbon economy and its relationship to the green economy and sustainability. It also outlines the importance of spatial analysis at the sub-national or local level. It is particularly concerned with the way that local action can complement global and national policy frameworks. The transition to a low-carbon economy will only succeed if firms, households and workers are engaged at the local level. Macro-policy instruments, such as a price on carbon, are necessary but not sufficient. Detailed analysis and strategies are required at the local level. The rich experiences of the case studies highlight the positive experiences and lessons of local action on climate change.
\end{abstract}

\section{Impacts of climate change}

The scientific evidence that anthropological activities are resulting in climate change is driving debate and action to shift economies towards a low-carbon and clean-energy path. All OECD countries and their local areas are vulnerable to climate change. Some of the impacts are already measurable. The UK, for example, is already experiencing the effects of climate change in the form of increased sea-surface temperature and rising sea levels. The scientific evidence suggests that Sydney's daily temperatures are now between $0.5-0.9^{\circ} \mathrm{C}$ hotter than the average last century. The metropolitan area is expected to be in the range of $1-3^{\circ} \mathrm{C}$ hotter by 2050 .

Impacts of climate change will vary depending on location. Cities and localities may be more prone to a combination of severe natural events including storms, bush fires, increased sea-surface temperatures, rising sea levels and drought. It is most probable that the increasing incidence of severe weather fluctuations has some association with climate change. The scientific consensus is that unless urgent action is taken to stabilise and reduce greenhouse gas emissions, then irreversible damage will be made to the environment and could possibly trigger calamities that will result in massive human and economic costs.

The seriousness of the climate change challenge has been recognised by the international community and different tiers of government, businesses and civil society in all OECD economies. Public authorities and the private sector will be required to invest more in infrastructure, new methods and services to adapt to climate change.

This report gives more focus to the issue of climate change adaptation and mitigation, which forms a subset of green growth and sustainability. The emphasis on climate change is important because it is recognised that climate change poses a fundamental challenge to the ability of the global economy to sustain historic economic growth rates without causing irreversible environmental consequences, and secondly, there is an imperative need to take short-term action to stabilise greenhouse gas emissions and prevent the risks of more costly and possibly dire consequences.

In responding to the threat of climate change, it is broadly accepted that costs will be imposed on economies, industries and households but, given the risks of delaying action, it will be less costly to take action in the short term to transform economic activity. This entails a commitment to reduce carbon 
pollution from high carbon intensive activities and to accelerate the expansion of low-carbon activities including renewable energy, energy efficient technologies, as well as to foster eco-innovation, including for instance advanced bio-fuels, hybrid and alternative fuel vehicles and waste recycling among others.

\section{Approaching the green economy}

Many terms associated with the green economy are used interchangeably - such as greening the economy, low-carbon economy, sustainable development and green growth. To date, there is not a consensus on what is meant by these different terms. This makes it difficult to identify programmes and projects, implement them and to measure outcomes. It also creates some confusion and policy incoherence. The starting point then is to determine what is meant by these terms in the context of this report.

A low-carbon economy is an economy where production and consumption of goods and services is more sober in carbon emissions. It is expected that over time there will be a major reduction in greenhouse gases in all sectors of the economy. Energy generation will shift over time from high carbon intensive sources such as coal fired power to lower carbon sources such as gas and zero carbon renewables. Vehicles will become more energy efficient and increasingly less reliant on fossil fuels and shift towards hybrids, electric and renewables among others ${ }^{4}$. Energy-intensive industries will either be phased out or will be restructured around energy-efficient technologies. Agricultural systems rely less on fossil fuels and emphasise sustainable farming techniques.

The green economy is different to the low-carbon economy. The green economy designates a set of activities associated with research, technologies and industries, which are directly geared to improve environmental outcomes, reduce pollution, conserve energy and protect natural resources. Their inputs into other sectors enable them to reduce their carbon intensity and enhance environmental outcomes. This includes industries and technologies explicitly aimed at reducing carbon but also includes broader environmental industries such as sewage treatment, environmental protection, soil management, biodiversity protection and wildlife management, and noise and vibration protection. The analysis of opportunities in the green economy is an important tool in assessing economic competitiveness.

Greening the economy is a broader concept. It is a comprehensive strategic approach that aims to improve environmental outcomes of all activities across the economy throughout a certain period, in a process. The latter involves not only the creation of new jobs and skills that did not previously exist, but also improving the "green" components of existing industries and occupations. Greening the economy is closely aligned to a low-carbon economy.

The concept of sustainable development was popularised by the World Commission on Environment and Development ${ }^{5}$. There, sustainable development was defined as a development that meets the needs of the present without compromising the ability of future generations to meet their own needs. ${ }^{6}$ This concept emphasises the broader perspective of sustainability encompassing economic, social and environmental dimensions. Sustainable development provides an important context for green growth.

Green growth has not been conceived as a replacement for sustainable development, but rather should be considered a subset of it. It is narrower in scope, entailing an operational policy agenda that can help achieve concrete, measurable progress at the interface between the economy and the environment. It provides a strong focus on fostering the necessary conditions for innovation, investment and competition that can give rise to new sources of economic growth - consistent with resilient ecosystems ${ }^{7}$.

Low-carbon economic development forms part of broader strategies to encourage sustainable development. In this context the challenge for all localities is how to enhance economic prosperity whilst continuing to improve social equity and environmental outcomes. Economic sustainability is concerned 
with competitiveness and value added production of goods and services. Social sustainability is associated with socio-economic indicators and opportunities for jobs, income, health, education and amenities. Environmental sustainability has carbon reduction as a central focus but it also encompasses biodiversity, air and water quality, waste management land degradation.

While an institutional definition of a low-carbon economy, green economy and sustainable development is an important start in identifying and promoting green growth in a certain place, it presents several problems. Firstly, it may be unclear who subscribes to this definition, raising the specific question of whether governments will agree with it and support it and the extent to which the private sector and broader community is aware of it. Secondly, if the definition is too narrow, focusing mostly on environmental preservation, it leaves the public with the impression that the green economy is about protection, hindering growth. Thirdly, unless the government endorses it and the public is aware of its acceptance, it is difficult for the definition to be used as a focal point for green growth strategies.

\section{The local dimension to climate change}

This report emphasises the local dimension of climate change and the importance of local action to attain the economic and in particular the employment benefits. In OECD countries, much of the responsibility for responding to climate change resides with sub-national agencies. State, provincial and local governments usually have responsibility for infrastructure, planning, economic development, environmental management and education policy. They interact with a range of parties at the local level including the private sector, households, employment and skills organisations and employment agencies.

To date, most of the focus has been on global and national policy frameworks. At the global level, this includes the Kyoto Protocol and international declarations and propositions emanating from Copenhagen and Cancun. It also includes policies and initiatives of national governments including setting greenhouse reduction targets and, in some cases, the introduction of a price on carbon through a carbon tax and/or an emissions trading scheme. Many countries have developed ambitious programmes to foster green growth, including increasing investment in R\&D, tax incentives and subsidies to encourage the growth of lowcarbon industries as well as increased infrastructure investment in public transport, water and waste recycling.

This report identifies four overarching drivers of industry change that enable economic development, innovation and job creation in the context of the transition to a green economy. These drivers are further discussed in Chapter 3, and include: market-based instruments, framework conditions, more direct/targeted policies (both supply-push and demand-pull) and consumer behaviour. The need to foster green entrepreneurship and to support partnerships for sustainability is further discussed in Chapter 4 of this report, as well as other market-pull policies that support the expansion of eco-innovations (e.g. public procurement, smart regulation).

The transition to a green economy poses many challenges for local authorities, particularly in ensuring the development of economic activity in new or cleaner sectors, as well as in terms of making the best use of the human, natural and financial resources available locally. Local 'low-carbon' or 'green' strategies do not fully take into consideration the necessity for enterprises to have a clear picture of the government strategy in order to reach out new markets, neither the need of prioritising in terms of policy intervention. Furthermore, a significant number of programmes and schemes are emerging, which complicates the governance of the 'green system' and makes it less effective.

Climate change is a reality now, and countries have to face several challenges in order to adapt and mitigate its effects on the economy and the employment base. This report argues that the greening of the jobs and skills will take place in all sectors, regardless their nature. Every job and every business can be 
greener in its output, product, service or processes. The greener the business model is, the stronger impact it will have on the economy as a driver for eco-innovation (for instance, greening the sector) or as a greener purchaser (for instance, greening its supply chain). The general greening of the economy must be taken into consideration when measuring the potential for a locality to be greener. Indeed, the skills available in place and local resources (human and natural) will be better utilised if the efforts converge towards reducing the environmental impact of the economic activity across sectors.

This report argues as well that the transition towards a green economy will take time. Because of this, the strategies will have to ensure short-term actions, long-term commitments, clarify a vision with measurable targets, and allow for adjustments to the local contexts. The most successful examples of greening localities have been those where the national strategy provides an enabling framework but where the leadership and actions take place locally.

Moreover, this report suggests that in order to facilitate the emergence of a greener economy, there is a need for detailed information on the labour market in general and the green economy in particular. This marks a basic handicap in pursuing green strategies: if the green economy cannot be defined, then it cannot be enabled. Furthermore, without a clear and meaningful definition, it is difficult to target support for green initiatives.

Analysis of the impacts, challenges and opportunities associated with climate change at the local level and coordination of responses between governments, business, employment, educational and training agencies, and households is critical if action on climate change is to be effective. It is important to emphasize that there are no one size fits all policies. Hence policies developed at the national level to combat change need to be amended and adapted to specific local conditions and, in most cases, supplemented by local policy and action. There are five major reasons why localities will become important players in the drive to reduce greenhouse gas emissions.

Firstly, these geographical areas are comprised of distinct concentrations of industries, households and infrastructure networks, and many are major greenhouse gas emission generators in their own right. It is recognised that the impacts of climate change across cities and regions will differ. Some regions are more vulnerable to climate change than others. Some may experience more floods, fires and droughts and damage associated with raising sea levels. This may require significant investment in retaining walls, fire management and water recycling.

Secondly, the agglomeration of innovative capacity, business networks and skills in localities and cities are important foundations to generate and diffuse new technologies and practices. Changes in behaviour are increasingly driven, not just by prices, but through interaction between firms, energy authorities, researchers, public sector agencies, and councils.

Thirdly, planning and investment in mitigation and adaptation measures are becoming increasingly important for households, industries and infrastructure networks. Many decisions impacting greenhouse gas emissions are long term such as public transport infrastructure, growth of sustainable urban centres with a low-carbon footprint and sustainable energy networks. These initiatives shape urban outcomes including business spinoffs to firms and demand for skills. They also often require coordination between public and private agencies to impact outcomes.

Fourthly, irrespective of global and national policy frameworks, there is a great deal of momentum at the micro and regional level, in business, the community and different tiers of government, to encourage the growth of low-carbon activities. This includes local innovation and diffusion of technologies, investment in carbon reducing local infrastructure, establishment and management of business and training networks. At the local level, a range of public and private actors - provincial and local government, 
business, education and training authorities, unions and stakeholders can influence the speed and direction of the transition.

Finally, the barriers to transition to a low-carbon economy are most acutely experienced at the local level. Important barriers include the lack of information about opportunities, skill shortages in emerging green industries, lack of capital to finance up-front investment, lack of knowledge and training in SMEs and poor coordination between local private and public agencies.

\section{Understanding the local context}

This report emphasises detailed analysis of specific localities and their broader context is required. In devising strategies in response to climate change, local agencies need to give consideration to the following:

\section{Macro-economic environment}

Arguably the greatest political and economic challenge is how different local economies can respond to the climate change crisis in the context of global economic turbulence and uncertainty. All economies have felt the impact of the Global Financial Crisis and its aftermath, but not all have felt it with the same intensity. In many cities and localities, resources to support new green initiatives are severely limited, particularly when there are competing demands for scarce resources, including supporting job creation, poverty alleviation and other social programmes. In the context of tight public budget, it can be argued that demand-side policies such as smart regulation may potentially be less expensive for governments in the longer term than direct support measures.

\section{Macro-economic policy settings}

Although there is general consensus that climate change is a major threat, there is intense disagreement about employment impacts, and political conflict regarding what to do about it. Opportunities for local agencies to engage in the climate change agenda can be enhanced or constrained by national economic policy, targeted towards a specific industry or type of intervention. For instance, countries that have established a carbon price, either through a carbon tax or emissions trading scheme, are likely to facilitate industry restructuring and occupational change at the local level, as industries attempt to shift out of high carbon activities towards low-carbon activities. Other national governments are supporting national R\&D and innovation programmes through tax concessions and direct assistance to stimulate the growth of specific green industries or clusters. Other countries may have less developed macro-economic policies, and this makes it more difficult, but not impossible, for local agencies to have an enabling framework and targets to effectively tackle climate change. This shows that the type and reinforcement of macro-economic policy instruments will also impact the local level.

\section{Industry structure and dynamics}

Local industry structure has a major influence of local carbon policy. Cities with strong research and innovative capacity, including a well-developed national and regional innovation system and a knowledgebased workforce, are well positioned to capture new investment and employment opportunities from lowcarbon growth in areas such as design, manufacture and installation of renewables such as photovoltaic systems, alternative fuels and transport technologies, carbon trading and energy-efficient technologies. Some countries are making major investments in green industries and technologies in a bid to strengthen international competitiveness. Industry size and concentration is also important. Global corporations active in large domestic markets with scientific, engineering and/or energy expertise, often have the resources and market access to develop new green products and services. Local economies with a high 
proportion of SMEs, often associated with smaller markets and low innovative capacity, will need to take a different approach.

\section{Labour markets}

Cities and localities with a high proportion of knowledge based workers, including the capacity to utilise tacit knowledge, and an education and training system that emphasises continuous upgrading of specialised and general skills, are well positioned to expand opportunities associated with the low-carbon economy. Cities and localities may have a strong formal education system of leading universities and technical colleges. Others may have strong informal learning systems, with emphasis on short courses, online programmes and a culture of learning by doing. Some fortunate areas will have both strong formal and informal learning systems.

Skills for innovation are also important, including the capacity to communicate across disciplines, team building and communication skills, as well as specialised IT, design, IT, electronics, engineering skills etc. Not all job opportunities associated with the low-carbon economy are high level knowledge based jobs. Low skilled entry level jobs can be facilitated in environmental care, forestation and recycling.

\section{Institutional capacity}

Significant differences exist across local areas in different countries and indeed within countries in terms of the institutional capacity to respond to and engage the climate change agenda at the local level. Awareness of the threat of climate change is reasonably high in most OECD countries but there are significant differences at local level, ranging from scepticism to outright denial. Many of the impacts and barriers are experienced at the local level. However, many localities lack the data, authority, resources and expertise to implement climate change initiatives.

\section{Governance}

Some localities believe that it is the responsibility of central agencies alone to organise the response to climate change through, for example, national tax, innovation and education policies and programmes. Coordination between agencies is a perennial challenge. One of the challenges is working out how different participants in the local economy - industry, education and training organisations, households, environmental agencies and local government - can improve their capacity to collaborate at the local level. This is particularly the case in emerging policy areas like climate change, where agencies have not worked together in the past.

\section{A snapshot of the project case studies}

Much can be learned by detailed analysis of different types of local areas. To illustrate the opportunities and challenges at the local level, the report examined a number of case studies: London, United Kingdom; Sydney, Australia; Extremadura, Spain; and Pomorskie and Podlaskie in Poland. It also makes use of a number of learning models, which highlight best practices in different countries in a range of areas including green business networks, sustainability and economic development and business attraction, green skills, green infrastructure and green incubators. This report incorporates the key findings of the detailed case studies. A snapshot of each of the four participant regions is provided hereafter.

\section{Extremadura}

This low density region offers a case study of a rural based area, with a strong base in agriculture and forestry, and contains important natural environmental assets, which offer opportunities in environmental and park management. The region recognises the importance of climate change and has launched a 
Regional Strategy to Combat Climate Change. The region is aligned to national policies and programmes to expand renewable energy and has renewable energy capacity including concentrated solar thermal. It has developed networks and infrastructure around an energy cluster and Science and Technology Park, and is planning to establish an Iberian Centre for Renewable Energy. These initiatives could be further expanded in terms of size and importance, and could be linked into national opportunities in renewable energies to position Extremadura as a reference in the sector.

The region has been one of the beneficiaries of national subsidies to the renewables industries, but there is concern that the transition to a low-carbon economy should not be too dependent on one green technology. The report emphasises the need for a sectoral approach to greening key sectors, specifically pursuing opportunities in agriculture and bio-mass, construction and eco-tourism.

\section{London}

London is one of the world's premier global cities. The Mayor of the City of London has developed many policies and programmes to reduce carbon emissions and to generate new employment opportunities associated with the low-carbon economy. Mayoral programmes give high priority to the development of decentralised energy systems, energy efficiency in homes and buildings, greening workplaces and expanding low-carbon transport opportunities.

The city already has a strong base in the low-carbon economy, with around 5500 firms active in this sector employing around 100000 people. Key industries include wind, alternative fuels, geothermal and building technologies, and all have good growth prospects. Overall, London's economy is dominated by business, finance and other services. The city aspires to build on its industry competitiveness in finance and become a global leader in carbon finance, an area where it is already in a strong position with around $18 \%$ of the global market.

The London workforce is highly skilled and most new jobs associated with climate change require the upgrading of existing skills. The London report, citing the dominance of new opportunities for highly skilled workers, recognises that the low-carbon economy needs to also spread employment benefits to lower skilled workers in areas such as energy auditing, waste and recycling.

\section{Podlaskie and Pomorskie}

The Polish report is based on detailed analysis of two regions, Podlaskie and Pomorkie. Podlaskie, in the east, is a rural based area with one-third of the workforce employed in agriculture. The population in the region is declining, with many migrating to higher growth regions in the EU; average incomes are only around $70 \%$ of the Polish national average, and unemployment rates are high. The region has a relatively undeveloped service sector, with proportionately fewer workers employed in information and communication, hotels and restaurants, financial services, real estate and professional business services. Pomorskie, on the other hand, is more developed, with a higher proportion of the population based in larger urban centres and higher concentrations of economic activity in tourism, electronics, machinery, food processing and construction. Average incomes are higher than Podlaskie but unemployment rates are relatively high.

Given Poland's abundant coal resources, which have long provided a relatively cheap source of energy and economic challenges such as high unemployment, the environment is considered a low priority and is frequently perceived as a cost rather than an opportunity. Training is underdeveloped in SMEs and entrepreneurial culture is weak. In Poland, there is little awareness and information about climate change and the institutional capacity to overcome this barrier is lacking. The Polish Government, through the Ministry of Economy, is preparing a National Programme for Reducing Greenhouse Gas Emissions, with 
emphasis on changing behaviour, stimulating new directions for less carbon intensive growth and implementing the most cost-effective methods for reducing greenhouse gas emissions. Arguably, national leadership is required to guide the regions. To respond to climate change, the two regions face multiple challenges. A vision for a green economy has not been articulated at the regional level. Strategic plans to specifically foster green growth in Podlaskie and Pomorskie have not been prepared, which makes it difficult to prioritise actions towards economic activities in this area.

\section{Sydney}

Sydney is Australia's largest city, and comprises around two thirds of the population of New South Wales (NSW) and around 20\% of the national population. Although it does not have the same global preeminence as London, Sydney is a global city with strong connections to the Asia-Pacific region, particularly in finance and business services, tourism and education sectors. The resource rich Australian economy has been a beneficiary of rapid growth in Asia, and, as a consequence, the economy emerged from the initial global financial shocks of 2008 in a relatively sound position, although strong terms of trade intensified competitiveness in key trade-exposed industries, particularly in major cities such as Sydney. Australia responded quickly to the Global Financial Crisis, injecting resources into green labour market programmes and incentives to encourage firms and households to shift to clean energy. The Australian Government has announced a Clean Energy Plan, including a carbon tax, compensation for industry and households and measures to stimulate the growth of renewables. This will create a sound framework for local initiative.

A key advantage of Sydney and Australia is a highly skilled workforce, which is underpinned by a high standard vocational education and training sector and reputable universities. The New South Wales Government played an important leadership role in developing the NSW Green Skills Strategy, which prioritised green training in key sectors, increased resources to build the capacity of trainers and establish green partnerships with industry. The state government also commissioned a report into business opportunities, which identified a number of industry opportunities, particularly in the area of business services that are required by a carbon constrained economy and green buildings.

The Council of the City of Sydney aspires to be a global leader in sustainability. Through leadership of the Lord Mayor and its Sustainable Sydney 2030 framework, the city has articulated a vision for a global, green and connected city. The City has established a target to reduce carbon emissions by $70 \%$ by 2030 through developing a network of green infrastructure to reduce energy, water and waste demands, and create opportunities for new green industries. With its large concentration of finance and business services, media and ICT industries, as well as tourism and education assets, the City contributes around 8\% to Australia's GDP. On the other hand, it is one of 41 local government areas in metropolitan Sydney and comprises around $4 \%$ of the metropolitan area's population. The challenge in Sydney is how to diffuse the best practice experiences throughout the whole metropolitan area to ensure that the metropolitan area city becomes sustainable and expands its opportunities to capture the employment benefits of a low-carbon economy.

\section{ENDNOTES}

\footnotetext{
${ }^{4}$ For further analysis, see OECD (2011a), Market Development for Green Cars, DSTI/IND(2011)20, Paris.
} 
${ }^{5}$ World Commission on Environment and Development (1987), Our common future, Oxford University Press, Oxford. See: http://www.worldinbalance.net/pdf/1987-brundtland.pdf

6 UNECE, OECD, Eurostat (2009), Measuring Sustainable Development. Page 27. Available at www.unece.org/stats/archive/03.03f.e.htm.

${ }^{7}$ OECD (2011), Towards Green Growth, Paris. Page 11. 



\title{
CHAPTER 2.
}

\section{LOCAL LABOUR MARKETS: GREENING JOBS AND SKILLS}

\begin{abstract}
This chapter analyses local labour markets and the factors that influence the supply and demand for labour at the local level. It also looks at how they are likely to be impacted by climate change and climate change policy. It discusses some of the specific issues that need to be addressed at the local level including the mobility of labour, unemployment and gender issues. Institutions at the local level - provincial/state agencies, the education and training system, employment agencies, business, unions and councils - all have an important role to play in facilitating the transition to a green economy. New jobs are being created, but more importantly, the chapter emphasises the restructuring of existing jobs with extra emphasis on what are termed "green" skills.
\end{abstract}

\section{Climate change and local labour markets}

While at the macro level the implications of climate change are being widely debated and in many cases acted upon, it is at the local level that impacts have yet to be considered in detail. Labour markets at local levels may find themselves under particular pressure to undertake the adjustments required to meet these new challenges. In local economies and among the dense networks of enterprises that underpin such economies, there is real concern that climate change mitigation and adaptation in labour markets will simply mean a reduction in the demand for labour as some jobs may be replaced by technology. This concern grows as some job profiles will be transformed and new skills will be required. However, the local level can lead the transition to a greener labour market and a more sustainable economic development if the current opportunity is seized appropriately.

In terms of the labour market impact, it remains to be seen how and to what extent jobs will be created, destroyed or adjusted as economies shift to greener growth. In some instances the transition to green growth will result in the creation of new jobs as new technologies and products emerge. However, it is also true, and perhaps more likely, that existing jobs will evolve into "greener" jobs as the requirements of the economy (and jobs) adapt to the changing consumer demand, government regulation and technological and market innovations. It is certain that many existing jobs and workplaces will begin to adapt to incorporate sustainability practices in the workplace and that the skills the economy needs will change too, as green growth becomes the goal of governments, business and communities and environmental sustainability is incorporated into everyday life.

There are different ways in which climate change can impact the economy and labour markets and these are analysed in this report. The direct impact of climate change on labour markets is potentially highly significant in the medium to long term, as a consequence of possible changes in weather conditions and from the occurrence of climatic events. Some economic sectors may be more affected than others (e.g. agriculture) and the labour market will have to adjust in the longer term. The indirect impact of climate change will be through policies and regulations, which is the primary focus of this study. It is particularly concerned with identifying and analysing the policy options available to authorities to maximise the economic opportunities arising from moving towards a low-carbon agenda, and to minimise any adverse impacts on the economy and the jobs base. Figure 1 shows the different ways in which climate change can impact on the economy and on labour markets. 
Figure 1. Impacts of climate change on labour markets

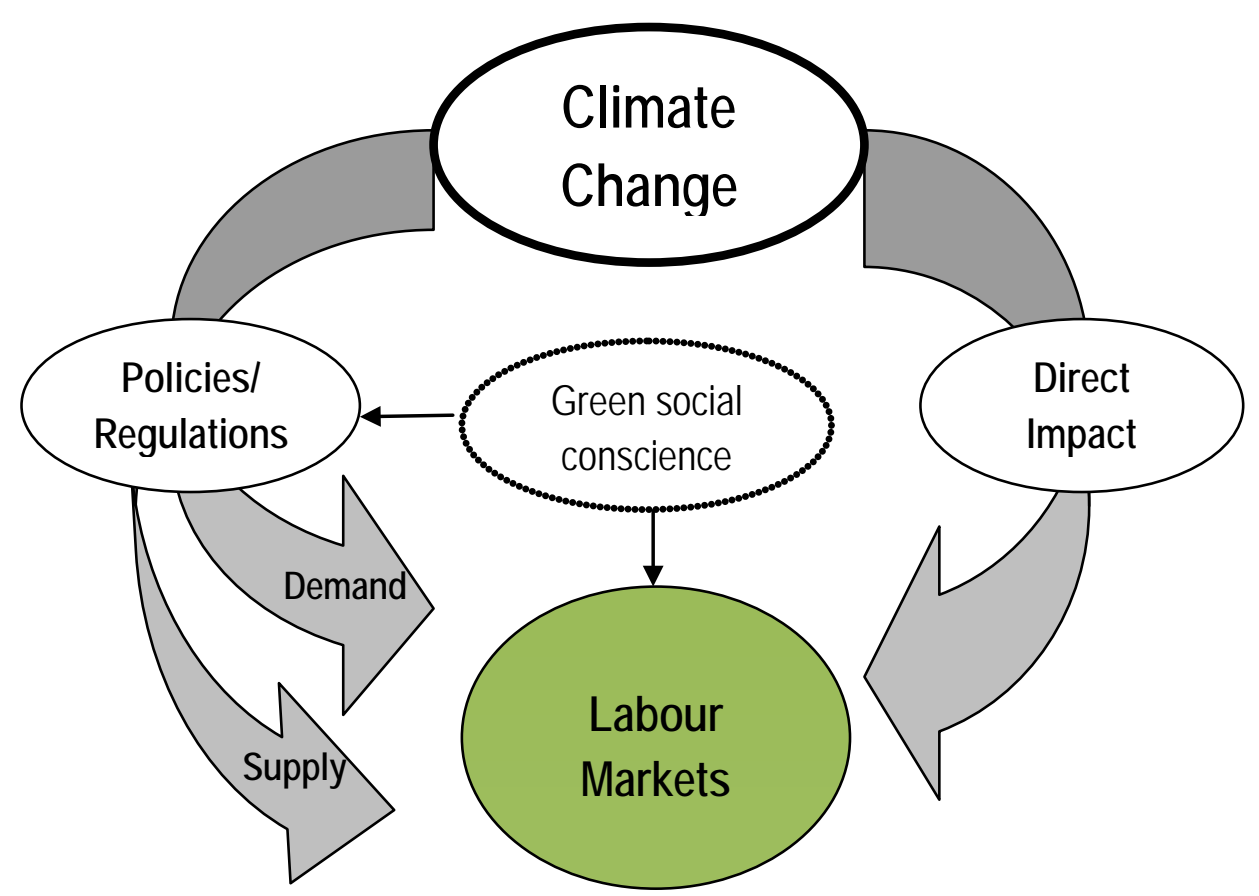

Source: Martinez-Fernandez C., Hinojosa C., Miranda G., "Greening Jobs and Skills: Labour Market Implications of Addressing Climate Change", OECD Local Economic and Employment Development (LEED) Working Papers, No. 2010/02, OECD Publishing.

The various ways climate change will impact on labour markets are further described below:

1. Direct impacts of climate change may be due to changes in climatic conditions and the occurrence of climatic events. For example, more frequent storms that damage crops may increase food prices, coastal cities will have to invest more on retaining walls to prevent rising sea levels from damaging low level areas, and local and infrastructure agencies may have to invest more to resist severe storm damage on building and infrastructure networks. Insurance companies are increasingly factoring in high premiums to reflect increasing claims associated with climate change damage.

2. Impact through climate change policies and regulations will affect both, the supply and the demand of labour and of products/services. OECD countries are implementing market oriented policies and regulatory measures designed to reduce carbon intensity and encourage clean technologies. For instance, carbon taxes and emissions trading schemes aim to increase costs associated with carbon intensive activities and send messages to businesses and consumers through the price mechanism to substitute low or zero carbon intensive activities for high carbon intensive activities. Regulations are also designed to shift towards low-carbon activities including green building codes, green public procurement, certification for green technologies and mandatory waste recycling. OECD countries are also engaging in direct assistance measures including public sector support for green $R \& D$, green infrastructure and technology transfer and diffusion incentives.

3. Labour markets will also be impacted indirectly by changes in consumer preferences. The global awareness about climate change is resulting in greater social conscience, regardless of market and regulatory trends. Some firms are incorporating green initiatives as part of their approach to corporate responsibility and their relationships with clients and customers. The rise of the green 
consumer, where consumers look for goods and services with green attributes, is an increasingly important phenomenon. The growing "green social conscience" is becoming a factor that drives policy, regulations, consumer choices, industry and therefore labour markets.

Further to this representation, the survey analysis as part of this project confirmed that climate change has effectively had an impact on businesses over the past 12 months. Overall, the impact of climate change on jobs has been nearly twice as much stronger in Sydney than in London (64.7\% vs. 33.3\%). As shown in Table 1, in London a very low percentage of firms have transformed jobs whereas in Sydney more than $60 \%$. Firms in London have registered a greater loss of jobs than those in Sydney and the share of job created is much lower. The number of jobs created as a result of the impacts (indirect or direct) of climate change on the firms is generally relatively small though ${ }^{8}$. However, it is interesting to highlight that one firm in Sydney created 100 jobs.

Table 1. Have these changes resulted in the creation, suppression or transformation of jobs?

\begin{tabular}{|l|c|c|c|}
\hline & $\begin{array}{c}\text { Job } \\
\text { creation }\end{array}$ & $\begin{array}{c}\text { Job } \\
\text { loss }\end{array}$ & $\begin{array}{c}\text { Job } \\
\text { transformation }\end{array}$ \\
\hline London & $22.2 \%$ & $11.3 \%$ & $3.7 \%$ \\
\hline Sydney & $37.9 \%$ & $7.7 \%$ & $61.9 \%$ \\
\hline
\end{tabular}

NOTE: Percentages calculated on the number of valid answers. The creation, destruction or transformation of jobs are not mutually exclusive. Therefore the sum for the three categories is not equal to $100 \%$.

The reasons behind these changes vary significantly across the countries involved in the survey. As shown in Figure 2, in Sydney and Extremadura environmental awareness is the main driver for adjustment, while changes in climate and/or environmental conditions seem to be the factor having less influence in determining the restructure of the workforce. The reason for this low incidence of climate/environmental conditions on changes within the firms may be related to the sector in which the firms function. On the contrary, the differences between the two countries are strong especially on two dimensions (i) make the production processes more efficient and (ii) change in consumers' preferences or in market trends.

The evidence gathered from this review also suggests that labour markets at the local level will be impacted differently in the short term, very much depending on the level of maturity of the labour market institutions, the effectiveness of the policies and programmes in place, and the rapidity of its adjustments to the new context. However, in the longer term, labour markets will be all impacted similarly as the businesses and markets respond to new demands and regulations. Indeed, the various cases analysed and the learning models identified have provided different scenarios which could be envisaged.

On the one hand, labour markets with weak labour market institutions appear to struggle more when it comes to identifying the future job and industry developments and, thus, are less effective in supporting those programmes that will facilitate the transition to a green economy. This is usually linked to a lack of labour market data at the local level, of infrastructure for training and life-long learning, of understanding of the implications of the green economy and also due to the lack of definitions.

On the other hand, labour markets with a more mature system and stronger institutional capacity will face the challenges of the transition to a green economy in a more optimistic and effective way. Indeed, the availability of reliable data, the capacity to analyse the labour market indicators, the ability to monitor business behaviour and the existence of a good quality training and skills system are essential elements to ensure the adjustments of labour markets at the local levels to the green challenges. 
Figure 2. Extremadura and Sydney: What are the main reasons for the changes?

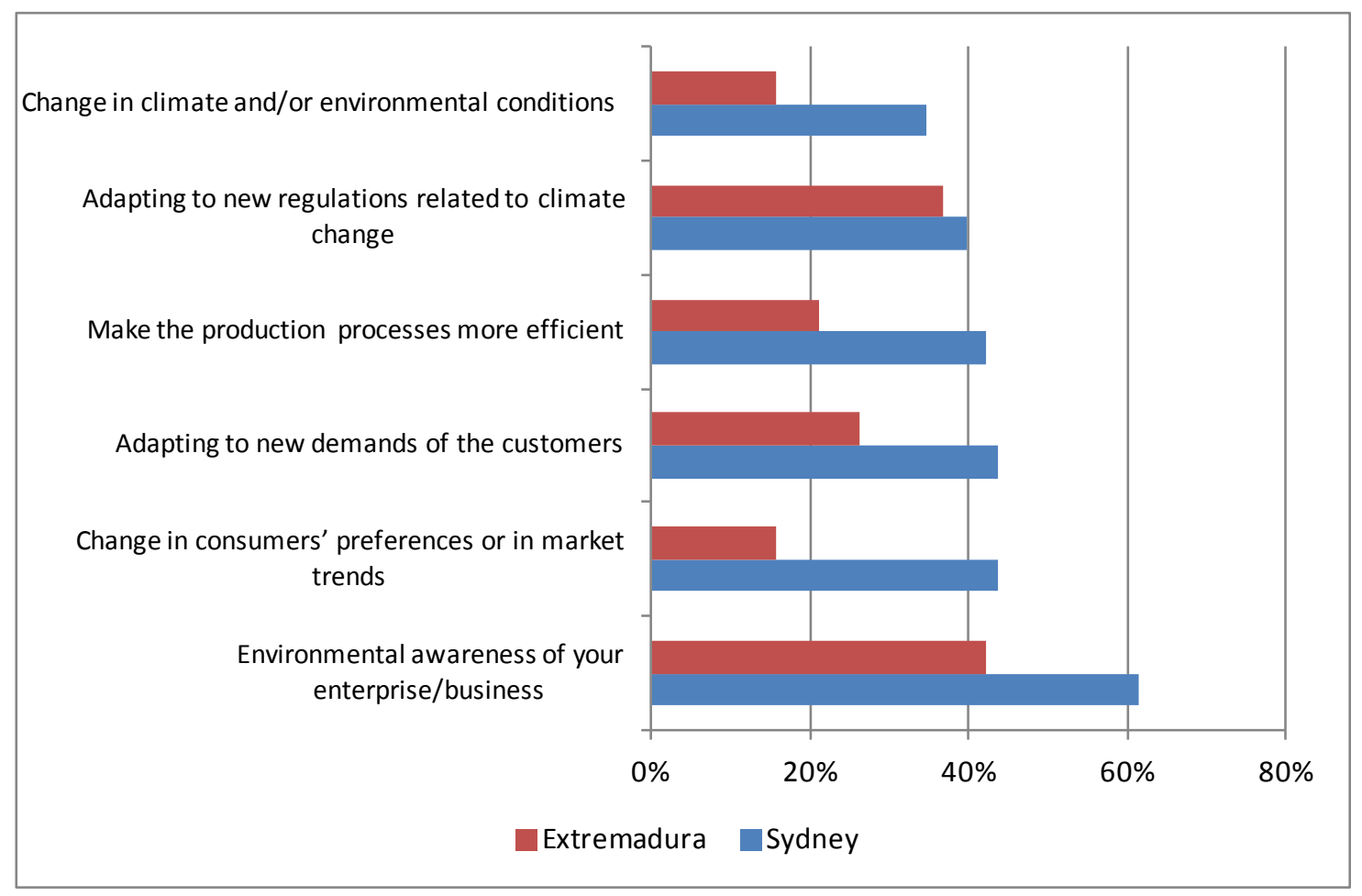

NOTE: More than one answer was possible to this question.

\section{Factors influencing labour supply/demand}

The factors influencing labour markets at the local level are diverse, and vary from place to place. However, some core factors may be identified as having a particular effect on the demand and supply of labour at the local level in the context of the transition to a green economy. Some of the key factors identified throughout the project are described below.

Concerning the demand of labour, a key influencing factor is the size and maturity of the businesses in place as well as the predominant sectors in the economy. Indeed, the demand of labour can be pulled by the restructure of some sectors in response to different conditions (e.g. climate change regulations) which may lead a sector to shrink or even disappear, or on the contrary may support the emergence of new sectors. For instance, the survey in Sydney shows that climate change has had an overall impact on firms created before 1990, which represent the oldest and more mature businesses of the sample. These firms have mainly introduced changes in purchasing practices, suppliers and production methods. As shown in Table 2 below, findings of the project in Extremadura show that the impact of climate change was very strong in the manufacturing sector and marginal in the construction and primary sectors. 
Table 2. Extremadura: impact of climate change by sector

\begin{tabular}{|l|c|c|}
\hline & YES & NO \\
\hline Primary & $21.4 \%$ & $\mathbf{7 8 . 6 \%}$ \\
\hline Manufacturing & $\mathbf{7 1 . 4 \%}$ & $28.6 \%$ \\
\hline Construction & $14.3 \%$ & $\mathbf{8 5 . 7 \%}$ \\
\hline Services & $31.4 \%$ & $68.6 \%$ \\
\hline TOTAL & $31.7 \%$ & $68.3 \%$ \\
\hline
\end{tabular}

Source: Miranda, G., et al. (2011a), "Climate Change, Employment and Local Development in Extremadura, Spain", OECD Local Economic and Employment Development (LEED) Working Papers, No. 2011/04, OECD Publishing.

The demand of labour is also influenced by the organisation of the workers in associations or trade unions. Evidence gathered throughout the project confirmed that industries with informally or formally organised workers structures are more likely to demand labour from the local labour market than those where workers do not pull an important weight. Trade unions and workers associations have proven to play an important role in supporting the anchorage of jobs to the locality, by ensuring training (informal and formal) for the workers, as well as by disseminating valuable industry information for the local labour market.

A third factor influencing the demand of labour locally is the reactivity and maturity of the local employment offices. These offices ensure the integration of businesses in a locality by monitoring their employment needs, the industry trends and the businesses' plans. If these offices work in isolation, against the business sector, the demand of local labour will be weak. On the contrary, if these offices are active, work closely with businesses and training institutions, and have strong monitoring systems, the demand of local labour will increase.

With regards to the supply of labour, various factors, depending on the locality, can cause an affect. One of the factors identified as part of this project is the quality of the training and further education institutions, which is considered as the main driver in skills formation in the workforce. Nonetheless, their role should be analysed in further detail as the infrastructure available as well as the type and quality of the programmes will influence the quantity and quality of labour supply. A more detailed analysis of the education and training institutions, and their role in greening the economy is provided in another section of this chapter.

Another factor affecting the supply of labour is the demographic constitution of a locality. It is clear that the transformation of the labour market will be achieved in a smoother manner if the population is young, if long-term unemployment is low, and if the levels of participation of women, elder and youth in the labour market are high. However, an in-depth analysis is needed in order to understand the impacts of demographics on labour markets, especially in places where these conditions are not favourable. Hence, further work on the impacts of demographics on labour markets will be carried out by the OECD LEED Committee $^{9}$ during the 2011-2012 programme of work.

Industry dynamics is a third factor influencing labour supply, these being affected by the market and the policies in place. Indeed, if an economic sector is shrinking, there will be a reshuffle of the labour 
supply allowing for labour mobility between different economic sectors. For instance, when the automotive sector closed in Styria, Austria, there was an important supply of workers into the labour market with useful skills but no employment opportunities. PV Products, a producer of mono- and polycrystalline photovoltaic modules, made use of this underutilised labour force from the local market, absorbing mostly workers from the former automotive sector. The company became operative very quickly as the jobs in the photovoltaic modules do not require much training or specific "green" skills for these kind of workers.

\section{The role of labour market institutions in the green economy}

Evidence from this project suggests that labour market institutions at the local level have an important role to play in facilitating the transition to a green economy. However, to fully achieve this and maximise their contribution towards this transition, local labour market institutions need to be involved in the process of defining and setting objectives towards a green economy, they also need to have a strong awareness of the challenges and opportunities of the green economy, as well as having the capacities, the empowerment and the tools to ensure effective actions.

Indeed, involving local institutions in the process of defining and implementing a green growth agenda is proving to be very useful in fostering a more effective and smooth local transition to the green economy. The national authorities should consult and involve labour market institutions to better understand the regional needs and to customise the actions to the regional context. A good example of how this can be done is the case of Extremadura, where the local labour market institutions (employment offices, regional ministry of employment and training institutions) have taken an active role in the definition of the green local agenda for the region. The institutions have also had the empowerment to decide upon actions targeted to specific regional needs. See Box 1.

\section{Box 1. Local labour market institutions in the green economy}

The signature of the Social and Political Pact of Reform by the regional government, local labour market institutions and unions indicates a willingness to work together. This Pact includes the green economy as one of four emerging sectors to be developed (the other three are tourism, proximity services and ICT), together with four traditional sectors with the potential for transformation into greener sectors (agriculture, food, retailing and ecobuilding). The various economic and social actors are thus well aware of, and involved in, the definition of the political and economic agendas for green growth in the region. This incipient capacity building effort should help the regional authorities to gain consensus and gather evidence to support its decisions towards a green agenda.

Source : Miranda, G., et al. (2011a), "Climate Change, Employment and Local Development in Extremadura, Spain", OECD Local Economic and Employment Development (LEED) Working Papers, No. 2011/04, OECD Publishing.

The participation of labour market institutions in the definition and implementation of a green agenda locally is also a good mechanism to raise awareness of the green economy. Evidence from this project demonstrates that the most successful adjustments and transitions towards a greener economy are taking place in cities and regions where the labour market institutions are well aware of the challenges and opportunities of the green economy. Labour market institutions are the perfect intermediaries between the market and the workforce, and should therefore have the information available to provide guidance and advice to both the supply (workforce) and demand (industry) on the opportunities and possibilities available.

In addition, labour market institutions need strong institutional capacity to ensure effectiveness of actions. Evidence gathered from this project suggests that labour market institutions' institutional capacity 
is still low to properly adjust as well as address the challenges, and support the transition to a green economy. The institutions have no real understanding yet of the "green dimension" of their activity, and they often overlook the possibilities of the green economy for the demand side (unemployed) and the supply side (employers). Strengthening the capacities of local labour institutions to better understand the green economy and to identify opportunities is essential in order to fill the jobs in the green economy with local workforce.

Part of this strong institutional capacity requires a solid and up-to-date set of tools, including accurate local labour market data. This was found to be a key aspect for better targeting the policies and support schemes towards green growth, as well as to better identify and anticipate skills and jobs gaps. To achieve this, labour market institutions should work closely with businesses and industry representatives to identify the trends, their needs and anticipate any changes well in advance. However, in order to effectively have and maintain an accurate and updated system of labour market data at the local level then resourceful and strong institutions are required.

For instance, London called upon DTZ and Innovas to carry out the collection, analysis and update of the labour market data necessary to identify the skills needs for the city's low-carbon agenda ${ }^{10}$. Sydney, on the other hand, has a strong labour market data system in place and used it to develop the Green Skills Strategy, which prioritised green training in key sectors, and increased resources to build the capacity of trainers and to establish green partnerships with industry. The regions with the weakest labour market data system were faced with more difficulties in identifying those skills and job gaps, and in developing tailored-made support schemes for the green economy. The findings of this project emphasise the importance of maintaining a continuous monitoring of the business sector to meet their needs in terms of skills, workforce and training. An up-to-date system of data collection, analysis and monitoring is essential to facilitate the transition to a green economy, anticipate needs and limit any negative effects.

\section{Considerations for labour market transformation}

The transition towards a green economy has led to a number of debates on whether the transition will be fair and whether there will be a sufficient amount of decent and good quality jobs available in the labour market $^{11}$. If these concerns are not addressed from the very beginning, the consequence of job restructuring during the shift to a green economy may widen the salary gap between highly-skilled and lower-skilled workers, and may lead to bottlenecks in the integration of vulnerable groups (elder, disabled, long-term unemployed) into the labour market. This may result in the creation of low quality jobs which impede the development of good career paths. Gender equality may also be put at stake as some of the sectors with high potential for job creation in the green economy (e.g. building and engineering) are perceived to be male-dominated.

Throughout this project, meetings were organised with trade union representatives and other social partners as they are an invaluable source of information and knowledge. They expressed their concerns about the issues raised above. Many specific examples were provided illustrating the complexity of the process at the local level. For instance, in Sydney trade union representatives of the mining industry expressed their concern about the proposal of closing coal mines and converting the areas into organic farming and wine production. They argue that salary levels and career ladders in these sectors are uncompetitive compared to the mining sector. Therefore, taking into consideration these concerns from the beginning and involving a majority of social partners in the process can only contribute to supporting a better job strategy in the green economy and help to limit social tensions.

Another consideration worth bearing in mind is related to the type of jobs that will be generated in the green economy. While it is certain that some new jobs will be created requiring a certain amount of new qualifications and skills, it is also true that some entry level jobs will be made available as the green 
economy adjusts. Indeed, evidence gathered from this project suggest that many opportunities will arise for lower skilled and entry level jobs in the green economy. The sectors that will offer the largest share of these jobs in the longer term appear to be tourism, agriculture and construction, although this does not mean that all the other new (e.g. renewable) and adapted (e.g. automotive) sectors will not offer different levels of skilled jobs. A more detailed analysis of this is provided in the following section.

\section{Women in the green economy}

The role and status of women in the green economy must be considered and requires special attention. Women make up half of the world's human resources. Fostering the participation of women in the green economy can be a source of political, economic, social and environmental innovation. The OECD recognises that, beyond their comparable capacities to men, women constitute a real potential source of innovation in terms of management style, company structure, community service, the use of technology, etc. (OECD, 1998). This could contribute not only to a reduction of environmental impact but could also add value to the economy and create more jobs.

Women have made progress towards gaining economic equality during the last several decades, but continue to be concentrated in traditionally female occupations. Women constitute less than three percent of many labour-intensive occupations such as construction workers, electricians and HVAC installers ${ }^{12}$. There are some concerns that the large percentage of green job growth is occurring in sectors where women are severely underrepresented in the workforce ${ }^{13}$. Jobs in building retrofitting, environmentallyfriendly transportation technologies, wind and solar power production, etc. are widely held by men. These sectors make an important contribution to green growth, create jobs and wealth, but they are perceived as male-dominated.

While not all women will be drawn to these jobs, their participation in these sectors should be reflected upon and considered from a strategic point of view. It is certain that regulations will need to be binding in order to encourage the participation of women in those sectors that will expand as the green economy develops. However, expanding education, training and skill-building programmes will also be essential to successfully including women in these jobs, allowing for the absorption of those (including women) that will leave shrinking sectors due to economic and labour restructuring.

A good example of an approach that could be put in place was identified in the Alsace region in France, with the initiative Les Elles du BTP (Women of the Construction Sector). As the construction sector is becoming greener, new skills and training is required to meet the needs of new regulations and energy-efficiency standards. This was perceived as a good opportunity to make use of these trainings in order to involve women in the sector. The initiative Les Elles du BTP aims at facilitating the insertion of women in the construction sector notably through customised training, a network of women in the construction sector who share their experience, and a 'taste' of the different jobs available in the sector (see Box 2). 


\section{Box 2. Les Elles du BTP}

Les Elles du BTP is an initiative that seeks to communicate the possibilities to women to work in the construction sector as well as to raise awareness among business owners and large companies of the advantages to hire women in the sector. Several reports have been prepared in this sense. The French Federation of the Construction Sector (Fédération Française du Bâtiment), the Regional Government of Alsace, the General Council of Haut-Rhin Department, the National Ministry of Employment and Social Affairs, and the Chamber of Crafts Industry support this initiative launched by the Women Group of the Construction sector in the Haut-Rhin Department in France.

The main objective is to increase the participation of women in the construction sector. According to the managers, green growth provides a unique opportunity to achieve this as some specific training is being put in place which could benefit women entering the sector. Also, as the work is less physical and more technical, women can be more easily integrated. Green building and energy savings require a more precise and better quality job to ensure environmental efficiency, and women have proven to have the right skills and attitudes towards this.

Source: Workshop on Green Growth and Employment, Mulhouse 21-22 October 2010. Also www.federationbtp68.fr

\section{Defining green jobs}

Defining "green jobs" is a concern for almost all of the countries and regions, as the definition will enable better targeting of support mechanisms and help in measuring the impacts of the green economy on labour markets. According to the UNEP (2008), green jobs include work in agricultural, manufacturing, research and development, administrative, and service activities that contribute substantially to preserving or restoring environmental quality. In the United States, the term "green-collar jobs" is more often used. It defines well paid, career track jobs that contribute directly to preserving or enhancing environmental quality (Apollo Alliance, 2008). Green-collar workers include professionals but also vocational or tradelevel workers, with opportunities for advancement in both skills and wages.

As argued in the conceptual report of this project ${ }^{14}$, green jobs span a wide array of skills, educational backgrounds, occupational models, and can be found at any point on the supply chain of what are considered to be green firms or businesses. A more systematic way to defining how green a job is could be to include a set of criteria and indicators with references to the sector, the output (product/service), the production method, value-chain position and awareness of the organisation, and the occupational profile, quality and green workload (see Figure 3).

Figure 3. Green equilibrium dashboard

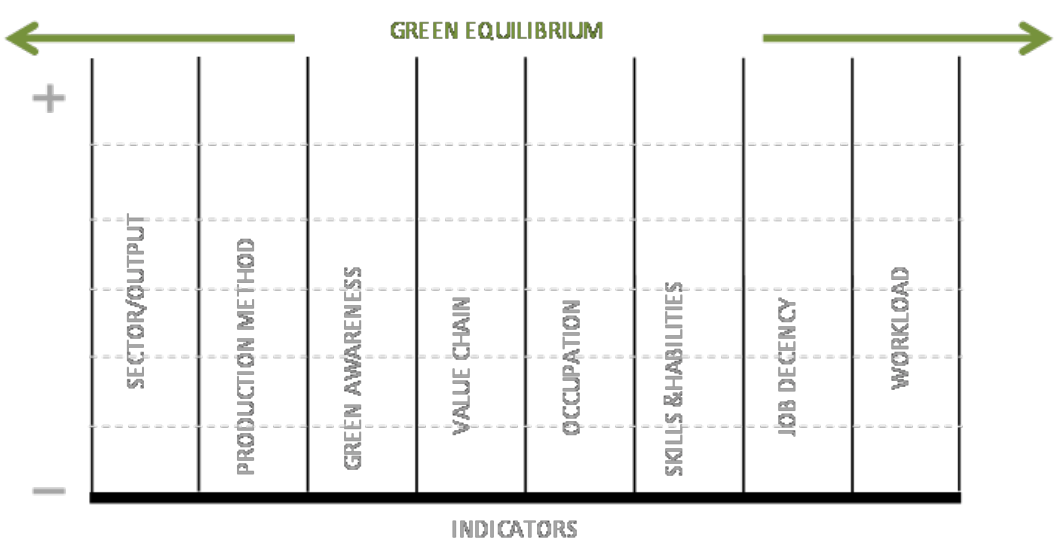

Source: Martinez-Fernandez C., Hinojosa C., Miranda G. (2010), Greening Jobs and Skills, Labour Market Implications of Addressing Climate Change. OECD Local Economic and Employment Development (LEED) Working Papers, $2010 / 2$ 
Based on these criteria, of which all can contribute to making jobs green, policy makers can come up with adapted definitions to their own context and needs, allowing them to harmonise their local conditions with policy objectives, as well as to facilitate the design, implementation and evaluation of local green economic and employment development policies ${ }^{15}$. The analysis from this project underlines the importance for each country or region to develop its own definition to ensure that it reflects the reality of the area and that it is endorsed by the various stakeholders in place.

Moreover, when defining a "green job" it is crucial to take into account its indirect components, as they will determine the impact of that specific job in other sectors and jobs. In other words, consider the relationship between products and services, and the processes used to produce them. Businesses produce products and services by combining inputs such as labour, capital, energy, and intermediate products. For all services and products, the relative amount of each input depends upon the particular product or service that might be green to a certain extent - or not. Figure 4 illustrates these interactions.

Figure 4. How green is a product/service?

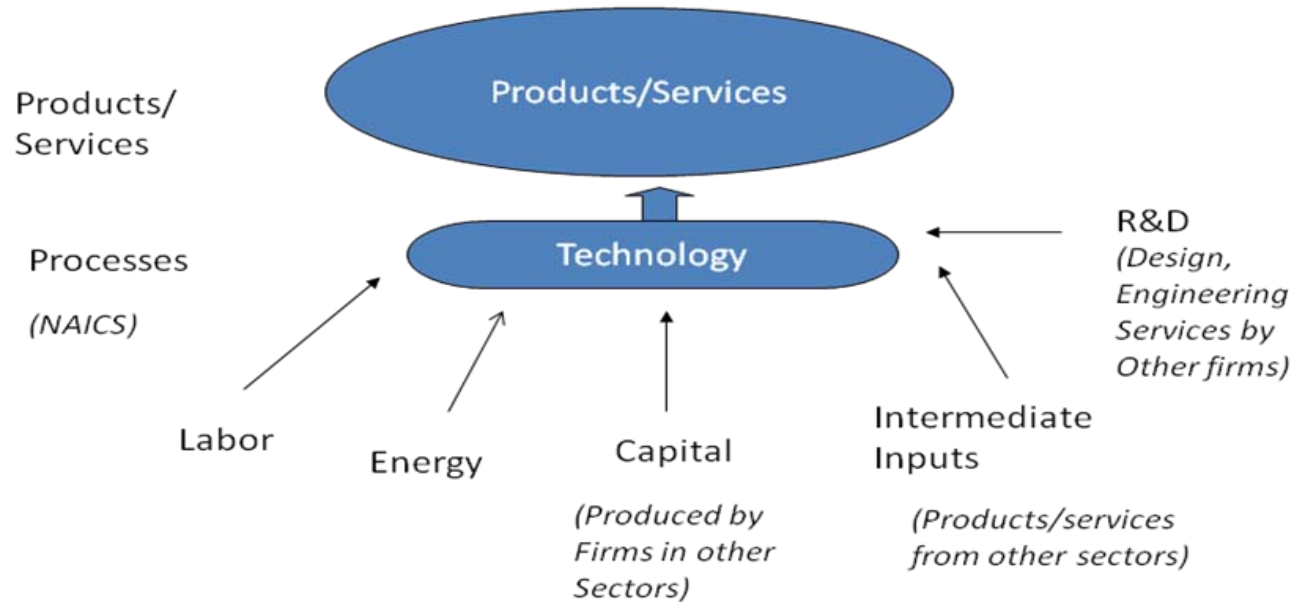

Source: Eberts, R. W. (2011), "Framework and Tools for Assessing and Understanding the Green Economy at the Local Level", OECD Local Economic and Employment Development (LEED) Working Papers, No. 2011/08, OECD Publishing.

The previous discussion shows the complexity of defining a "green job", especially if policy makers are to avoid the risk of being too constricted and picking winners, or being too broad and not supporting well enough the full potential of green jobs in the territory. Overseeing these aspects could result in the creation of false expectations as regards the potential of the green economy to create jobs, and as regards the "greenness" of the jobs themselves, thus losing credibility.

As it has been argued, there is no one single official definition of "green jobs". However, it is clear that governments need to take a more proactive role in defining the green economy in terms of potential job creation and in terms of its potential to replace declining sectors in an economy. This would facilitate the anticipation of labour market restructures and the adjustments of policies.

Many national and sub-national governments have taken the lead in defining the green economy and describing the potential in terms of jobs and future growth sectors. But in order to have an effect on jobs, the definition has to take into account the local context so that the opportunities seem realistic to the local stakeholders. A good example of this approach is the case of London (see Box 3). In a Mayoral directive, London undertook a detailed analysis of its low-carbon sector from which a comprehensive definition of 
the low-carbon jobs was developed, reflecting the priorities of the city in terms of investment and other support schemes.

Numerous studies have attempted to quantify the growth potential of the low-carbon sector. Many of these findings suggest strong growth prospects, often above forecast trend growth rates, which support much of the consensus on the scale of opportunity. However, converting these numbers into potential employment opportunities is more difficult. Whilst the majority of these studies generally find positive job trends, these figures should be used with caution as the methodologies from which job numbers are derived are of variable quality ${ }^{16}$ and, as discussed above, the definition of what qualifies as a green job is not fixed. Despite this, the prospects surrounding green growth suggest that the employment potential of the transition to a green economy remains strong in the longer term, but much is needed in order to exploit the potential.

\section{Box 3. Defining Green Jobs: The Case of London}

The Mayor of London and the London Development Agency were keen to develop a more refined understanding of the labour market potential of moving to greener growth in London. In order to do this the LDA worked alongside Innovas and DTZ to define and developed a working definition of the low-carbon economy and the number, type and skills levels of low-carbon jobs in the London labour market. The definition includes activities undertaken by companies across the whole environmental supply chain, from R\&D, through manufacturing into distribution, retail, installation and maintenance services. Companies are included in the supply chain where $20 \%$ of their turnover is supplied into the LCEGS sector, but importantly only the sales activity relating to this sector is included in this study. The study uses 'bottom-up' data based on what companies actually do, rather than what they are classified as doing under the SIC system. In doing so, it identifies and measures 2490 Environmental, Renewable Energy and Emerging Low-carbon activities within 23 sub-sectors.

The definition outlined in included three levels of granularity. Level 1 applies to the broad sector split within lowcarbon. Level 2 applies to the sub-sector breakdown of activity, and Level 3 applies to a sub-sub-sector breakdown. This methodology was then applied to London in order to determine the size of activity and number of businesses in each category starting with Level 3 and working up to Level 1 definitions. The model also enabled London to assess the number of employees working in the low-carbon sector.

The approach adopted by London draws on new market data to develop a bottom-up picture of the low-carbon sector without having to try and classify occupation and industrial classifications. In effect it maps business activity and is therefore a more accurate account of activity. Whilst this approach may not be suitable everywhere, it offers an alternative and experimental approach to mapping green jobs and skills in the economy.

Source : Miranda, G., et al. (2011c), "Climate Change, Employment and Local Development in Sydney, Australia", OECD Local Economic and Employment Development (LEED) Working Papers, No. 2011/14, OECD Publishing.

\section{Green economy: where are the jobs?}

For the purposes of this project, green jobs were defined as jobs that contribute to protecting the environment and reducing the harmful effects human activity has on it (mitigation), or helping to better cope with current climate change conditions (adaptation) ${ }^{17}$. This definition is intentionally broad and strategic so that it could be used as a starting point for more locally adapted definitions in line with the wider aims of local green economic and employment development policies. Moreover, any definition derived today will almost certainly need to be adapted over the coming years as green technologies evolve and as the understanding of "green jobs" and green growth increases.

This project has therefore adopted the use of the term jobs in the green economy or greener jobs. The former refers to all those jobs created in the context of the green economy which incorporates the 
sustainable component, making investment in the environment a new source of economic growth. The latter refers to those jobs that will be transformed over a period of time, in a process. These greener jobs are not necessarily associated to any specific so-called green sector (e.g. renewable energy) but are jobs that are gradually adjusted to the new demands of a greener economy. This report argues that the greening of the jobs and skills will take place in all sectors, regardless of their nature. The green economy will have to expand as the regulations and policies become more restrictive. The whole economy will eventually have shades of green, as represented in Figure 5.

As the entire economy transforms, jobs will be created, however others will be replaced or suppressed. Even though this project did not aim at quantifying the number of jobs in the green economy, and even less so the number of green jobs, the various case studies undertaken as part of this project did shed some light on some of the sectors with particular potential for expansion. These are discussed below as an illustration of some of the different options for job creation in the green economy. The description below does not intend to limit the potential of other sectors, nor the emergence of new (still unknown) sectors that will certainly contribute to job creation.

Figure 5. Representation of the green economy

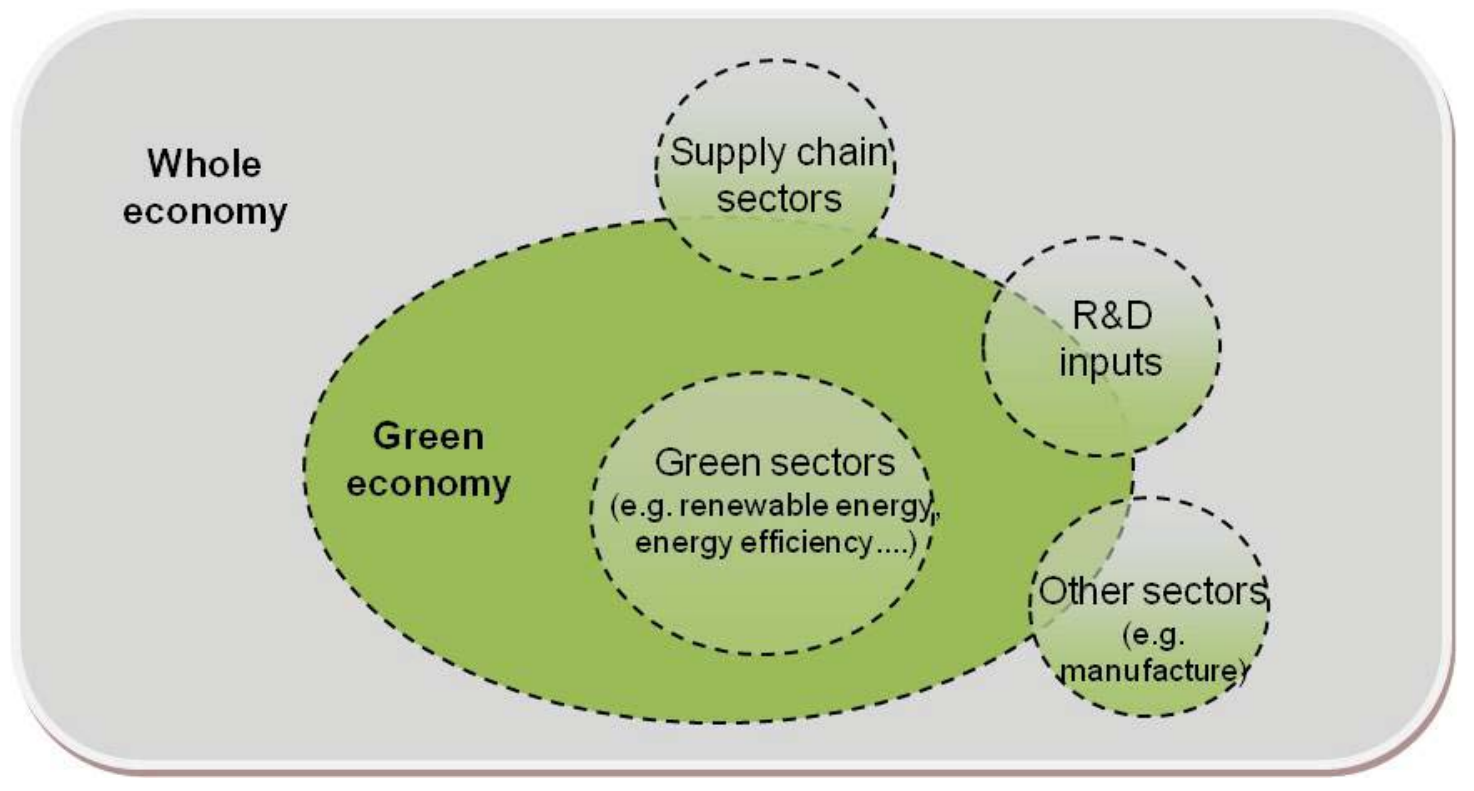

Source: Adapted from Miranda, G., et al. (2011a), "Climate Change, Employment and Local Development in Extremadura, Spain", OECD Local Economic and Employment Development (LEED) Working Papers, No. 2011/04, OECD Publishing.

\section{Renewable energies}

The renewable energies sector is one of the most obvious sectors of job creation in the green economy. Most of the countries analysed touch upon some sub-sectors of the renewables. However, the quality and the types of jobs in renewable energies vary. Indeed, some of the most developed projects visited, for instance solar PV power generation facilities, have a very strong demand for labour during the process of manufacturing the PV panels and installing the facilities, but the number of jobs in the longer term are marginal. Once installed, these kinds of PV power generation facilities usually retain 1-2 technicians in charge of maintenance and the same number of specialised engineers responsible for the management. Other types of renewable energies analysed, such as wind and thermo solar, present the same trend in terms of jobs. It is certain that there will be an increase in the use of renewable energies as countries seek more oil-free solutions to meet their energy needs. However, the implementation of 
renewable energies as a response to job creation should be evaluated carefully. Renewable energies are certainly an option, but not the only solution. A project currently being developed by the OECD ${ }^{18}$ is looking into this in more detail, namely in rural areas.

\section{Manufacture}

The different places analysed as part of this project had already undergone a transformation of their manufacturing sector as a consequence of trade liberalisation, regulations and changes in consumer demands. The survey analysis of this project has also confirmed that businesses in the manufacturing sector are those that have undergone the most changes and adjustments in terms of jobs due to climate change regulations. However, this does not necessarily imply job suppressions but rather a transformation of the job profiles and the skills required for the production of low-carbon manufacturing goods. Evidence from this project suggests that manufacturing will continue to be an important source of job creation in the green economy. Hence, special emphasis should be given to growing manufacturing clusters in the green economy. For instance, as illustrated above by the solar, wind and thermo solar sectors, the majority of the jobs in many niche sectors of the green economy will tend to be in manufacturing and not in design or operation. ${ }^{19}$ Also, manufacturing jobs typically pay higher median wages than median wages overall. ${ }^{20}$ Finally, manufacturing is a major driver of economic innovation and wealth generation. For example, in the United States, the manufacturing sector accounts for $70 \%$ of all private research and development spending and $90 \%$ of all U.S. patents. ${ }^{21}$ So, as businesses adjust internally within the manufacturing sector, new jobs will be created and others transformed. To illustrate this, the case of Michelin could be useful (see Box 4).

\section{Box 4. The case of Michelin}

The French tire producer, Michelin, is facing difficulties in buying better quality products (i.e. long-life, more efficient) at their real value. On the other hand, as the tires become more efficient and long-lasting, Michelin is concerned about the sales and income for the future. Instead of opting for in-bound obsolescence, Michelin's business model was transformed. Michelin does not sell its tires but rather is responsible for providing maintenance and service throughout the life-cycle of the tire, once installed. This implies that workers within Michelin are not just technicians producing tires, but have been transformed into customer's relations, maintenance technicians and driving advisors. The customers do not pay the tire in itself (product) but rather the amount of kilometres driven. This has led to an improvement in the quality of the tires, an extended life-cycle of the tires, and in a reduction of the amount of tires produced. Despite this adjustment to an environmental concern, Michelin has increased its income share in real value and its customers save up to $36 \%$. Michelin has 300.000 vehicles using its tires in 24 countries.

Source : Workshop on "Économie de la fonctionnalité", Mulhouse, France, 21 October 2010. For further information visit the website: http://economiedefonctionnalite.fr

\section{Tourism}

The tourism sector is one of the more labour intensive and one of the key sources of income for many OECD countries and regions. This sector is already under transformation, setting new certifications and creating environmental labels (e.g. Natura Extremadura in Spain) to attract the consumers looking for these kind of services. Some special traineeships have been put in place by the tourism industry to enhance their energy efficiency, reduce water consumption and improve waste management. However, the sector will still need to adapt further as it will be directly affected by climate change. It is also one of the sectors that has a higher level of water and energy consumption, and will need to seek solutions to the restrictions to be imposed. Jobs in the tourism sector will also vary in the level of skills required. Further analysis on this 
sector will be undertaken as part of a follow up project on eco-innovations in the tourism sector (in collaboration with the Tourism Committee).

\section{Agriculture}

Another sector of potential for job creation in the green economy is agriculture. As the demand for food increases, the agriculture sector will have to increase supply while deploying green technologies and following more sustainable practices. The agriculture sector will also have to adapt as it will certainly be impacted directly by the effects of climate change - as is already the case in some places. These transformations will not necessarily mean the suppression of jobs. On the contrary, the transformation will create opportunities for alternative agriculture (e.g. urban agriculture in London), for new goods (e.g. organic food), for new related activities (e.g. agriculture tourism in Castille and Leon), as well as for other forms of organisations leading to reduce environmental damage (e.g. reforestation), for new kinds of approaches (e.g. homeopathic farming in Chile) or even new areas for R\&D related to the sector (e.g. agriculture advisors in Poland). Another area related to agriculture is the waste management of crops. In some agriculture-based places like Styria, this has led to the implementation of circular processes that include the collection of agriculture waste and the production of biofuels, biomass, and bioenergy in the same place (see Box 5). However, due to the scarcely populated areas surrounding the agriculture sector, it is important to enhance collaboration among the different local actors and organise the sector to make it more productive. Furthermore, evidence gathered from this project confirms that there will be different levels of skills required and very diverse occupations will be linked to agriculture.

\section{Box 5. South Styrian Cooperative for Energy Production, Mureck}

Bioenergie Mureck is an example of a co-operative model in the energy sector in a rural area, involving more than 500 local farmers. Bioenergie Mureck comprises three companies, namely SEEG Mureck, Nahwärme Mureck and Ökostrom Mureck, which cooperate to run the so called "Mureck Energy Cycle", whereby they supply the entire Mureck region with electricity, heat and fuel. The Energy Cycle is based on the production of biodiesel and heating (for public and private buildings) from rapeseed and used cooking oil, but also from biomass (mainly wood and waste wood).

The main environmental results of this model entail an economic benefit for the region. For instance, in the last three years, $\mathrm{CO}_{2}$ output was cut by more than $70 \%$. The cost of biodiesel from the cooking oil, used by participating surrounding communities (e.g. by the city of Graz for the public bus transport network) and sold locally, is currently about $20 \%$ below the market price of traditional diesel. The Mureck Energy Cycle is an environmental friendly model, which adds value to the local economy and secures a number of jobs.

Source : OECD Study Visit to Styria, Austria, October 2010

\section{Construction}

Construction is also one of the more labour intensive sectors. Evidence from this project has highlighted the necessity to improve energy efficiency in buildings (public, commercial and private) in order to reduce $\mathrm{CO}_{2}$ emissions and energy consumption. Also, with the endless needs of infrastructure for transport and more specifically for projects such as the Olympic Games, there is an opportunity to continue the demand for workers with a different approach to sustainability. As the London-based Centre for Efficient and Renewable Energy in Buildings $\left(\mathrm{CEREB}^{22}\right)$ confirms, buildings generally under-perform by the factor of 2 due to a lack of skills in installation and maintenance of the systems. The lack of skills or awareness is also applicable to the end-users. Indeed, the fact that consumers do not have the ability to properly use smart building technology, due to a lack of training and awareness, has also been identified as 
a barrier to good energy performance. Therefore there will be many different opportunities for job creation in the sector.

The quantity and quality of the jobs in these sectors may vary. The outcome will depend on the anticipation of the industry needs in terms of market evolution and occupations, and on the facilitation of up-skilling services that will meet their needs. The project found that the quality of the jobs is enhanced when labour market institutions, the education and training system and the industry communicate regularly, as well as when social partners (notably trade unions) are involved in the process of transformation. It is therefore advised to ensure that jobs are seen as a result, not as a mean, and that the coordination of actions to support adjustments in the green economy in the different sectors are defined and consulted with all the stakeholders - including the workers themselves. This will reduce tensions and will support the approval of actions by those directly affected.

\section{Skills for green economy}

The evidence suggests that there is strong potential for job creation in the green economy, but the skills needs may vary depending on the industry and the locality. This means that some workers may suddenly realise that their skills are obsolete if they are not involved in the definition of adjustments necessary to keep abreast of the transition, and also if the training is not made promptly available. Evidence gathered from this project suggests that the skills required to cope with the adjustments of the industries or the market are not necessarily "green", but will be such that enable workers to progress and have a decent quality of job, while businesses expand their activities in the green economy.

The meaning of skills refers to the abilities and capacities people have to perform tasks that are in demand in the workforce. These skills can be generic or specific regarding functions at work such as managing people, computing, collaborating or dealing with risk and uncertainty or developing a new product or service (Tether et al., 2005). These skills are usually acquired through education, training and/or experience.

The OECD has not endorsed a definition of "green skills" that could be adopted by all of its member countries, nor has it categorised any specific kind of "green skills". However, as suggested in the conceptual paper for this project, "green skills" could be considered converging, meaning that they do not necessarily represent a completely new set of skills but rather a mix between traditional skills with new skills. For the specific purposes of this project, "green skills" were defined as specific skills required to tailor products, services, processes or operations due to climate change/low-carbon adjustments, mitigation, requirements or regulations ${ }^{23}$. No specific "green skills" were identified as part of this project $^{24}$, but these so-called green skills were rather assessed to the needs of the businesses in the context of the transition to a green economy. The analysis of the key findings is described below.

\section{Green skills demand}

As it is likely that existing jobs evolve into "greener jobs", it is also more likely that existing skills sets become greener. From the various interviews with business representatives, it was made clear that the main concern remains the low level of generic skills base of the workforce which hinders the ability to adjust to new activities. The project surveys confirm this, as the results show that the skills demanded by firms in the context of the transition to a greener economy will continue to be relatively generic including literacy, numeracy, team working, communication and problem solving.

Moreover, attitude towards change was often considered by employees as a more difficult barrier than technical skills were to overcome. In addition, this project identified that certain skills of traditional sectors, including those shrinking sectors, can be essential in the green economy. There are very few 
unique skill sets required that do not already exist and that are not already applied to different sectors. Evidence from this project suggests that there will be some specific new skills required for the green economy $^{25}$, but that a strong basis of generic skills, with a complementary training, the identification of transferrable skills and some shades of green, can contribute to making a better and smoother transition towards a greener economy, facilitating the move of workers from one sector to another (see Figure 6).

Figure 6. What skills for the green economy?

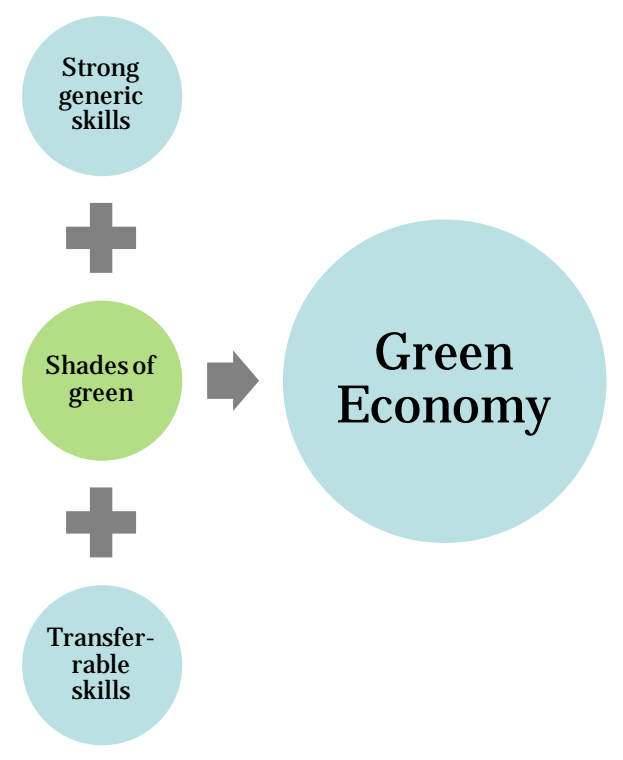

Source: Author

In Sydney, $70 \%$ of the surveyed firms said that the environmental sustainability changes resulted in the need to upgrade the skills of the workers or train them. Among these firms, the skills needed for the new jobs were mainly technical and managerial (see Figure 7). Also in London, according to the survey findings, technical skills have the highest demand. It is interesting to notice that in Sydney, the demand for specific green skills comes in third place. 
Figure 7. Sydney: What skills were needed in the new jobs?

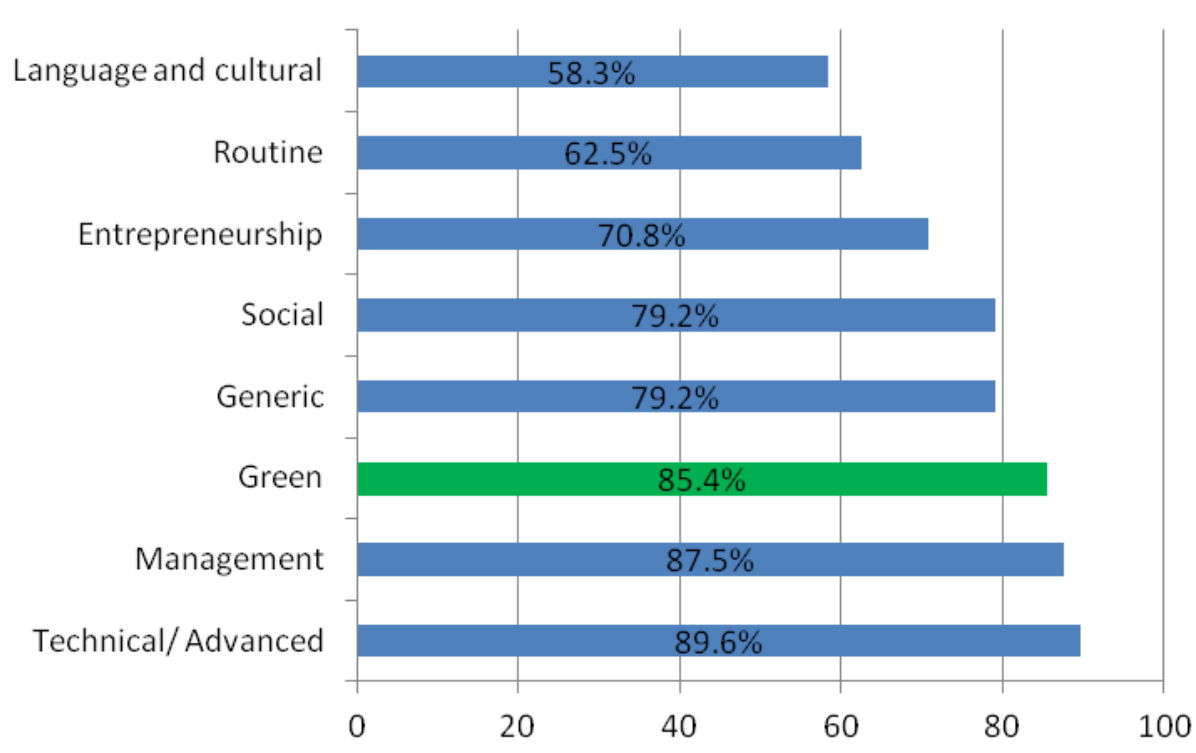

Source: Miranda, G., et al. (2011c), "Climate Change, Employment and Local Development in Sydney, Australia", OECD Local Economic and Employment Development (LEED) Working Papers, No. 2011/14, OECD Publishing.

For the purposes of this project, and specifically from the survey, a set of "green skills" was identified as presented in Table 3. During the interviews and in the surveys, the use of these "green skills" was assessed, namely with business and trade union representatives. The skills related to green management and green procurement were also tested with public authorities. Evidence from the study visits shows that there is little understanding of what a "green skill" is, and that there is no clear vision of the effects of the transition to a green economy on the workforce. Yet it is clear, notably in the private sector, that this transition will affect all kinds of occupations and that more generic "green skills" may be required namely to make processes, methods, products and services more environmentally friendly as the consumers' behaviour changes, and as regulations become more strict.

Table 3. Sydney: What specific "green" skills did your workforce acquire?

\begin{tabular}{|l|l|}
\hline Knowledge on certifications and standards & $81.5 \%$ \\
\hline Waste minimisation & $77.8 \%$ \\
\hline Energy efficiency & $74.1 \%$ \\
\hline Green procurement & $59.3 \%$ \\
\hline Technical use of new equipment & $59.3 \%$ \\
\hline Green management & $55.6 \%$ \\
\hline Measurement of greenhouse gas (GHG) emissions & $29.6 \%$ \\
\hline New low-carbon processes & $14.8 \%$ \\
\hline Carbon finance & $14.8 \%$ \\
\hline
\end{tabular}

Source: Miranda, G., et al. (2011c), "Climate Change, Employment and Local Development in Sydney, Australia", OECD Local Economic and Employment Development (LEED) Working Papers, No. 2011/14, OECD Publishing. 
Table 6 shows the results from the survey in Sydney which confirm the previous analysis. It is interesting to note that the types of "green skills" acquired by the workforce in Sydney among the surveyed firms is mainly concentrated in knowledge of certification and standards, and in efficiency (waste and energy) which are applicable to all kinds of occupations, at all levels of employees (high and low-skilled) and to private firms as well as to public sector organisations. On the contrary, the acquisition of particular green skills such as the knowledge of carbon finance or the new low-carbon processes, targeted mainly to highly specialised occupations, remains low.

\section{Meeting skills needs for new sectors}

Even if there is not a huge demand for specific "green skills", some new sectors in the green economy (e.g. renewable energy) may require new skills sets currently unavailable in the local labour market. Two scenarios to respond to the demand of new skills have been observed throughout this project under different contexts. A first scenario where the labour market institutions worked in more isolated environments, usually in places where regional ministries and policies are uncoordinated, skilled workers were mainly attracted from abroad. This means therefore that the jobs created were not taken by the local workforce, which creates reluctance towards these industries and social tensions in general.

A second more advanced scenario was found in places where the labour market institutions, education and other social partners (NGOs and trade unions) worked in close collaboration with the industry to identify and anticipate skills sets required for emerging sectors and to incorporate these into training or education programmes. This could only be achieved in a policy context where the actions are coordinated and clear to the market, and where the entrepreneurs have a high level of certainty regarding their business plans. The example of Extremadura is a good illustration of this approach (see Box 6).

\section{Box 6. Renewable energy training in Extremadura}

Solar photovoltaic energy was planned to increase in Extremadura from $0.54 \mathrm{MW}$ to $13.39 \mathrm{MW}$ between 2004 and 2010. In order to respond to demand of qualified workers, the regional government of Extremadura led the training for renewable energy specialists, as well as renewable energy project managers. The programme was managed by the Extremadura Regional Employment Office (SEXPE) together with a public regional enterprise FONAMA, in close cooperation with regional enterprises. Courses are oriented towards workers in the construction sector, employed in SMEs or self-employed. Its success lays in the coordination efforts made so that the labour market is able to anticipate future skills demands with accuracy. The objectives in solar energy involved the creation of 1069 jobs in solar photovoltaic energy and almost 2000 jobs in solar thermal energy during 2005-2010.

Source : Miranda, G., et al. (2011a), "Climate Change, Employment and Local Development in Extremadura, Spain", OECD Local Economic and Employment Development (LEED) Working Papers, No. 2011/04, OECD Publishing.

\section{Up-skilling to green existing sectors}

Another important issue regarding the skills for the green economy relate to those additional skills that will facilitate the transition to a green economy using the existent workforce. Evidence gathered from this project suggests that most of the occupations in the public and private sector will have a shade of green to a certain extent. The greenness will vary between the types of occupations and the sector involved. It is clear that jobs in the public sector may remain more traditional than jobs in the energy sector. However, all of the occupations will require some green skills that will be added to the standard skills. In the case of the public sector these skills may be on green public management or green public procurement, while in the case of the jobs in the energy sector these may be skills related to installation or specialised engineering. 
To ensure an up-skilling of workers in existing sectors turning "green", it appears essential to include raising awareness as a way to communicate the needs and benefits of acquiring these skills. Also, it is important to provide these skills through training in close proximity in order to ensure that the training is effective and has enough demand. The case of the Green Technology Centre in Poland provides a good illustration of a successful approach to up-skill workers and business owners to the needs of a green economy (see Box 7).

\section{Box 7. Green Technology Centre in Podlaskie}

The Green Technologies Centre is a publicly financed non-for-profit project in Podlaskie, Poland, that aims at developing business, creating jobs and counteracting unemployment on the basis of sustainable development activities. The GTC offers free training courses in 6 thematic areas and helps to adapt businesses to green opportunities. In addition, GTC offers more practical up-skilling methods such as workshops and visits to other countries' initiatives in sectors of relevance to the region such as wastewater and waste packaging treatment, traditional building and roofing, ecotourism, regional organic products and production of biomass. The beneficiaries of the project are workers and employers - mostly SMEs - connected with these activities.

The GTC shows a more holistic approach which is one of the key factors for its success. Indeed, it has promoted the creation of a local network that involves both public and private actors; it carries out sensitisation activities in the territories involved, while researching ways of improving local actors' competitiveness, exchanging experiences and methods and creating common products. The role of the GTC as broker between the businesses and the new market opportunities has proven successful in supporting the adaptation of businesses to a green economy.

Source : Miranda, G., et al. (2011d), "Climate Change, Employment and Local Development in Poland", OECD Local Economic and Employment Development (LEED) Working Papers, No. 2011/22, OECD Publishing.

\section{Identify transferable skills}

In the context of the transition to a green economy, evidence gathered from this project highlights the importance of identifying the transferrable skills that can be used in the greener sectors while making the best use of the human resources available locally. Industrial transformation is happening in most of the places analysed. Some industries are shrinking or have disappeared (e.g. shipyard in Pomorskie or automotive in Styria) while new industries are emerging or expanding (e.g. carbon finance in London or renewable energy in Extremadura). The identification of transferable skills from shrinking to expanding sectors is a powerful tool to facilitate the mobility of one sector to another, limiting the negative effects on employment and maximising the use of the skills available locally.

There are different approaches to do this. For instance, job placement offices receive regularly the information on the types of skills and occupations required in a local labour market. On the other hand, they are in direct contact with the unemployed and job seekers, and can identify the skills availability in the market and try to match them. However, this implies a strong capacity of the job placement officers to collect and analyse the data which is not always the case. A sophisticated system has been put in place in Alsace, France, (see Box 8) which identifies the opportunities for workers in shrinking sectors (e.g. textile or automotive) to move to an emerging or expanding sector (e.g. construction). This system requires a very advanced system of data gathering, analysis and monitoring. This example illustrates how to make use of this information to facilitate the transition to green economy activities. 


\section{Box 8. TransverS'AL}

The employment office of Mulhouse (MEF Mulhouse) undertook a mapping of existing sectors, the diagnostic of the opportunities in the low-carbon economy and the identification of potential or emerging sectors. This was combined with the distillation of the skills in each of the sectors (shrinking and expanding) and the potential use of these in the context of the green economy. Since 2003, almost 8000 manufacturing jobs have been lost in the automobile, chemical, food processing and machine construction/electronics industries in the region. MEF worked with partners on a "horizontal approach" to better support the transition of workers to more stable career paths within emerging sectors.

MEF opened dialogue within regional stakeholders by creating a platform for communication and exchange on industrial change, employment and skills. A four-month period of consultation took place with relevant regional actors in order to analyse the principle challenges facing the region, including economic change, the recognition and valorisation of the skills possessed by local people, and the need to define a common strategy for employment development which would make local career pathways more sustainable.

The focus was on the emergence of new jobs, particularly in the construction industry, where a number of local building firms came together to form a new "low-carbon" sustainable construction cluster. MEF Mulhouse undertook a number of related studies, including an analysis of the shifting labour market within the region to better identify the local destruction and creation of jobs. A study on the impact of the car industry in the region was carried out to examine the transferable skills possessed by its workers. Textile sector and the CFDT union also asked the MEF to double its efforts in tackling unemployment in the sector, through facilitating a transfer of skills to other sectors.

Most of the research was based on work already prepared by the some of the networks in place, for instance the association of professional training for adults (AFPA) and the industry representatives. The analysis of the sectors was carried out by the MEF Mulhouse in collaboration with the trade unions and the sector federations. The actors of the VET system were also involved in the process as they provide the training to meet the skill demands in expanding sectors. For instance, the pilot study for the project was called TEXBAT (acronym for Textile to Building sectors). It was prepared in collaboration with the federation of training in the textile sector (FORTHAC). Other analyses like this have been undertaken for shrinking sectors, such as steel and the automobile.

Source : Miranda, G., et al. (2011b), "Climate Change, Employment and Local Development in London, UK", OECD Local Economic and Employment Development (LEED) Working Papers, No. 2011/05, OECD Publishing. For further information on the platform, visit the website: www.monmetierdedemain.com

\section{Training for the green economy}

Training needs for the green economy are not very different from the needs in the traditional economy. As it has been argued in the previous section, specific green skills development is not high in the firms' training and skills needs. Other more generic skills seem to be more useful for the green economy. Evidence gathered from the project Leveraging Training and Skills Development in SMEs ${ }^{26}$ confirmed that SMEs face important obstacles to accessing training in general, but that informal knowledge intensive activities offer more flexible access to the knowledge required by firms to take advantage of green opportunities arising in the market.

The OECD surveys on "Leveraging Training and Skills Development in SMEs" and "Climate Change, Employment and Local Development” found low levels of demand for specific green skills training. When asked 'What formal education training have you or your staff undertaken in the past 12 months?' few respondents confirmed having had formal training on green skills. As Figure 7 shows, apart from Australia and Belgium, participation in specific green skills training remains marginal and firms do not demand green skills development. Indeed, despite the differences in business size, sectors and localities among the seven countries compared, there seems to be a margin for improvement in the quantity of training provided by private and public training institutions, as well as in raising the awareness to improve the training demands for green skills by enterprises. This confirms that specific "green skills" are generally still not considered as a key need for firms. Training in this field remains underdeveloped. 
Figure 8. Formal training in green skills (as \% of surveyed firms)*

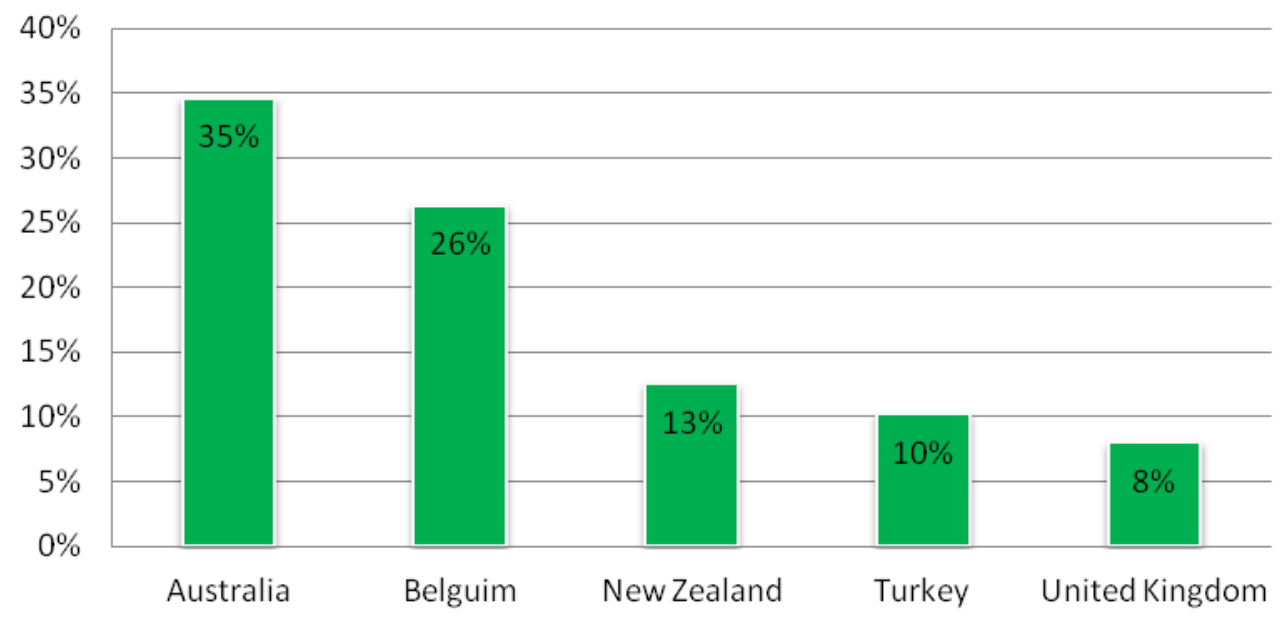

*Responses to OECD LEED surveys "Leveraging Training and Skills Development in SMEs" and "Climate Change, Employment and Local Development". The responses from the survey in Extremadura and Poland do not allow for comparison.

As shown above, Sydney in Australia has the highest level of participation in green skills training, probably thanks to a very well-positioned and state of the art system of vocational and educational training providers (Technical and Further Education, TAFE Institutes) along with the high level of sustainability awareness among the population. It is interesting to note that firms in London show low levels of training in green skills. This could be explained by the fact that businesses participating in the survey ${ }^{27}$ belong to the low-carbon sector and have therefore less need to train or up-skill their workforce to the changes towards green growth.

\section{Training: how to address the green economy?}

Evidence gathered from this project suggests that there are two reasons for this low level of demand of training in green skills. On the one hand, the limited availability of green training services in the market makes it difficult for businesses to find the right training. On the other hand, the difficulties for VET firms and trainers to design curricula that are relevant for businesses in their adjustment process also plays a role in explaining this low participation in green training.

To respond to this, governments need to invest in skills identification through labour market data collection, analysis and monitoring, but this implies a close collaboration with key stakeholders (businesses, trade unions, industry representatives) who could share valuable information for skills and training definition. Moreover, coordination between regional ministries of labour, employment, industry and environment is essential to ensure the actions are coherent with a regional plan. All this should be accompanied with infrastructure and good qualified trainers. More often, the best trainers are the business owners but also the industry representatives and even some of the firm representatives of the supply chain. Also, evidence from the project suggests that informal ways of skills acquisition are valuable sources of knowledge and should be considered more systematically. Some of the most effective approaches identified are described below.

\section{Offer solid skill base, then add-on}

As previously discussed, the findings of this project suggest that a solid basis of generic and core skills, together with positive attitudes towards the green economy, are essential for the transition to a greener economy. Additional expertise in emerging sectors in a specific locality (e.g. wind, marine, solar, 
geothermal) could best be acquired through the integrated provision of 'add-on' specialism modules such as within third and fourth years of undergraduate courses, through Masters Degree/ Postgraduate Diploma provision and through training courses. Indeed, training programmes should take account of the skills individuals already possess and then provide additional up-skilling in the specialism area required to obtain employment. This kind of up-skilling is usually provided internally, either within the firm itself or in collaboration with providers and other firms of the supply chain (Box 9). However, training institutions could facilitate these courses by designing them in collaboration with the private sector. Certified training programmes could also attract more demand as they would be recognised across the whole industry.

\section{Box 9. Bartosz company: On-the-job training provision}

Bartosz Sp.j. Bujwicki, Sobiech Cybulko is a sanitary engineering company, providing equipment and complete systems that deliver significant cost savings by reducing water, heat and electricity consumption. The company has also recently entered the field of ventilation combined with heat recovery.

The company employs a mix of university-educated workers and manual labourers: $30 \%$ of the employees are estimated to have been educated to tertiary level (engineers), $40 \%$ are skilled manual labour (trained largely on the job) and $30 \%$ are lower-skilled workers. The company provides them with a clear career path to progress ('individualised training paths') and workers tend to change job profile over time.

On average, engineers require 3-4 years of internal training on-the-job. This is considered a pivotal part of their learning and development. They also require training by suppliers of the various components of the technology. The company cooperates with renowned research centres in Poland and offers extensive training programmes for external engineers so they know how to install the company's components elsewhere. The company also hires external companies to provide training to welders and manual labourers. Other training requirements include health and safety, which requires certification.

Source : Miranda, G., et al. (2011d), "Climate Change, Employment and Local Development in Poland", OECD Local Economic and Employment Development (LEED) Working Papers, No. 2011/22, OECD Publishing.

Information gathered from the various study visits confirms that formal training for green skills development is still irrelevant. From the interviews it was clear that this was partly due to the absence of a clear definition of green skills in the localities, as well as the poor availability of this kind of training in general. For instance, in London, among the firms experiencing skills gaps, only $42 \%$ address these gaps through the provision of formal training, while $29 \%$ recruit new staff.

However, Sydney is certainly an exception. As the survey results show, in Sydney the formal training is fairly varied (see Figure 9). Green skills development is provided in about 1 in three of the firms surveyed. These results are relatively high when compared to the other countries. This may be explained by the high environmental awareness of the population, the excellent vocational and further education institutes, as well as the NSW Green Skills Strategy which identifies nine priority industries for the region $^{28}$. 
Figure 9. Sydney: What formal education training have you or your staff undertaken in the past 12 months?*

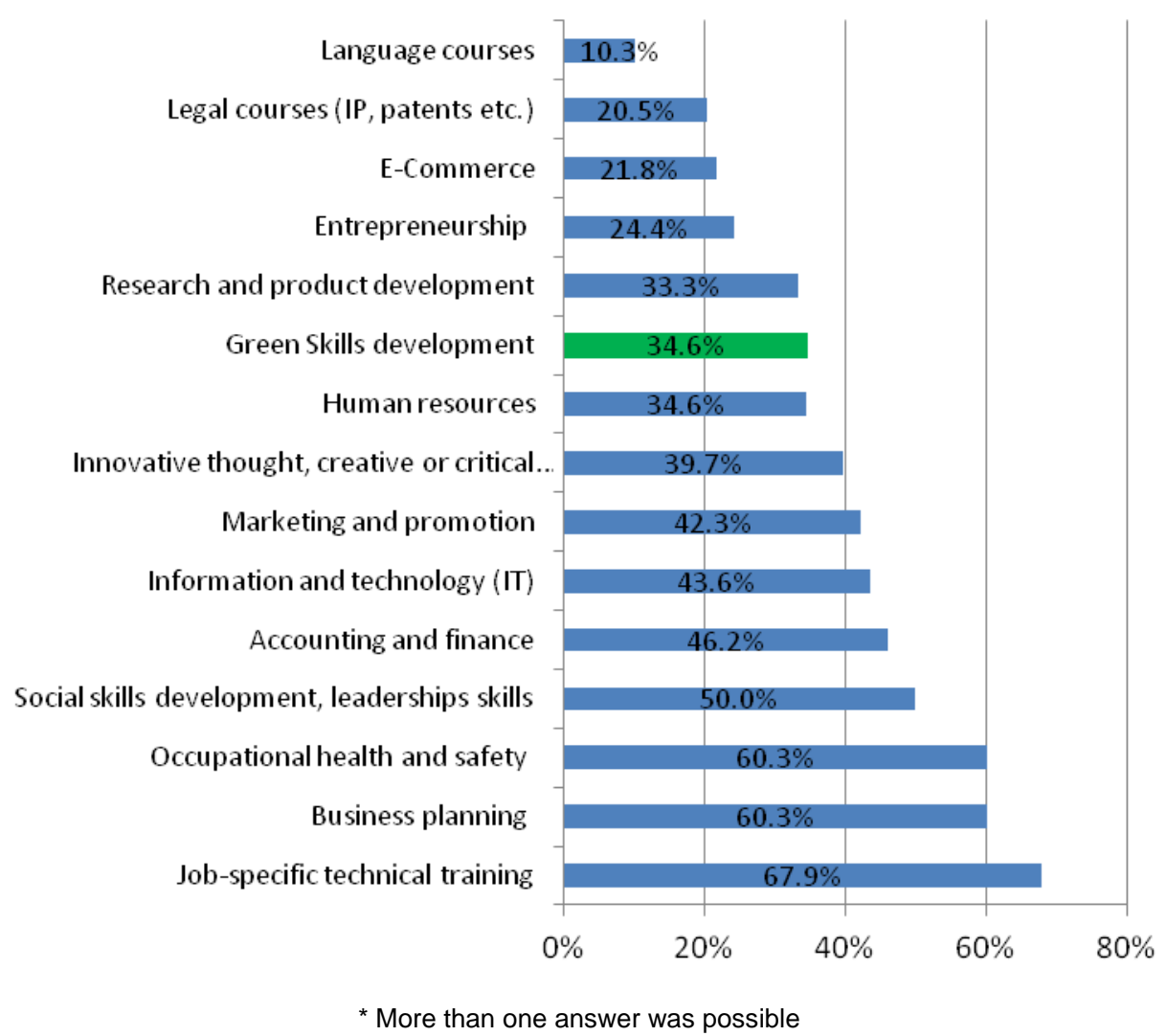

Involve businesses in curricula development

Findings from this project suggest that a more structured system of linking employers, HEIs / VET institutions and labour market institutions with one another to identify skills gaps and develop skills development responses needs to be established. In part, this requires a need for greater business representation to ensure qualifications are selected correctly and that the training and education programmes designed are relevant to the industry. An enterprise could help by collaborating with education in the shaping and development of project-based course work. Many companies consider well structured internship programmes to enhance graduate employability and benefit both the student and employer. Internships could identify learning goals and outcomes, with credits given towards the achievement of a qualification award. Smaller companies could come together within a locality, pooling resources to offer a graduate internship opportunity between them.

Businesses often take their own initiative to offer training to students in this area and are seen as more reactive in comparison with the public sector. In addition, some companies have well-developed and rigorous selection procedures, which make them well-placed to make observations about the suitability of current graduates when filling certain job profiles.

\section{Green the curricula across disciplines}

More diversity needs to be promoted in university faculties in terms of the variety of courses provided relating to environmental skills provided. Currently, universities are limited in providing courses on environmental engineering and protection, whereas courses need to be developed that encourage more 
innovation in science and technology and R\&D. Plans are currently underway to introduce a pilot scheme that provides technical universities with grants to develop curricula and to open new facilities in relation to renewable energy, more initiatives such as this need to be developed.

\section{Validate informal qualifications}

Evidence from this project confirms that the recognition of informally acquired qualifications is an important way to up-skill the labour force and to respond rapidly to an emerging demand. A flexible approach towards validating skills acquired through on-the-job training or informal training offered by trade unions and other social partners should be adopted to ease the transition to new or greener occupations. The system of validation should concentrate on effectiveness and avoid procedures which are too cumbersome in terms of allowing recognition of the more informal skills which have been developed by low-skilled workers in particular. In the Pomorskie region in Poland, for instance, efforts are moving in this direction, with a programme for validating 'informal skills' being initialised to recognise those with no formal qualifications. Trade unions are also actively involved in validating the competences of workers within the construction industry, and are working with employer organisations to validate those of the bricklaying and roofing sectors ${ }^{29}$.

\section{Training: who does what?}

\section{Public training institutions}

To facilitate the participation of business in training and to have a relevant vocational education and training system, it is essential to have the right programmes and facilities to make training more industryoriented and practical. This requires investment in programme definition, infrastructure and quality trainers. A state-of-the-art model is the TAFE Institutes in Sydney (Box 10) which combine modern and innovative teaching facilities and techniques relating to education and training in the sustainability agenda.

TAFE's model relies on a mix of aspects. The recent investment in green skills infrastructure was partly derived from the Australian Government's investment in green capital infrastructure. In addition, industry is engaged with developments in the VET sector, but also with having contacts with local businesses or having recently joined teaching from industry. This has enabled the VET sector to develop a wide range of industry relevant training - often top-up courses - to equip the existing and future greener workforce in Sydney as needs change.

\section{Box 10. TAFE NSW Metropolitan Institutes}

The NSW Technical and Further Education (TAFE) Institutes provide a range of vocational education and training in Sydney with more than 500K enrolments annually. TAFE NSW operates through ten Institutes, four of which are based in the Sydney metropolitan area. All four metropolitan institutes are involved in providing skills training for sustainability and each offers leadership in different areas as shown below.

- The Sydney Institute has established a Sustainable Hydraulic Trade Centre at its Randwick College campus, funded by a $\$ 6.4$ million grant from the Federal Government's Education Investment Fund (EIF). The Centre allows training in best practice green building skills to be delivered with a focus on hydraulic trades, including waste water treatment and reuse, evacuated tube water heating and rain water harvesting.

- In 2010, the Green Skills Hub facility was opened at the Nirimba Precinct of the Western Sydney Institute. This facility is a Living Laboratory designed to model sustainable practices and provide innovative training in the subject areas of green electrical engineering, plumbing, refrigeration and information technology. It was funded under the Federal Government's Training Infrastructure Investment for Tomorrow initiative.

- In August 2009, the Northern Sydney Institute obtained a Federal Government grant to expand an onsite 


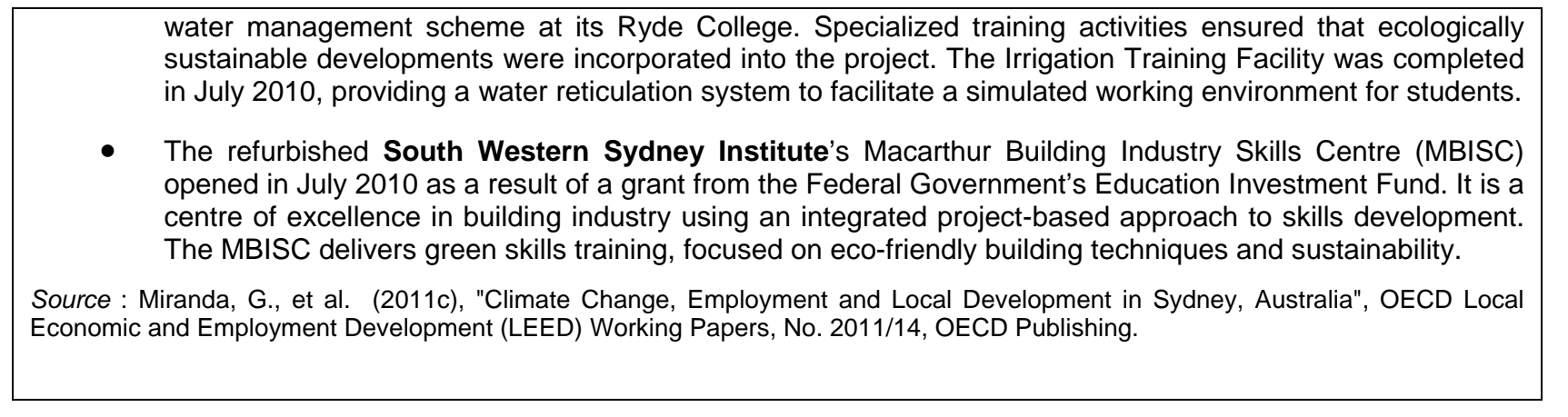

\section{Non-governmental organisations}

NGOs are typically involved in the definition and delivery of training. Their role is often underestimated as their training is usually highly relevant to the industry needs as they are often closer to the people and understand the local context better thanks to their proximity. Evidence gathered from this project suggests that NGOs are very valuable in providing "green" skills training in the non-formal sector. They provide a wide range of activities to move people out of social exclusion through learning and social work. Some places are attempting to recognise such non-formal learning through the qualifications system, but greater support should be given to NGOs to allow them to enhance their role as training providers.

Further to training provision, some non-for-profit organisations are playing an important role putting together economic and ecologic activity, showing the possibilities regarding the creation or adaptation of new activity and jobs in the green economy. As an example, at the Pomorskie-based Learned Society of the Organisation and Managements $\left(\mathrm{TNOiK}^{30}\right.$ ), an 85-year old NGO has worked within EU funded projects in mapping competences in the labour market, detecting the need of introducing horizontal "green competences" and training low-qualified workers, private managers through the social corporate responsibility, as well as public servants. TNOiK acts also as a mediator between ecological NGOs and the public sector, and between the scientific sphere and the general public in awareness raising campaigns.

\section{Cooperatives and social enterprises}

From the study visits to the more rural areas in Extremadura in Spain, and Podlaskie in Poland, as well as to Trento and Styria as part of the broader set of field visits ${ }^{31}$, it was clear that training provision in more sparsely populated areas is more difficult. There is not enough critical mass to actually drive the adjustments as in places where there is either a concentration of businesses (even small) or a specialised industry cluster. The connectivities among the businesses are weak, and the collaboration between the private sector and the training and education providers is almost inexistent. The challenge is therefore more difficult to tackle. The traditional industries abundant in these regions are usually reluctant to adopt new approaches to change, including up-skilling. An interesting approach to training delivery was found in the Province of Trento, in Northern Italy whereby the cooperatives contribute to organise, simplify and rationalise training infrastructures by easing the collection and analysis of skills needs (see Box 11). 


\section{Box 11. Cooperatives as training providers: The case of Trento, Italy}

Trentino, with a population of approximately five hundred thousand inhabitants, is home to 600 cooperatives involving 227000 members (i.e. two families out of three are involved in the cooperative movement). The "Federazione Trentina della Cooperazione" is a unique model, supplying its affiliated companies with a number of services including training, financial services, and social services. Cooperatives and other forms of social entrepreneurship have played a key role in the flourishing of the economy in Trento, which is one of the richest provinces and best organised in Italy. The "Federazione Trentina della Cooperazione" organizes education and training supply and information and awareness raising services. Education and training provision is managed by "Formazione Lavoro", which undertakes a "holistic approach" to training by carrying out skill needs analysis for the Federazione's members. For instance, "Formazione Lavoro" developed a "curriculum of the cooperative member", whereby each person's skills and career development is taken care of, from skills audit, to a service of counselling and continuous assessment, also with reference to new skills, to the evaluation and validation of skills and competences. With a majority of SMEs, an important green potential, large agricultural production, and the need to manage adaptation to green transformation, the cooperatives seem to be a model relevant to sparsely populated areas.

Source : Miranda, G., et al. (2011a), "Climate Change, Employment and Local Development in Extremadura, Spain", OECD Local Economic and Employment Development (LEED) Working Papers, No. 2011/04, OECD Publishing.

\section{Trade unions}

Beyond training provision on-the-job, trade unions play also an important role in raising awareness and communicating the opportunities of the green economy. A good illustration of this is the Trade Union of Manufacturers of Renewable Energies in Pomorskie which is working in collaboration with the Polish Biogas Association and the Learned Society of the Organisation and Managements to raise awareness of opportunities in the green economy. It is an interesting approach to foster the links and cooperation between entities of the third sector and social partners in order to raise awareness, support economic activity, prepare the workers to the green economy and ensure that jobs are decent. The role that trade unions can play in the transition to a green economy should therefore be enhanced, by supporting their activities and by involving them in decisions made towards workforce development and job transformation. This would guarantee a smoother transition in terms of social impacts and a more positive attitude towards change.

\section{ENDNOTES}

${ }^{8}$ The survey shows that in London, $60 \%$ of the firms having created jobs, have opened just 1 or 2 positions, $30 \%$ between 3 and 10 jobs and only 10\% of the firms have created more than 10 job positions. The survey in Sydney shows that $44 \%$ of the firms created 1 or 2 new jobs, 39\% between 3 and 10 jobs and only $17 \%$ of the firms created more than 10 jobs.

$9 \quad$ OECD LEED Project on The impact of demographic change on local employment (PoW 2011-2012)

See: London Development Agency (2010), Skills for a Low Carbon Economy, DTZ and Innovas. 
See for instance TUAC (2009) "Trade Unions Statement to the Pittsburgh G20 Summit: Global Unions Pittsburgh Declaration", available at: www.tuac.org/fr/public/e-docs/00/00/05/57/document_doc.phtml, accessed 17 October 2011. Also: UNEP, ILO, IOE, ITUC (2008a), "Green Jobs - Towards Decent Work in a Sustainable, Low-Carbon World", report produced by Worldwatch Institute and commissioned by UNEP, ILO, IOE, ITUC, Nairobi.

According to Wider Opportunities for Women, a Washington DC-based economic advocacy organisation

Wider Opportunities for Women-WOW (2009), Women and the Green Economy, An Opportunity for Economic Security, USA. www.WOWonline.org

Martinez-Fernandez, C., Hinojosa C. and Miranda G. (2010), “Greening Jobs and Skills: Labour Market Implications of Addressing Climate Change”, OECD Local Economic and Employment Development (LEED) Working Papers, 2010/2.

For further details on each criteria, see Martinez-Fernandez, C., C. Hinojosa and G. Miranda (2010), "Greening Jobs and Skills: Labour Market Implications of Addressing Climate Change”, OECD Local Economic and Employment Development (LEED) Working Papers, 2010/2. Page 26

See for instance Michael and Murphy, (2009) 'Green Jobs: Fact or Fiction? Institute for Energy and Research

Martinez-Fernandez, C., Hinojosa C. and Miranda G. (2010), “Greening Jobs and Skills: Labour Market Implications of Addressing Climate Change”, OECD Local Economic and Employment Development (LEED) Working Papers, 2010/2.

Project named: The Production of Renewable Energy as a Regional Development Policy in Rural Areas. Led by the OECD Rural Development Programme.

Fitzgerald, pp. 35, 147; Apollo Alliance, Make it in America: the Apollo Clean Transportation Manufacturing Action Plan, October 2010, available at: http://apolloalliance.org/downloads/tmap_fullreport.pdf.

Nisha Mistry and Joan Byron, The Federal Role in Supporting Urban Manufacturing, Pratt Center for Community Development and Brookings, What Works Collaborative, April 2011, p. 16, available at: http://www.brookings.edu/papers/2011/04_urban_manufacturing_mistry_byron.aspx.

Executive Office of the President, A Framework for Revitalizing American Manufacturing, December 2009, available at: http://www.whitehouse.gov/sites/default/files/microsites/20091216-maunfacturingframework.pdf.

\section{See: $\underline{\text { www.cereb.org.uk }}$}

Martinez-Fernandez, C., Hinojosa C. and Miranda G. (2010), “Greening Jobs and Skills: Labour Market Implications of Addressing Climate Change”, OECD Local Economic and Employment Development (LEED) Working Papers, 2010/2.

The ILO is carrying out work on the identification of green skills. For further detail see work by ILO on Skills for Green Jobs (ILO, 2011) and the series on sector-specific skills needs for the green economy of the EC and the ILO Skills and Employability Department. Full references in the bibliography of this report. 
$25 \quad$ For further detail on these skills, see work by ILO on Skills for Green Jobs (ILO, 2011) and the series on sector-specific skills needs for the green economy of the EC and the ILO Skills and Employability Department. Full references in the bibliography of this report.

See OLIS document CFE/LEED(2011)12, Leveraging Training and Skills Development in SMEs: Enhancing Productivity and Return on Investment.

See information on survey and samples for further details.

The NSW Department of Education and Training, in partnership with the Department of Environment and Climate Change and Water and the NSW Board of Vocational Education and Partnership, has released the NSW Green Skills Strategy. The Strategy identifies nine priority industries: manufacturing, electricity and gas, water, construction, agriculture, forestry, fishing and land management, wholesale and retail trade, transport and storage, property and business services and government administration (especially local government). For further information see Miranda, G., et al. (2011c), Climate Change, Employment and Local Development in Sydney, Australia, OECD Local Economic and Employment Development (LEED) Working Papers, No. 2011/14, OECD Publishing. Local Economic and Employment Development (LEED) Working Papers, No. 2011/22, OECD Publishing.

For further information see: www.tnoik.org

Four full case studies (Miranda, G. et al 2011a, Miranda, G. et al 2011b, Miranda, G. et al 2011c, Miranda, G. et al 2011d): Extremadura (Spain), London (UK), Sydney (Australia), Podlaskie/Pomorskie (Poland). Capacity building seminar and study visit: Local strategies for greening jobs and skills (Trento, 9-11 June 2010). Study visit: Styria, Austria (11-13 October 2010). Seminar: Green growth - An opportunity for local development and employment (Paris, 8 December 2010). 


\title{
CHAPTER 3.
}

\section{INDUSTRY DYNAMICS AND THE GREEN ECONOMY}

\begin{abstract}
The chapter examines the responses of local industry to climate change. It examines different regional industry characteristics and how industries in some local economies are better positioned than others to respond to the challenge of climate change. The chapter explores some of the forces that are driving or will increasingly drive change at the industry level. Further, it examines some of the barriers to green growth, including low take-up of new technologies and lack of skills. The chapter outlines some of the experiences that are relevant to industries seeking to position themselves in the low-carbon economy.
\end{abstract}

\section{Climate change and industry restructuring}

Climate change policy has significant implications for industry in different ways. This includes limiting greenhouse gas emissions from carbon intensive industries; restructuring and, in some cases, phasing out of industries that can meet the cost of carbon pollution; encouraging the shift from higher carbon intensive industries to lower carbon intensive or renewable industries. It also involves promoting the development of low-carbon and renewable technologies, as well as skills, that can be incorporated in existing and new industries.

The conceptual framework of this project ${ }^{32}$ suggests that all local economies with significant emissions will not only need to develop longer term low-carbon economic strategies, but they will also need to take short-term steps to accelerate industry restructuring to reduce carbon emissions. Reaching the

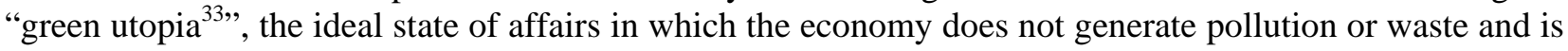
hyper-efficient in its use of energy, water, and materials, will take time and coordinated efforts to support industry adjustments through eco-innovation (see Figure 10).

Figure 10. Stairway to green utopia

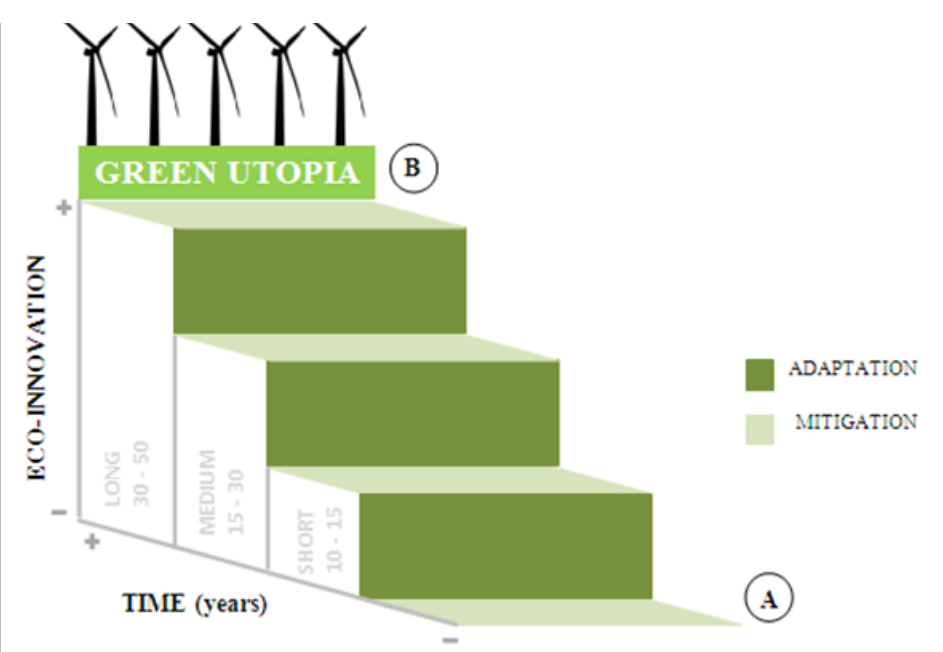

Source: Martinez-Fernandez, C., Hinojosa C., Miranda G., Greening Jobs and Skills: Labour Market Implications of Addressing Climate Change, OECD LEED Working Paper No 2010/02. 
Linking local carbon reduction, not only with the costs of abatement, but also through identifying and implementing new economic opportunities, is central. If industries and households invest earlier in carbon adaptation and mitigation measures, this may enhance new industry and employment opportunities. This is particularly the case for early-mover enterprises that invest timely enough in low-carbon technologies to enhance their competitive advantage. Further, enterprises and local economies that do not invest in lowcarbon technologies will be at risk of being locked out of low-carbon growth markets and may experience reduced market share in existing markets because they are unable to meet higher environmental standards.

\section{Drivers of industry change}

Market and public policy are significant forces driving local industry change towards the lower carbon economy ${ }^{34}$. Industry investment and employment trends are increasingly associated with a price on carbon (or anticipation of a carbon price), restrictions on more carbon intensive activities, and direct action to provide incentives for low-carbon industries ${ }^{35}$. In OECD countries, households are beginning to change their consumer preferences towards products and services with green attributes, particularly when they are well-informed and are given incentives to shift towards greener consumption ${ }^{36}$. This shows that public policy can re-orient incentives towards patterns of production and consumption that reduce emissions, encourage clean energy and facilitate the growth of low-carbon industries.

To assess how industries are responding to climate change policy and trends, this project has identified four main drivers that are impacting industry investment and employment decisions: (1) marketbased policy instruments, (2) the regulatory environment, (3) green stimulus packages, and (4) household behaviour and consumer preferences. These are briefly analysed in this section.

\section{Industry and market-based instruments}

Many countries are adopting carbon taxes and/or emission trading schemes. The main rationale for putting a price on carbon is that it sends signals to industry and households to cut their emissions. Hence, with carbon pricing, the price of goods and services will not only reflect inputs of capital, labour and raw materials, but it will also reflect the cost of a negative externality, environmental damage associated with producing the final good or services. Many economists argue that if markets work well, then carbon pricing, by creating an incentive to shift from carbon intensive to less carbon intensive activities, will be the most efficient of reducing emissions. Although there is a debate about the impact of carbon pricing on industry competitiveness, much of the modelling and economic literature suggests that the impact on most industries will be slight, with the exception of highly energy-intensive industries such as aluminium and cement $^{37}$.

Evidence from this project suggests that, even when the market sends messages to firms to shift from higher to lower-carbon intensive activities, they will not always do so. Indeed, the four case study reviews for this project highlight the low level of awareness of energy-efficiency cost savings in the private sector. There are several reasons. Many companies, particularly SMEs, do not have good information about the most efficient carbon abatement measures. Some companies lack good market intelligence about emerging opportunities. They often do not have the skills and internal resources to address emerging challenges, such as the implications of climate change policy in their business, and will continue to engage in more carbon and energy intensive activities even if the life cycle costs of low-carbon technologies are lower. These "capability failures" concern not only the internal development of new products and technologies, but also lack absorptive capacity within companies to make use of externally generated knowledge. Moreover, some small firms will not invest in low-carbon $R \& D$ and innovation technologies because of concern that other larger companies will exploit the opportunities. 


\section{Regulatory environment}

The case for environmental regulation as a driver for innovation has been made by industrial economist Michael Porter. The Porter-Hypothesis, as it is called, argues that environmental regulations can make companies more competitive ${ }^{38}$. This is because regulations can establish market conditions favourable to rapid sustainability innovation. Governments at all levels have introduced a plethora of regulations and instruments to direct and control industry behaviour in relation to climate change. These include mandatory carbon reduction targets, technology-based standards, performance-based standards, fuel content, energy efficiency targets and directives, eco-labelling, renewable targets, compulsory reporting on carbon reductions, and certification requirements. It is important to highlight that these regulations will have a different impact on industry depending on their level of stringency, flexibility, predictability, depth and incidence ${ }^{39}$. For instance, the OECD has found that the more "flexible" (or technology-neutral) a policy regime is, the more innovation takes place. This implies that rather than prescribing certain abatement strategies (such as technology-based standards), wherever possible governments should give firms stronger incentives to seek out the best means to meet a given environmental objective (OECD, 2011d).

Regulations can be designed to focus on specific industry sectors such as commercial buildings, vehicle manufacturing and energy intensive industry. In many cases, they can spur innovation within localities, businesses and across supply chains, and increasingly push enterprises up the value-added chain. For example, green specifications can be enforced through sub-contracts as it in the case of the Olympic site in London where the eco-building standards go beyond the national standards. Also, green public procurement can pressure companies to upgrade technologies and skills as is the case in Styria, Austria.

Evidence from this project confirms that the regulatory environment is also a driver of industry change. A successful transition to a low-carbon economy will therefore require a combination of marketbased and regulatory policies to drive innovation and diffusion of low-carbon technologies, practices and processes. Low-carbon regulations need to be designed in a way that they complement market-based instruments and not compete with them. Related to this, local initiatives, including regulations, need to be closely aligned with national and global policy frameworks and objectives. To be effective, regulations need to be carefully designed, implemented and monitored. They need to be clear what their objectives are, they should not lock localities into inappropriate technology trajectories, they should be administratively simple and their impact on industry competitiveness needs to be constantly monitored and reviewed.

\section{Industry and green stimulus}

The economic and employment opportunities associated with low-carbon and other forms of green growth were highlighted by different government responses to the onset of the Global Financial Crisis. Many governments adopted policies to stimulate the growth of low-carbon and broader green industries. Others used fiscal stimulus/recovery packages to support the growth of local low-carbon industries ${ }^{40}$. The substantial commitment by governments during this period was, in part, an attempt to respond to their climate change responsibilities. But they were also an attempt to capture global competitive advantage by supporting the growth of green industries and employment. These industries were seen to have long-term growth prospects.

Evidence from this project emphasises the importance of these stimulus packages in providing a virtual laboratory to evaluate the effectiveness of different approaches to encouraging green growth ${ }^{41}$, encompassing a whole range of measures including energy efficiency upgrades of existing buildings, development of renewable energy sources, public investments in green infrastructure, car-scrapping programmes and basic green R\&D. However, these stimuli can only have a positive impact on industry if they are clearly presented, easy to access and within a long term framework. From the analysis of this 
project it was made clear that shifts in governmental decisions and unclear objectives in the longer run create more vulnerability in the market and uncertainty in the industry.

\section{Household behaviour and consumer preferences}

Findings from an OECD survey conducted over 10000 households in 10 OECD countries ${ }^{42}$ confirm the importance of providing the right incentives to spur the greening of households. The study found that the provision of good information and public education, which can be linked to changing norms and sense of civic responsibility, has important impacts on changing demand patterns. The survey also reinforced the importance of clear information about product characteristics, particularly the eco-labels that identify the public and private benefits of particular products. More local authorities are involved in green purchasing programmes and therefore have an important role to play as market participant (see Chapter 4). By using their purchasing power, local authorities not only support climate protection, but they also stimulate demand and hence improve opportunities for local industry to supply greener products. Same for businesses, as they are users of inputs from other firms in the supply chain and can trigger a spill-over effect.

Evidence from this project suggests that changes in household behaviour and consumer preferences have an impact on local industry composition, as companies respond to the growing significance of green attributes in the goods and services they produce. This corresponds to the "green social conscience" represented in Figure 1 of this report. The growing environmental awareness, supported by market-based incentives, regulatory measures and education and information-based policies, can be a spur for industry to focus more on green product and service development and innovation, particularly in areas such as the deployment of energy-efficient technologies, smart meters and low-carbon supply chains. As consumers, including businesses and governments, shift their preferences toward products with green attributes, this will send signals to industry to improve the environmental quality of their products in order to remain competitive and to increase their market share.

\section{Emerging industry models in response to climate change}

Enterprises and industries are responding to climate change policy. This project has analysed some of the different local approaches in the various case study localities and learning models identified. Some originate as a result of central government policies and programmes to accelerate the transition to a lowcarbon economy. Some arise out of the need for industries to collaborate at a local level to enhance competitiveness. In some cases, major upfront investments are made to establish new low-carbon industries, while, in other cases the emphasis is on restructuring existing industries. This section looks at four broad approaches and a number of specific learning models that aim to accelerate industry dynamics in different conditions.

\section{Industry clusters}

Some localities are making the transition to a low-carbon economy through identifying green industry clusters sectors that are responding to the challenges and policies associated with climate change. Industry clusters are geographic concentrations of interdependent firms and institutions. Through local collaboration, improvements can be made across a whole supply chain. This includes a reduction in carbon-intensity. The rationale for clusters is that strengthening interaction between local companies, research and education organisations and government agencies will improve competitiveness, not only of an individual company, but of a whole sector or group of activities. Examples include renewable energy, green buildings and materials, energy-efficient vehicles and bio-fuels, lean manufacturing, and waste and recycling. Successful green clusters are not only concerned with reducing environmental damage but they also give attention to improving resource efficiency, product development and cost competitiveness. 
Evidence from this project confirms that green or clean tech clusters are an effective way to support the emergence of economic activity in a locality in the context of a green economy. Examples of successful green clusters identified as part of this project include the Habitech Energy and Environment Cluster based in Trentino, Italy (see Box 12), and the ECO World Styria clean tech cluster in Austria. These models give high priority to the development of green and ecological technology and products, and have put a number of initiatives in place designed to enhance their respective regional industry competitiveness in the green economy. These models have had important effects on the regional economy. Firstly, they have led to the increase innovation and knowledge transfers among businesses and to the strengthening of collaborations between businesses and research/education institutions in the locality. Secondly, these have contributed to position the region at national and international levels as references in their sectors. Thirdly, these clusters have contributed to the identification of skills needs, to the provision of customised training, as well as to anticipate industry adjustments to meet the demands of a green economy. Lastly, these clusters have resulted in the creation of jobs and other intangible assets (such as eco-standards) that contribute to the valorisation of the region and the retention of human capital and investment locally.

\section{Box 12. The Habitech Cluster in Trento}

The Habitech Energy and Environment Cluster consists of over 300 companies and 8000 employees, and involves research organisations and public agencies. Formed in 2006, an initial priority was to improve green credentials of manufacturers and companies associated with the building industry. The first project was in the area of sustainable construction. The aim was to promote green building through the introduction and adaptation of green building standards to the regional context. Habitech worked with the US based LEED® (Leadership in Energy and Environmental Design) to adapt it to Italian conditions, resulting in the formation of the Green Building Council Italy. Habitech provides a number of services including support and technical assistance for any project aspiring to LEED ${ }^{8}$ certification, consultancy and technical support for manufacturers and industry associations seeking to produce LEED ${ }^{\circledR}$ compliant products, and consultancy to public agencies and governments. Networks of member firms collaborate and use their green credentials to bid for projects. Over time, the cluster has expanded its activities into new areas. The group is supporting the formation of Energy Service Companies, including technical support to provide solutions which include designs and implementation of energy savings projects, energy conservation, energy infrastructure, power generation and also energy supply.

Source : OECD Study visit to Trento, Italy, 9-11 June 2010

\section{Transformation of existing industries}

Traditional industries in OECD countries are experiencing long-term restructuring due to trade liberalisation and associated intensification of global competition from lower cost countries. Many are concentrated in localities with relatively high unemployment, and contain a relatively high share of companies in low growth industries. Some of these industries are energy intensive and engaged in mature markets. As a consequence of intense competition and low margins, they lack resources to invest in more advanced technologies to improve efficiency. The climate change policy agenda, by imposing costs on carbon polluting industries, puts further pressure on these industries. On the other hand, many companies in these industries have important technological and infrastructure assets and highly skilled workers. In a growing number of instances, companies in traditional industries are exploring investment opportunities in the low-carbon economy as a means of shifting production to high growth green industries.

An interesting example of the transformation of an existing industry into a greener industry is the case of the Gdansk shipyard in Poland, as well as the Harland \& Wolff Heavy Industries in Belfast, Ireland (see Box 13). The latter, confronted with declining market opportunities in its core ship building and offshore platform construction activities, embarked on a strategy over the past decade to diversify into emerging 
technologies, particularly renewable energy. The company has managed to evolve through transferring skills derived from ship building and manufacturing offshore oil and gas equipment, and adapting the workforce and their supply chain to produce wind turbines. The company's competitive strength is the shipyard facility, because part of the assembly must be done in a shipyard, before tower sections, rotors, and nacelles to the site for final erection and assembly.

The opportunity to restructure the company towards renewables is driven by the commitment by the United Kingdom to significantly increase the share of energy provided by renewables to $20 \%$ by 2020 . The United Kingdom is today the world's largest generator of offshore wind power generation. Offshore installations are growing faster than onshore power generation, with one projection indicating the United Kingdom will construct 7500 new offshore wind turbines between 2008 and 2020.

\section{Box 13. From shipyard to wind turbine}

Harland \& Wolff (H\&W) is a heavy engineering company created in 1858 in Belfast. Its ship building operations were large and varied and included the construction of HMS Titanic. As demand for ocean liners declined with the emergence of the aviation industry and cheaper shipyards around the world reduced their competitiveness, the company diversified into offshore oil and gas markets (constructing offshore platforms, oil rigs, floating production storage and offloading equipment, and drill-ships). In 2002, using the skills and infrastructure from their ship building and offshore platform experience, $\mathrm{H} \& \mathrm{~W}$ embarked on a further diversification strategy, changing their name to Harland \& Wolff Heavy Industries. While they continue to retain a foothold in the shipbuilding and offshore oil and gas markets, they now also produce a range of renewable energy products, such as turbines for offshore wind farms, wave and tidal energy devices, as well as decommissioning ships at the end of their lives in an environmentally sustainable manner.

Another successful example is the Gdansk shipyard in the Pomorskie region in Poland. The Polish Wind Energy Society, headquartered in Gdansk, has recently launched initiatives to explore the installation of offshore wind farms in the south Baltic Sea region. Gdansk's strong scientific and technical base has supported organisations that have the expertise to pursue this kind of innovative ventures.

Source : Miranda, G., et al. (2011d), "Climate Change, Employment and Local Development in Poland", OECD Local Economic and Employment Development (LEED) Working Papers, No. 2011/22, OECD Publishing.

Another example of a larger industrial transformation was identified in the United States ${ }^{43}$. A smaller onshore wind project in Lackawanna, New York, has an aspiration to convert the Rust Belt to the Wind Belt. At one stage the Lackawanna Steel Company employed 20000 workers. The steel plant declined and closed in 1982, although some small metal and engineering companies, as well as a significant skill base, remain in the city. Local authorities worked with the federal and state governments to transform a highly contaminated industrial area into a useable area for industry development. The outcome was a partnership between the public and private sectors to develop a wind farm, with a capacity to generate electricity for about 7000 homes. The private company, BQ Energy, opened on the old plant's slag heaps in 2006. BQ Energy is piloting a new 2.5 MW turbine, which are almost twice as large as the typically turbine. While the wind farm, referred to as Steel Winds, is relatively small, both in output and employment, it is an opportunity to position an old industrial centre in a higher growth green industry.

These two examples illustrate the alternatives of industrial transformation in the context of the transition to a green economy, making the best use of the human resources and assets locally. This requires a long-term vision of the industry as well as the support of the local authorities to ensure that the investments and efforts put in implementing the transformation will contribute to the overall regional strategy in line with the government's priorities. 


\section{Government-initiated industrial policy}

Some localities are seeking to expand opportunities for local industries in the low-carbon economy, even if they lack R\&D and industry capabilities. Although local authorities have limited influence, central governments do have some powerful levers that maximise spinoffs to local industry, particularly where industries are experiencing rapid growth, such as renewables. Specific examples of industry related policies include procurement policy, foreign direct investment, and technology transfer.

Evidence from this project confirms that government-initiated industrial policy can lead to the emergence of economic activity in green-related sectors if the policy framework is in place and the actions are prioritised and targeted correctly. A good example to illustrate a successful approach is the recent development of the Portuguese wind industry, which is resulting in significant regional industry spinoffs in terms of business investment and jobs (see Box 14). To address concern about energy security and to meet the EU renewable energy target of $20 \%$ by 2020 , Portugal has embarked on a major initiative to transform its energy sector. Attention has been given to a range of energy sources, including expansion of hydro, solar and biomass, but wind energy, which made a very small contribution 10 years ago, has become the most significant renewable growth industry. Thanks to the industrial policy in place, Portugal has installed wind capacity of around $4000 \mathrm{MW}$, which meets around $17 \%$ of its national electricity demand.

\section{Box 14. Industrial policy: The case of Eólicas de Portugal}

Portuguese government-led industrial policy has resulted in an entirely new cluster of industries based on wind energy, which helps shed some light on the impacts that green jobs can have at a more local level, and on the specific conditions which make such a large-scale intervention possible. In 2005 the Portuguese government issued a public tender bid to award new connection rights for up to $1700 \mathrm{MW}$ of renewable energy. In the initial stages, this was a topdown national project, with bidders free to choose their location, taking into consideration the need to look at underprivileged locations. Hence, although local development was an objective; local authorities were not involved in setting up the project. The scale of the project provided the government with some leverage to influence broader outcomes. The tender documents established strict criteria for selected project, including the obligation to provide investment and employment in some of the country's underprivileged locations.

ENEOP - Eólicas de Portugal, S.A. is a consortium of five companies: a German expert in wind technology and four Portuguese renewable energy developers. The German company is the turbine manufacturer ENERCON, a world leader in wind turbine technology. The Portuguese companies include a renewable energy subsidiary of a Portuguese electricity utility, a subsidiary of a Spanish utility, a Spanish/Portuguese industrial conglomerate and an independent renewable energy operator, providing specialised technical and funding support. The consortium proposed to concentrate the core of the project in the Viana do Castelo region in the North of Portugal, a traditional industrial region hard hit by industrial restructuring since the 1980s with a relatively high unemployment rate.

The commitments of the winning consortium included establishment of a state-of-the-art industrial cluster to manufacture all the components of ENERCON's wind turbines. ENEOP has already built 7 new plants and an R\&D and training centre. The project industrial estate is the core of a cluster made up of 29 national and foreign associated companies. These will supply all the goods and services required for manufacturing and installing the turn-key wind farms.

Source: Prata Dias, Gabriela and Tomás B. Ramos (2010), Climate Change, Employment and Local Development: The Case of Eolicas, paper prepared for the OECD LEED Programme.

\section{New industrial sectors, seizing the opportunity}

Some localities are looking to making better use of under-utilised resources including water, energy and waste to improve environmental management and create new industry opportunities. The challenge is not easy as the exploitation of these resources requires long-term investments and a strong support of the community towards a project that may not always be perceived as attractive as other industrial choices. The attitudes towards environmental activities and other related industries need to be positive. Local leadership is essential to obtain the support required and to change attitudes towards this kind of projects. 
A good example to illustrate this kind of industry emergence is the case of Peccioli in Italy (see Box 15). This case study demonstrates how new industry opportunities and environmental management can emerge and be managed through an innovative approach to waste management.

\section{Box 15. The case of Peccioli, Italy}

In the late 1980's, Peccioli was collecting waste from surrounding areas. The landfill had reached capacity and the provincial authorities proposed to close it. Following evaluation of options and community consultation, the local municipality decided to extend the landfill and to utilise revenues to invest in technologies to minimise the impacts of waste and to expand new opportunities. The Mayor undertook an active campaign of awareness raising and communication, to ensure the community's support towards this project. The municipality created Belvedere S.p.A., a public company, with the majority of shares held by the municipality and the rest of the shares owned by community shareholders.

Peccioli now accepts the waste of 40 municipalities (including Florence). Peccioli is benefitting from this as the waste is used for biogas, teleheating for hot water supply, and the generation of electric energy. Profits from the landfill site and from electricity production generated income for the community and helped to finance and improve local infrastructure and social services, including alternative energy generation using solar and wind power, respectively. The projects based on the landfill generated over EUR 250 million in the last 20 years, and created some 300 jobs (both directly and indirectly).

Source : Miranda, G., et al. (2011a), "Climate Change, Employment and Local Development in Extremadura, Spain", OECD Local Economic and Employment Development (LEED) Working Papers, No. 2011/04, OECD Publishing.

\section{Obstacles towards industry change}

As it has been argued earlier, a number of forces are driving industry towards the low-carbon economy. However, there are a number of obstacles currently being faced by industry to effectively adjust to greener demands and expand activities in new areas. From the analysis of the various case studies, some key issues currently hindering industry restructuring were identified. These are described below.

\section{Lack of information regarding low-carbon economic opportunities}

To meet ambitious green targets, knowledge and information about emerging markets and regulations, policies and regulation need to be broadly diffused throughout the local economy. Industries will not usually pursue investment opportunities unless there is a realistic understanding of the return on the investment. The case studies all highlight the importance of addressing information barriers. The quality and timeliness of information is critical in changing industry behaviour.

Evidence from this project suggests that there are currently low levels of awareness about the economic benefits of transforming the economy towards low-carbon activities, and many business representatives see a tradeoff between economic and environmental objectives. In some cases, companies and local authorities believe that carbon reduction initiatives will cost jobs. This is particularly the case in localities that are dependent on carbon intensive industries (like the case of Poland) and/or localities experiencing high unemployment as a consequence of global economic turbulence (like the case of Extremadura). The best way to win business support is to demonstrate that the transition to a low-carbon economy, although not without costs, can also underpin the restructuring of economies towards high value added as well as "cleaner" industries. This is why good information and well-targeted programmes are so important. The impact of climate change policies and programmes on businesses need to be continuously monitored and evaluated, with particular emphasis on informing and supporting SMEs. 


\section{Lack of coordination across government}

The analysis of the various localities shows that policy alignment, as well as long-term commitment and coherence, are required across all tiers of government - national, sub-national and local - to accelerate low-carbon industry dynamics. Indeed, in places where the national and regional policies to combat climate change are reasonably well aligned the industry response was very positive. For instance, the Spanish Government has demonstrated national leadership in the relation to renewable energy. As a consequence, Spain became the world's second largest producer of wind energy, behind Germany, creating opportunities for a number of local companies to become globally competitive in wind technology markets. The regional government of Extremadura aligned its strategy to support industry development in the area of renewable energy, particularly photovoltaics. A number of solar plants, manufacturers and technology centres related to renewables were created, attracting national and European investments to the region and positioning Extremadura as a reference in solar energy production. However, with the global financial crisis and high unemployment rates, as well as soaring national subsidies for renewable energy and cogeneration plants, this policy framework is being reviewed which has led to the deceleration of this industry in Extremadura and the whole of Spain.

Evidence from this project suggests that the existence of a governance structure to ensure coordination, coherence and long-term commitment has positive effects on industry change. Indeed, in London the Low-Carbon Agenda was developed successfully and a critical mass of businesses was reached thanks to the action of the London Development Agency. On the contrary, while Sydney is moving towards better policy alignment between national, state and local governments on carbon policy, the limited authority and small scale of local governments in metropolitan Sydney, with the important exception of the City of Sydney, creates difficulty in implementing low-carbon industry initiatives at the local level. Although the City of Sydney (1 of 41 councils) is strongly engaged in climate change initiatives with industry, metropolitan Sydney lacks the metropolitan governance structure of London and this makes it more difficult to develop coherent metropolitan strategies that support industry make the transition to a low-carbon economy.

\section{Mismatch between local demand and supply}

In the transition to a low-carbon economy, changes in industry demand and supply need to be closely coordinated. The widespread introduction of environmental regulations, emission standards, green procurement initiatives and subsidies for renewables and energy-efficiency has resulted in a rapid increase in demand for low-carbon goods and services. The London case study, for example, found the introduction of levers at the national and local levels, including procurement, regulation and policies (such as the Mayor's Green Procurement Code) was influencing the growth of green economy and driving behavioural change $^{44}$. To respond to this demand, industry needs to understand the time horizons of demand-side initiatives and be confident that they will be stable over a period of time so that they can make decisions regarding changes in supply - such as investing in skilled workers, changing product composition and investing in low-carbon production processes. However, the stability of the market needs to be combined with flexibility to avoid path dependence and technological lock-ins. Enterprises are predominantly small and lack resources and skills to undertake these adjustments and accelerate green growth opportunities. Policies and programmes need be implemented in line with industries capacity and capability to meet them

Evidence from this project confirms that there are risks to industry if demand for green products and services outstrips supply. Green stimulus packages associated with the onset of the global financial crisis offer some important lessons for industry. For example, the Sydney report cites the Australian Government's Home Insulation Program, a commitment to roll out a low-carbon initiative quickly to stimulate the economy in response to the global financial crisis. Many firms lacked capacity to increase supply quickly and many workers did not have the right skills training ${ }^{45}$. This was an apparent example 
where a potentially valuable government program failed, with disastrous consequences, at least in part because industries could not keep pace with an industry opportunity.

\section{Short-term political commitment}

The analysis of the various local case studies showed the effects of political and economic decisions on industry. Indeed, when the political directions were consistent and the signals were clear, the industry in general reacted positively - changing production or methods, and looking for "green" market niches in new or existing sectors. The illustration is Extremadura, where the renewable energy sector flourished after the national and the regional governments announced the objective of supporting the industry. On the contrary, when the political commitment and the economic decisions shifted, the consequences were devastating - notably as the industry slowed down dramatically, jobs were lost, and new businesses and entrepreneurs suffered the effects. Long-term effects of this kind of decisions are extremely negative as the trust is lost, the "green" economy is perceived as an obstacle, and attitudes towards change are pessimistic.

This finding is reinforced by a recent OECD report which concluded that policy predictability can reduce uncertainty for investors, while uncertainty and irreversibility give rise to a commercial risk associated with innovative activities. The report suggests that investment in R\&D is therefore often suboptimal. In the case of "environmental" innovations, this market uncertainty can be compounded by environmental policy uncertainty. This may arise due to concerns over the "predictability" of the policy framework, as well as of the signals provided by the policy itself. In such cases, uncertain signals and "irreversible" investments give rise to great option values, implying strong incentives to postpone investments (OECD, 2011d, p. 24). Political and economic interests, and their predictability, have indeed an important impact on employment and economic activity in the context of the transition to a green economy that should be considered carefully.

\section{ENDNOTES}

Martinez-Fernandez, C., Hinojosa C. and Miranda G. (2010), “Greening Jobs and Skills: Labour Market Implications of Addressing Climate Change”, OECD Local Economic and Employment Development (LEED) Working Papers, 2010/2.

Term described by the UNEP, ILO, IOE and ITUC in UNEP, ILO, IOE, ITUC (2008a), "Green Jobs Towards Decent Work in a Sustainable, Low-Carbon World", report produced by Worldwatch Institute and commissioned by UNEP, ILO, IOE, ITUC, Nairobi. pg. 35

Watson, Robert T., Marufu C. Zinyowera, and Richard H. Moss (1996), "Technologies, Policies and Measures for Mitigating Climate Change", IPCC Technical Paper I, Intergovernmental Panel on Climate Change.

Nicholas Stern (2009), A Blueprint for a Safer Planet, Vintage Books, London, pp. 99-123

OECD (2011), Greening Household Behaviour - The Role of Public Policy, OECD, Paris. 
Smale, Robin; Hartley, Murray; Hepburn, Cameron; Ward, John; Grubb, Michael, The impact of $\mathrm{CO}_{2}$ emissions trading on firm profits and market prices, Climate Policy, Volume 6, Number 1, 2006 , pp. 3148(18)

Porter M. E. (1991), America's Green Strategy, Scientific American, Apr., p. 168, and Porter M. E. and C. von der Linde (1995), Green and Competitive, Harvard Business Review, Sep-Oct 1995.

See OECD (2011) Invention and Transfer of Environmental Technologies for a typology of policies and environmental instruments, and their impact on innovation.

For instance, the Republic of Korea allocated nearly $80 \%$ of total fiscal expenditures to green investments, China allocated one third, and the United States allocated around $12 \%$ of its total fiscal commitment.

See Miranda, G., et al. (2011c), Climate Change, Employment and Local Development in Sydney, Australia, OECD Local Economic and Employment Development (LEED) Working Papers, No. 2011/14, OECD Publishing. Page 79.

OECD (2011), Greening Household Behaviour - The Role of Public Policy. OECD, Paris

See: Miranda, G., et al. (2011c), Climate Change, Employment and Local Development in Sydney, Australia, OECD Local Economic and Employment Development (LEED) Working Papers, No. 2011/14, OECD Publishing.

See: Miranda, G., et al. (2011b), Climate Change, Employment and Local Development in London, UK, OECD Local Economic and Employment Development (LEED) Working Papers, No. 2011/05, OECD Publishing.

Hawke, Allan (2010), Review of the Administration of the Home Insulation Program, report for the Department of Climate Change and Energy Efficiency, 6 April 2011. www.climatechange.gov.au/ /media/publications/energy-efficiency/Home-Insulation-Hawke-Report.pdf. 



\title{
CHAPTER 4.
}

\section{THE ROLE OF PUBLIC SECTOR IN SUPPORTING LOCAL GREEN GROWTH}

\begin{abstract}
The chapter explores the role of the public sector in supporting the transition to a green economy. It looks at the rationale for public sector leadership in certain circumstances, the role of public assets and services, and the capacity of the public sector to coordinate action between central agencies and local stakeholders. The chapter highlights the importance of partnerships as a central means to address climate change and enhance local jobs and skills. The chapter develops a strategic approach, emphasising the different elements of a local strategy that are required to support green growth at the local level, as well as the role that the public sector can play to support local green growth.
\end{abstract}

\section{The public sector in the local green economy}

The public sector plays a key role in supporting the development of green growth at the local level. Local authorities must pursue policies that provide proper incentives to develop green technologies and form green businesses, ensure that market pricing signals are not distorted by misdirected government policy, and make available sufficient resources to shift the economy from its current trajectory of intensive carbon dependency to one that is much more dependent on greener technologies and sustainable consumption practices. To achieve this, government must have a clear and decisive strategy, and policies must be coordinated vertically and horizontally among all relevant government units. Markets are tightly integrated and extend beyond regional and national boundaries. Public policies have to be similarly integrated and coordinated. The role of public sector is key in defining, facilitating and supporting the transition to a green economy.

As discussed in previous chapters, evidence from this project shows that the internal adjustments of the firms are being and will continue to be driven by the market and their own internal needs (e.g. new products/services or new market opportunities). However, during the various interviews, it was clear that new regulations and other public support schemes towards a green economy have an important effect on industry. Hence, the public sector has an important role to play not only in facilitating the access to information on the market opportunities (as a broker) but also in shaping the nature of the business within the private sector through policies and regulations to reinforce the transition to a green economy. For instance, the survey in Sydney clearly shows this trend (see Table 4). Most of the firms having had formal green skills training confirmed having done so due mainly to anticipation of new business opportunities but also very much in response to new regulations or legal requirements. 
Table 4. Sydney: Why did you take green skills development training?

\begin{tabular}{|l|l|}
\hline Training anticipating a future need or business opportunity & $77.8 \%$ \\
\hline New regulation or legal requirement & $63.0 \%$ \\
\hline $\begin{array}{l}\text { Adjust to new products/services that already exist in the } \\
\text { enterprise }\end{array}$ & $37.0 \%$ \\
\hline $\begin{array}{l}\text { Take advantage of a public training programme / training support } \\
\text { scheme }\end{array}$ & $29.6 \%$ \\
\hline
\end{tabular}

Source: Miranda, G., et al. (2011c), "Climate Change, Employment and Local Development in Sydney, Australia", OECD Local Economic and Employment Development (LEED) Working Papers, No. 2011/14, OECD Publishing.

The role of the public sector in enabling green growth should go beyond including the environmental component in the economic strategy. Indeed, linking environmental goals to broader social equity goals in a sustainable economic development strategy is a much more complex task as it requires effective policy integration and coordination. The public sector therefore needs to develop a comprehensive approach in order to maximise the potential for creating good quality jobs in the green economy, particularly for disadvantaged and marginalised communities, while ensuring to meet the environmental demands of a greener economy. Local governments can therefore play several roles. Evidence from this project suggests a series of functions that fall directly under responsibility of the public sector. As identified by the various case studies and also by Estolano ${ }^{46}$ for OECD LEED, the different roles that the public sector can play to enable green growth can be categorised as follows.

\section{The public sector as promoter of collaborations}

As previously discussed, an effective local green growth strategy should be carefully thought through, consulted and endorsed by a wide array of stakeholders. Evidence from this project confirms that publicprivate partnerships are a good mechanism to ensure collaborative participation in a region around a specific topic. The public sector, through regional ministries and labour market institutions should seek to strengthen collaboration with businesses, trade unions, civil society, education institutions, economic development agencies and local authorities to ensure that public initiatives and programmes aimed at greening the economy are well defined, effectively implemented and meet the local needs. A coordinated approach and consistency with the national and regional levels, are also essential elements of an effective local green growth. There is no governance mechanism that fits all institutional frameworks, but partnerships have a certain value in bringing different stakeholders together to develop appropriate and realistic strategies (OECD, 2008e).

\section{Public private partnerships}

Working around a specific economic area, such as a green sector, offers a unique opportunity to build and develop public-private partnerships bringing together economic, social and political factors to define a regional green strategy. The outcomes may vary depending on the maturity of the institutions involved, the level of flexibility of the local level to adapt the policies to the local context and the capacity to engage local stakeholders. But evidence gathered from this project suggests that partnership ensure a longer term action, better engage stakeholders and promote a regional vision endorsed by the community. A good example of a public-private partnership for green economic development was identified in Styria, Austria, which led to the establishment of the Green Tech Cluster, Eco World Styria (see Box 16). 


\section{Box 16. Local partnerships for green growth}

The Regional Government of Styria recently passed the Energy Strategy 2025 which provides a clear signal of co-ordination and political direction towards energy efficiency. In the context of this Strategy, the Styrian Business Promotion Agency, the Regional Government, and the City of Graz engaged in ECO World Styria.

Eco World Styria is public-private partnership whose main tasks are to support Styrian companies and the region in further strengthening and extending their position as international technology and market leaders 'with services and projects focusing on innovation, know-how and new markets' (ECO, 2010). Their activities comprise publications; information about companies and their products, the ECO Future radar showing the 60 most important trends in environmental engineering, and the improvement of regional support, e.g. by organising subsidies for apprenticeships and trainings, R\&D, or initiatives with universities.

For the coming years, ECO World Styria is branding the region as "The World's Green Tech Valley", combining by purpose the positive image of Silicon Valley and the Green Tech strategy. The aim is to create the highest density of leading environmental technology in the region.

Source : OECD (2011), Partnerships for Environmental Issues

\section{Top-down and horizontal collaboration}

As illustrated in the example of Styria, even the most effective and ambitious efforts at the local level require some degree of policy coherence with national efforts to remove policy barriers that hamper green growth. Top-down coordination is therefore required to advance a policy agenda in the right direction, making the best use of the programmes and schemes available at national and international levels, and ensuring that the local actions will have a clear and long-term framework to evolve. The importance of coherent, multi-level green governance is hence a key element to maximise the potential of a local green strategy. The public sector has a key role to play in ensuring this national-regional coordination.

Moreover, it is essential that the public sector aligns education, employment and economic development policies at regional levels to ensure that there is clarity in the vision and strategy in general. Evidence gathered from this project shows that there is a substantial amount of green economy-related activity underway, but currently these are largely piecemeal and with no clear message. Better horizontal coordination would allow for more effective programmes and tools to be put in place to support the development of a healthy labour market, with a good provision of skills which that can be absorbed by the business sector creating wealth and economic development locally. This could be achieved, for example, by establishing a committee with representatives of employment, education and economic development departments at national and regional governments that meets regularly to adjust the policies and define programmes according to the lines of action agreed (see the example of WIRED in the USA, Box 17). 


\section{Box 17. Workforce Innovation in Regional Economic Development (WIRED)}

The WIRED Initiative by the U.S. Department of Labor (DOL) focuses on the integration of workforce development with economic development activities. Effective partnerships among key regional entities are seen as essential in developing the workforce talent necessary for the U.S. to be competitive in a global economy. The US Department of Labor provided funding on a competitive basis to regional partnerships based on specific criteria, including the understanding of the power of partnerships among workforce, economic development, business, etc.

Thirty-nine regional partnerships were selected. Each region had to engage in a series of activities starting with a detailed analysis of their regional economy that identified the key industries and their strengths and weaknesses. They then had to form a core leadership group, which was tasked with identifying a shared regional identity and vision for the regional economy. Based on that vision, the group was required to develop a regional strategy with a set of actionable and measurable objectives. Businesses from the key industries identified were required to leadership roles in the regional partnerships. Community colleges provided much of the skills training required by businesses while universities offered research, technology transfer, and technical assistance to local businesses. The effectiveness of the WIRED regions varied, depending upon the level of leadership and the commitment of the key partners.

Source : Miranda, G., et al. (2011d), "Climate Change, Employment and Local Development in Poland", OECD Local Economic and Employment Development (LEED) Working Papers, No. 2011/22, OECD Publishing.

\section{The public sector as local leader}

As it has been argued, working partnerships are a powerful way to move a green agenda forward and support green economic activity in a region while pursuing the creation and retention of jobs locally. However, even through partnerships, the success is not assured. Evidence from this project confirms that public sector leadership is essential to ensure that the local green strategy is taken forward and that the interventions are correctly prioritised and targeted. Indeed, information gathered during the study visits show that lack of local leadership is also a problem in raising public awareness of the importance of the green economy and in spearheading various initiatives. A partnership without clear leadership does not go far, and limits its positive effects. The public sector should also lead by example in the transition to a green economy. The image and actions of the public sector as leader will contribute to shape the local economy. A good example of local leadership was identified in London, as illustrated in Box 18.

\section{Box 18. Local Leadership}

The Mayor of London has demonstrated strong leadership in response to climate change. Despite the limited local powers available to the Mayor, London still sets store by his significant public and political profile and therefore the Mayor's ability to 'show the way', 'set the standard' and set a good example. The approach makes practical use of the powers that the Mayor does possess - using procurement, policy and regulation to maximise his position. To demonstrate leadership and ensure London's sustainable future, the Mayor of London, Boris Johnson committed to challenging carbon reduction targets. He committed to a steep reduction in the city's $\mathrm{CO}_{2}$ emissions by $60 \%$ between 1990 and 2025. It is estimates that it will cost around GBP 40 billion investment and create a workforce of 225000 people to achieve these ambitious goals ${ }^{47}$. Moreover, the Mayor has seized the opportunity of the London 2012 Olympics to drive behaviour change and practice through procurement of the Games and London's broader infrastructure. Where possible, new targets and aspirations have been introduced into the preparation, building and planning for the Games.

Source : Miranda, G., et al. (2011b), "Climate Change, Employment and Local Development in London, UK", OECD Local Economic and Employment Development (LEED) Working Papers, No. 2011/05, OECD Publishing. 


\section{The public sector as service provider}

As previously discussed, the public sector can facilitate the emergence of a green economy by coordinating the policies and the delivery arrangements, ensuring that the local/regional initiatives are coherent among them and are also in line with the national strategy. Decentralisation offers greater flexibility for regional and local government units to meet the demands of workers and businesses in their regions. However, it also opens the possibility that these government units may not have the capacity, with respect to leadership, skilled staff, and resources, to take advantage of this flexibility. Weak institutional capacity may lead to fragmented and confusing policies and practices across regional and local governments.

Strengthening the institutional capacity of local and regional authorities is essential to ensure a better definition, coordination and implementation of priority actions in relation to the green economy. This capacity building should be thoroughly considered and designed in collaboration with public sector officials and training institutions to maximise its potential. For instance, the TAFE Institutes in Sydney provide green training modules for public sector officials. This has led to an increase in the understanding of the green economy and in the enhanced implementation of programmes in the region.

\section{The public sector as market participant}

\section{Green public procurement}

As discussed before, the public sector could lead by example and help to stimulate innovation and greener practices among the private sector in different ways. Government's role as consumer of local goods and services is a powerful way to support business development and behavioural change locally. Green procurement policy is in its early stages in most of the places analysed, and there is the potential to do even more. A good example of green procurement was identified in Vienna. The outcomes have been very positive and have led to changing behaviours of consumers and businesses equally (see Box 19).

\section{Box 19. ÖkoKauf Wien}

The City of Vienna was one of the first local authorities in Europe to implement a Green Public Purchasing Programme, called "ÖkoKauf Wien" ("EcoBuy Vienna", 1991), as a substantial contribution to reach the targets of Vienna's Climate Protection Programme "KliP". The programme is carried out in partnership between the City Council Departments and public enterprises, (e.g. the Vienna Hospital Association) and led by a steering group and three consultative Committees. About 180 persons, including both internal staff and external experts, are involved. 18 thematic working groups (construction, food, cleaning, paper, electrical appliances, fleet of vehicles, winter services, etc) are developing environmental criteria for specific products and services. Until now, about 60 sets of environmental criteria for different product groups have been developed. Pilot projects and specific research are focused on effective implementation of the environmental criteria, keeping in mind the availability of green products and services on the local market. About 103000 tons of $\mathrm{CO}_{2}$ and 45 million EUR have been saved since 2004 .

An efficient communication strategy to inform both private consumers and local business is also part of the "ÖkoKauf Wien" project. The public at large is informed via media conferences, press releases and news articles. Films, brochures, info folders and posters are available on specific topics, and even working materials and games for kindergartens and schools have been produced. A key aim of the project consists in informing as many people as possible on the importance of "buying green", both as a private customer and as a bulk purchaser for the City of Vienna, and on clear-cut criteria that every single person can apply to be more eco-friendly in daily life.

Source : Miranda, G., et al. (2011b), "Climate Change, Employment and Local Development in London, UK", OECD Local Economic and Employment Development (LEED) Working Papers, No. 2011/05, OECD Publishing. 
There are various ways in which green procurement can be strengthened and further developed. Green procurement policies will be more effective if resources are devoted to train staff to be more knowledgeable of green products and services as well as on how government can lead by example by being a "greener" organisation. For instance, the city of Toronto replaced old roofs in public schools with new solar-panel roofs to show how the public sector can lead by example while at the same time saving money in the long run. Procurement of this type could also be extended to promote green infrastructure, so as with respect to highway construction and new municipal projects.

Local governments have an important role to play in guaranteeing that greener standards are taken into consideration when purchasing or tendering for major events and projects. This indirect form of green procurement encourages private sector enterprises to adjust to new regulations. The governments should develop environmental criteria for specific products and services in different areas and adjust these to the local context and market.

Finally, findings from the project suggest that green procurement can leverage small business creation to reach a critical mass of businesses in the local green economy. Within the procurement processes, the participation of SMEs in tenders should be encouraged and a positive discrimination could be applied to support their development and growth.

\section{Public-owned enterprises}

Through public-owned corporations, the public sector may also contribute to lead the 'green wave' by establishing standards of sustainability that become reference to other businesses in the sector. To have a positive effect, these standards must be supported and endorsed by the government authorities. With such references in place, the businesses create a reference for other businesses which triggers the transformation of the entire sector and promotes the development of green activities in local economies. Landcom, a government land housing developer operating in the Greater Metropolitan Region of Sydney (Australia), represents a good example of the types of actions being taken by publicly owned corporations. Landcom promotes the growth of green activities and green skills through the diffusion of sustainability standards in Greater Metropolitan Sydney and beyond (see Box 20).

\section{Box 20. The case of "Landcom" in NSW, Australia}

Landcom is a government-owned land and property developer operating in Sydney and the surrounding Greater Metropolitan Region in the state of New South Wales (NSW). Landcom's main mission is to increase the supply of homes, improve housing affordability and protect the environment of the region. Over the past decade, sustainability has become a central organising principle for its planning, operations and partnerships with the public and private sector. Landcom is one of the main agents that promote the government's land development and environmental policy. This position has allowed Landcom to diffuse its guidelines for sustainability, design, demonstration projects, policies and practices across the development and construction industries, resulting in new specialist and sustainability jobs in firms and the growth of training and sustainability skills in traditional building and construction occupations. For example, all major developers in Sydney have now followed Landcom's lead and appointed sustainability directions.

Landcom optimised the use of BASIX (Building Sustainability Indicators), a state regulation requiring new houses to meet water and energy reduction targets which require $40 \%$ improvements in GHG emissions and water management across all new housing in NSW. Landcom demonstrated how it could work and then partnered with the private sector to drive reductions beyond the $40 \%$ requirement through learning from each project. An interesting feature of BASIX is that the final policy encouraged building designers and households to develop customised solutions to meet reduction targets rather than focusing on a "one-size-fits-all" policy. By doing this BASIX is driving innovation and demand for new skills across the building industry, impacting training and re-training of plumbers, electricians, carpenters and builders.

Source : Larcombe, G. (2010), Climate Change, Employment and Local Development: The Case of Landcom, NSW, for OECD LEED 


\section{The public sector as broker}

The public sector also plays an important role in facilitating the access to useful information to economic and social actors in the region. Throughout the project it was clear that the public sector often has very sophisticated data and analysis of the vision of the "green" transformation, but it was usually the case that the private sector and other public sector representatives were not aware of this. And when available, the information was not adapted to the audience (e.g. businesses, universities). The role of the public sector as a broker implies not only a strong communication strategy, a definition of a clear message and awareness raising campaigns (as the ÖkoKauf example, Box 19) but also easy-to-access platforms for all the economic and social actors in the region. The success of a local green growth agenda will strongly depend on the ability of the public sector to act as a broker between the green market opportunities and the industry. Facilitating the access to the necessary information was identified as being useful to engage mainly small businesses and the community in the efforts towards a low-carbon economy. On-line platforms and one-stop shops are useful tools in this respect.

\section{The public sector as regulator}

Throughout this report it has been made clear that the public sector plays an important role in regulating the "green" component across the economy, being it products or industries. This regulation

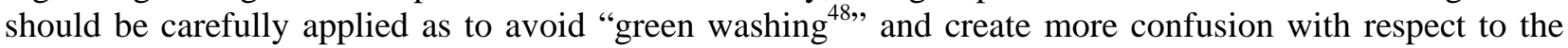
real meaning of the 'greenness' of a product or sector. Although too many labels undermines labelling, certifications and labels can be useful in facilitating the choice of products and services. However, to be effective, the criteria of these should be defined on the basis of comprehensive studies of the environmental aspects related to the entire life cycle of the product/industry and should have a limited valid period to ensure quality. Consumers need to be informed about the meaning of the labels and certifications in terms of environmental friendly components.

According to the OECD (2011d) an eco-label can be "shallow" (i.e. indicating whether the product passes some established level of energy efficiency performance) or "deep" (i.e. giving the estimated level of performance itself). Beyond the quality and the clear criteria of the eco-labels, consumers need to be educated about the advantages of purchasing green products. Through promotions, handouts, special deals, and other means, the public sector can drive consumers' behaviours and build capacities among the consumers. This eco-label is important for businesses to attract "green" customers and strengthen the value of the products, but it can only be effective if the consumer is aware and demand those products. Some illustrations of the approaches to eco-labelling are provided in Box 21.

\section{Box 21. Eco-labelling}

The U.S. has more than nine independent certification organisations, of which all but two are non-governmental. For instance, Green Seal is a non-profit organisation that since 1989 has used science-based programmes to set product standards to help shoppers find truly green products. The reputation of the Seal brand has grown to symbolize environmental leadership, and it continues to represent unquestionably green products and services.

Germany's Blue Angel is the world's first and oldest environment-related label. Created in 1979 by the Federal Minister of the Interior, the Blue Angel label is recognized as identifying the best possible ecologically friendly products and services. The designation is determined by the Environmental Label Jury, an independent decision-making body composed of representatives from environmental and consumer associations, trade unions, industry, trade, crafts, local authorities, science, media, churches and federal states. Today, more than 11000 products, from 990 suppliers ( $21 \%$ from outside of Germany) display a Blue Angel label.

Source: Miranda, G., et al. (2011d), "Climate Change, Employment and Local Development in Poland", OECD Local Economic and Employment Development (LEED) Working Papers, No. 2011/22, OECD Publishing. 
The public sector can also act as regulator by setting standards for direct regulation, both technologybased and performance-based, which are the most commonly implemented environmental policy measures. Evidence from this project confirms that these direct regulations have an important influence on industries, and confirms a previous OECD report arguing this (OECD, 2007b). Setting this kind of standards ensures that industry complies with a minimum level of performance or prescribes the technologies that are allowed to be used under certain circumstances ${ }^{49}$.

\section{The public sector as facilitator}

\section{Catalyst of activities}

The public sector also plays an important role as coordinator of activities at the local level, given the proximity with economic and social actors in the region. In some areas where markets are not well integrated, it may be necessary for local governments to help coordinate activities by convening the different actors and focusing efforts towards a common goal. An example is the formation of a biomass market, in which disparately located farmers must be connected to more centrally located facilities, through providing the proper information and linking the entities through better transportation. The efforts of the City of Kristianstad, Sweden, as described in Box 22, are a good example of the role that local governments can play in creating a market by reducing its dependence on fossil fuel and promoting the use of biomass-related fuel.

\section{Box 22. Kristianstad: Using Biogas to Transform a Community}

When Kristianstad, Sweden, a city of 80000 in the southern, rural area of Sweden, could barely afford to heat its schools and municipal buildings during the 1980 oil shock, its local government vowed to wean the community of the use of fossil fuels. Thirty years later, the city and surrounding area essentially use no fossil-fuel based energy to heat homes and businesses. Recognizing the potential of using by-products of the bustling agriculture sector in the region, their energy is generated from a large biogas facility that transforms biomass into biogas. The 10-year-old plant transforms ingredients like potato peels, manure, used cooking oil, stale cookies and the like into a form of methane gas. That gas is burned to create heat and electricity and is refined as fuel for cars. Start-up costs to construct the biogas plant and build a centralized heat distribution system were sizable. The city received grants from the Swedish government to help with some of the costs. But the payback has been significant, saving the municipal government alone more than $\$ 3.5$ million a year compared to what it would have had to pay if it still relied on oil and electricity. The city also saved tax dollars by not having to pay the Sweden carbon emission tax, which was imposed after 1991.

The benefits of the system go beyond saving money on heating. Farmers can now dispose of their waste by sending it to the biogas plant, whereas before they had to pay a fee to dispose of it. The large quantities of waste needed to fuel the biogas plant has created a collection system for the waste. It has also raised awareness about how pollution can be reduced by disposing of farm by-products, which otherwise would have affected water supplies, and by reducing emissions by burning less fossil fuels.

Source: Miranda, G., et al. (2011d), "Climate Change, Employment and Local Development in Poland", OECD Local Economic and Employment Development (LEED) Working Papers, No. 2011/22, OECD Publishing.

\section{Support green entrepreneurship}

The public sector can also support the transition to local green growth by supporting entrepreneurship and innovation for the green economy. Indeed, local governments have the power and possibility to put in place different support schemes (infrastructure, funds, and programmes) that support entrepreneurs, venture capitalists and small businesses to seize the opportunities of the green economy. However, evidence from this project suggests that the government is not fully addressing these issues. 
Findings from this project show that there is a clear lack of support for green entrepreneurship. Indeed, to reach a critical mass of businesses in a specific green sector, it is essential to support targeted entrepreneurship. Several regions have established green incubators to provide low-cost space, networking with like-minded companies and technical assistance. A good example of a green incubator is provided in Box 23.

\section{Box 23. Bethesda Green Incubator}

The Bethesda Green incubator was founded in Maryland, USA, in autumn 2009 to complement Bethesda Green's mission through the creation and support of companies that will contribute to our dynamic sustainable community. Like all incubators, it is intended to provide resources and services that will increase the likelihood of entrepreneurs' chances of success. What defines and differentiates this incubator is its focus on creating and growing companies that offer products and services that improve our environment and promote energy efficiency.

The Bethesda Green incubator works closely with Montgomery County's Department of Economic Development to promote the creation, expansion, attraction and retention of businesses with a focus on environmentally sustainable technologies, products and services. It helps leverage Montgomery County's strengths to create a green industry cluster that will generate economic, environmental and social value for the County's businesses, residents and the region.

Source: Miranda, G., et al. (2011d), "Climate Change, Employment and Local Development in Poland", OECD Local Economic and Employment Development (LEED) Working Papers, No. 2011/22, OECD Publishing.

\section{Support business growth}

Evidence from this project suggests that there are very low levels of technical assistance for businesses to enter green markets, notably internationally. Providing technical assistance is particularly important in regions where the economy is almost completely dominated by small or micro-businesses. Businesses of this size generally lack the knowledge and experience to take an idea, particularly when it is based on new technologies, and transform it into a viable business. Also, businesses have difficulty accessing international markets and competing in global market niches. An example of a successful initiative towards business growth and access to international market was identified in Poland. The Ministry of Environment of Poland created GreenEvo, a green technology accelerator, to provide international markets with a guaranteed quality of Polish environmental technologies (see Box 24).

\section{Box 24. Green Technology Accelerator, GreenEvo}

GreenEvo was established by the Polish Ministry of the Environment in order to promote Polish companies and technologies in international markets, guaranteeing quality environmental technologies. Companies selected for GreenEvo offer tested innovative solutions, have undergone specialised training (including market and management), and have been advised on specific regulations as well as technical standards applicable in global markets. The Ministry of the Environment has identified 510 companies, predominantly in small companies, that offer green technology. The technologies include wastewater and water treatment technologies, innovative hazardous waste technologies, solutions supporting renewable energy sources, technologies for the cooking industry, and energy saving.

Source : Miranda, G., et al. (2011d), "Climate Change, Employment and Local Development in Poland", OECD Local Economic and Employment Development (LEED) Working Papers, No. 2011/22, OECD Publishing. 


\section{Branding and positioning}

The public sector can also facilitate the emergence of green activities by positioning a region or locality as reference in certain technologies or sectors. This is very much linked to the cluster approach, but goes beyond the industrial dimension as it has to do with the branding of a whole locality to attract human capital, investment and firms to the locality while opening new market opportunities. Evidence from this project suggests that branding and positioning are strong mechanisms to support economy and drive industry change. Examples of this approach were identified in London with the designation of the city as the Low-Carbon Building Area (drawing on the sustainable building and energy efficiency programmes) as well as the case of Styria with the positioning of Eco World Styria as the Clean Tech Cluster of Austria. At a larger scale, the EU has launched the Smart Specialisation project to support specialisation and positioning based on regional strengths ${ }^{50}$.

\section{The public sector as investor}

There are different types of investment that the public sector may put forward to support the transition towards and development of a local green economy. Evidence from this project and information gathered throughout the visits suggest that the types of investment can be distinguished as follows:

\section{Subsidies}

In most of the places visited, there is a misalignment between subsidies to consumers and to producers. From the interviews it seems that local governments could do more to support businesses by offering subsidies to the consumers of a green product or service, rather than providing subsidies mainly to businesses. If the market is not receptive to new "green" products or services, there will be demand for these and therefore businesses will not move towards more environmentally-friendly or efficient products. This illustrates potential issues of misaligned subsidy policies and government coordination and responsiveness to business needs.

\section{Investments}

The public investment on infrastructure, such as the construction of new highways, may sometimes encourage the use of intensive carbon-based modes of transportation over less polluting modes. On the contrary, public investment may enhance green growth by providing the jump start for proper waste management and water treatment. Public investment may also be necessary when the investment is too large and the risk too great for any one investor to create a new market, such as for biomass, wind farms, or other types of renewable energy production. Government assumes the risk and creates a new market, which once created the private sector can build upon with investments of its own.

\section{Grants}

The public sector can also act as an investor by providing grants and other kind of direct financial support to businesses and sectors within a larger strategic plan. These grants can be provided on the basis of public call for projects or on the basis of funds managed by incubators or other local public departments. To reach a critical mass of green industries in a locality, the support of business development and growth is essential. For instance, in Israel, the Office of the Chief Scientist (OCS) at the Ministry of Industry, Trade and Labor (MOITAL) supports business development in the form of conditional grants: if the project fails, the support is treated as a grant, whereas if the project succeeds, it is treated as a loan that the company has to pay back. Projects funded within the "Green Tnufa" programme must lead to the development of a new product or to the significant improvement of an existing product to make them more environmentally friendly. The scope of assistance is $66 \%$ of the approved budget, up to a limit of 250000 NIS. 


\section{Incentives}

Investment can also be made indirectly, through incentives that will lead to the transformation of an industry, to changing behaviours and to directing demand. Public authorities may also directly support businesses and individual consumers with incentives such as tax incentives or other benefits for purchasing particular eco-products and services. This is an approach to proactively use demand support measures to shift the course of technology and product development. A good example of these kinds of incentives is the case of eco-primes for energy efficiency in Paris. The city offers tax credits of up to EUR 16000 which allow households to deduct a percentage cost of certain energy improvements from their income tax, regardless of whether they are the owner or the tenant of the property. These tax credits can be used in conjunction with, or in addition to the "Eco-primes" which are loans granted under certain conditions to residential property owners in the city who are willing to undertake refurbishment works to improve energy efficiency.

\section{ENDNOTES}

See: Miranda, G., et al. (2011c), Climate Change, Employment and Local Development in Sydney, Australia, OECD Local Economic and Employment Development (LEED) Working Papers, No. 2011/14, OECD Publishing.

Mayor of London in foreword to 'Leading to a Greener London - An Environment programme for the Capital’ July 2009

“Green washing” refers to false claims of environmental virtues by companies, training providers, policy makers or NGOs, aiming at the creation of a positive image of their goods or services, which look more environmentally-friendly than they really are. See OECD (2011), Climate Change, Employment and Local Development in Extremadura.

See the glossary for a definition.

For further information, see: http://ipts.jrc.ec.europa.eu/s3platform.html 



\title{
CHAPTER 5.
}

\section{ENABLING LOCAL GREEN GROWTH}

\begin{abstract}
The chapter develops a strategic approach, emphasising the different elements of a local strategy that are required to support green growth at the local level. The chapter outlines a methodology to integrate sustainability into local economic development strategies as a way of setting local areas onto low-carbon growth paths. The importance of local eco-innovation is emphasised, not only through generating new green products and services, but also through adapting and implementing new learning models that diffuse green technologies and practices throughout a local economy. New investment is required in infrastructure that contributes to carbon reduction, ranging from public transport to green incubators that nurture green start-up companies. The relationships between strategic planning, job growth and the low-carbon economy are explored.
\end{abstract}

\section{Enablers of green growth at the local level}

This chapter is concerned with what localities can do to enable green growth and to integrate economic development initiatives with environmental well-being. No two localities are the same and they are confronted with different challenges. The starting point is to analyse the specific features and context for the locality in question. Local features include industry structure and dynamics, energy sources, energy consumption patterns and urban or regional form, institutional capacity, skills and technological trajectories. But national policy commitments on climate change are also important.

As it has been demonstrated throughout this report, it is not always national governments that are driving climate change policy. Some localities are leading their national governments in taking action on climate change, due to concern about the impacts of climate change and/or recognition of emerging employment opportunities in low-carbon industries and jobs. Some are developing global partnerships in response to concern over climate change and to advance a sustainability agenda, even in the absence of comprehensive and sustained national policies such as cap-and-trade and carbon pricing.

The aim of this chapter is to explore ways localities can strengthen their response to climate change as in order to enhance opportunities for green growth at the local level. This chapter looks at seven enablers of green growth at the local level:

1. A framework for local sustainable economic development

2. Innovation and low-carbon growth

3. Local planning and sustainable infrastructure 
4. Local governance and green growth

5. Employment policies

6. Capacity building to address climate change

7. Financing green growth

\section{Local sustainable economic development}

The starting point for localities is an understanding of the impacts of climate change on local economies and a strategic framework to protect aggregate employment, and to expand economic and new employment opportunities associated with the transition to a low-carbon economy. This reinforces the need for economic development strategies that are based on sustainability principles and give attention to lowcarbon growth.

As it has been discussed, integration and coordination of sustainability and economic development strategies is challenging and requires a comprehensive approach in order to maximise the potential for creating well paid jobs in the green economy, particularly for disadvantaged and marginalised communities $^{51}$. Hence, an effective sustainable economic development strategy at the local level requires a mix of elements to maximise its potential and ensure effectiveness. Seven critical elements of an effective green growth strategy at local level have been identified as part of this project (see Box 25).

\section{Box 25. Seven elements of an effective green growth strategy at local level}

1. Clear vision. An effective strategy starts with a vision that can inspire behavioural and policy changes. Elected officials and civic leaders must make the case that a green growth model is necessary to address critical environmental issues and that it can lead to business and job growth in the area.

2. Industry strategy. An approach could be the development well-designed cluster strategy for the green economy, targeting a particular green sector based on a realistic assessment of the local competitive advantages. It should build on existing assets and collaborative dynamics. The strategy should use data to better inform, link, leverage and align existing programmes to stimulate innovation, entrepreneurship, and job creation in green economic sectors.

3. Invest in infrastructure. Local governments can invest in infrastructure that help to build a green economy (e.g. smart grids, energy efficiency upgrades of existing buildings, expansion of public transport systems, the upgrading of water and sewer systems) can be a significant driver for green growth. Major metropolitan areas with publicly owned utilities are particularly well-positioned to leverage their scale and financing capacity to make investments that will be the building blocks of a green local economy.

4. Sector workforce strategy. Integrate demand-driven workforce development strategies with green economic development policies through meaningful partnerships with business, unions and intermediaries. Cluster or industry strategies for green economic development must be coordinated with sector workforce development strategies to be effective in supporting green growth.

5. Promote collaborations. Foster creativity and innovation through collaborations among universities and research institutions, venture capital and other investors, industry innovators and key government officials to support the development of new and emerging green sectors. The key is to leverage existing assets through partnerships and collaborative projects around specific new or emerging green business lines.

6. Leverage the roles of government. Local governments can influence the size and character of the green economy at this early stage in its development depending on the nature and scale of government activity and to what extent the distinct roles that government plays (as regulator, consumer, landowner, convenor 
and investor) have been aligned to support green growth.

7. Engage stakeholders. Local governments should meaningfully engage community members, businesses and other stakeholders in developing green growth policies and maintaining their interest in assisting in the implementation and monitoring of such policies. The responsibility to maintain contact with and be responsive to citizens can be an asset to local governments who can articulate a compelling vision for green growth and build a strong and enduring coalition to support green growth policies.

Source : Miranda, G., et al. (2011c), "Climate Change, Employment and Local Development in Sydney, Australia", OECD Local Economic and Employment Development (LEED) Working Papers, No. 2011/14, OECD Publishing.

\section{Support innovation and green growth}

One of the major challenges for localities is how can they exploit climate change policy, specifically market-based instruments and regulatory adjustments, to drive rapid innovation and diffusion of sustainable technologies, practices and processes across local industries and households. Innovation at the local level is central to combating climate change. To be effective, innovation initiatives in response to climate will need to drive change across the whole economy. This will only occur if knowledge and learning about sustainable technologies and practices are diffused across the economy. For this to happen, there needs to be a focus on strengthening collaboration between firms, government, councils and households at the local level.

From the project analysis it has been demonstrated that most local innovation is incremental. Incremental innovation occurs through ongoing interaction between many participants including firms, government, $\mathrm{R} \& \mathrm{D}$ organisations, users such as clients and suppliers, and competitors. Local regulators and other public sector agencies, as well as industry accreditation organisations, can also drive local lowcarbon innovation. In many emerging sustainability and other low-carbon industries, which integrate technologies and expertise across different industries and occupations, ongoing interaction, including faceto-face interaction, is critical. Radical or "breakthrough" technologies are necessary but not enough. To bring about the green transformation at the local level, these technologies need to be complemented by innovative incremental models that diffuse innovation across firms, particularly SMEs, and the workforce.

Local innovation associated with carbon reduction initiatives is likely to be most effective when it is tailored to meet emerging local demand and addresses local barriers to take-up of low-carbon technologies. A local low-carbon innovation strategy should usually be built around local industry strengths. Innovation drivers will be different depending on the character of specific localities. These characteristics include industry structure (e.g. size and diversity of firms and their position in supply chains), the type of market, infrastructure and skill base.

Some localities are more successful at capturing the benefits of innovation than others. Localities where industries and entrepreneurs are more flexible make use and adapt new technologies. They continually search for applications for new technologies that are well positioned to capture the benefits of low-carbon innovation. The ability of localities to become innovative places often depends on the availability and adoption of new technologies, both in manufacturing and service fields where new platform technologies, most notably IT, have been used to transform activities ${ }^{52}$.

Evidence from this project suggests that one of the most significant local barriers to innovation is that many companies, particularly SMEs, do not have good information about the most efficient carbon abatement measures and emerging project opportunities. This can be exacerbated by lack of entrepreneurialism to search out low-carbon opportunities. Local authorities working with industry can diffuse market intelligence about emerging projects and their project specifications by acting as brokers. Regen SW in South West England is a good example identified as part of this project to illustrate this 
approach. Regen SW is a sustainable development agency established with the aim of deploying sustainable energy technologies and boosting green jobs across local supply chains. The agency works with local developers to identify prospective suppliers. It has created a local supply chain directory and addresses key hurdles to facilitate sustainable projects including finance, planning and regulations ${ }^{53}$.

\section{Local planning and sustainable infrastructure}

Planning for climate change adaptation and mitigation is becoming an important issue. Understanding the geographical impacts of climate change on localities and preparing adaptation measures is part of this. For example, coastal settlements need to strengthen retaining walls to protect existing buildings and prohibit or limit development in areas that may be impacted by rising sea levels. Further, localities exposed to increased hurricanes and cyclones may be required to strengthen building codes.

Cities and regions are places where much planning takes place. This includes land use planning, which sets out areas where jobs, housing, research and education facilities, and infrastructure will be located. Local authorities also have regulatory powers to determine the built form, including materials used, heights, and increasing codes that establish standards for energy and water use and waste management. In addition, local planning can influence the location of innovation zones, such as incubator areas and science parks.

Some localities are establishing low-carbon precincts or zones as the case of London. These are geographical areas where a range of co-ordinated actions take place over a period of time with the objective of reducing carbon emissions ${ }^{54}$. This may include public private partnerships to co-ordinate infrastructure management and delivery, undertaking emission audits of major facilities and implementing best practice sustainability approaches to design an operation of new buildings and retrofitting existing buildings.

The challenge is how to shift resources from infrastructure that contributes to carbon intensive activities, either directly or indirectly, towards infrastructure that results in lower emissions. For example, in Poland there is a debate about how to shift resources from road infrastructure to public transport, particularly in localities where investment in public transport has lagged over a long period of time. There are many economic and environmental benefits associated with improving public transport, including reducing congestion, improving efficiency of the economy, and carbon reduction.

Traditionally, infrastructure policy has been concerned with large scale urban infrastructure. The shift towards decentralised energy infrastructure is a case study where smaller localised solutions are becoming more relevant and economically viable. Hence, in some cases, there is a shift to smaller scale urban infrastructure. Increasingly, there is a shift towards demand-management strategies, such as smart metres and smart grids, as an alternative to constructing large scale and carbon intensive infrastructure such as fossil fuel-fired power stations. Further, there is increasing emphasis on knowledge infrastructure to address climate change challenges. Knowledge infrastructure refers to specialised university sustainability research centres, green incubators and vocational facilities that incorporate green technologies.

\section{Governance and green growth}

Improving governance is an essential enabler of green growth. To be effective, governments at all level will need to work towards policy alignment and coherence. Although there is a lot of attention on climate change policy, there is also a lot of duplication and fragmentation. In many cases, there is poor coordination and communication within public sector agencies in one particular tier of government, poor coordination across different tiers of government such as central and local agencies, and poor coordination between the public and private sectors, unions and the broader community. 
In the case study localities and in most of the OECD countries there is a plethora of public and private agents involved in developing and implementing green policies and programmes. This includes a growing emphasis on the green economy, greening existing industries and jobs. Many of these initiatives overlap and compete for scarce public resources. In the rush to get out new initiatives, particularly with the onset of the Global Financial Crisis, some green programmes, particularly in relation to green employment, have not been effective and have instead coordinated with other programmes. Greater emphasis is needed to improve vertical integration of decision making and initiatives between different tiers of government and to deliver sustainability and economic outcomes at the local level. Further, there is a need to foster horizontal partnerships and networks at the local level that are working towards carbon reduction that benefit employment.

Local authorities do not often have the resources or the expertise to go it alone. Municipalities in particular have an important role to play in linking a range of policy areas. This includes articulating an economic and sustainability vision for their areas, diffusing sustainability ideas and practices, managing local regulatory, planning and approval instruments, designing green infrastructure, promoting new industry and skill opportunities, and working with industry, households and energy authorities to promote critical mass in low-carbon energy use.

Evidence gathered from this project suggests that there are three principles that should guide governance at the local level.

\section{(i) Strong leadership}

As it has been discussed, leadership is an essential component of governance. The legal authority and resources of local areas are generally limited. However, it has been made clear that local leaders need to demonstrate that the locality has a thoroughly thought out strategy and is taking action so that it can persuade other parties of the benefits of taking action. Local leaders also need to demonstrate that they are employing the appropriate policy levers to drive local green growth agendas including an appropriate mix of regulation, incentives, local infrastructure investments and human resource initiatives to drive green economy objectives. The example of the city of London is a good illustration of local leadership.

\section{(ii) Building partnerships}

The need to build effective partnerships between government, industries and communities is at the core of the transition to a green economy. In relation to the low-carbon economy, the way partnerships are identified, established and managed is a critical factor which determines success or failure of government policies. They need to bring together the range of government activities, industry, science and technology specialists as well as being representative of social groups impacted by change. Multilevel governance is required and it should involve all the actors from individual citizens to public authorities.

These partnerships can be locality wide, industry sector specific, such as the commercial building sector, or thematic partnerships such as eco-innovation. The challenge is to link up and connect diverse disciplines and agencies that add value to each other working within a network or partnership, and implementing initiatives that lead to measurable low-carbon economy outcomes.

\section{(iii) Community engagement}

Climate change and strategies for a green economy are opening up new opportunities for communities to be actively engaged. If the argument put forward by leading climate change scientists is correct that it is essential to take immediate action to stabilise and reduce carbon emissions, then all sectors of society need to understand and be involved in this process. Sustainability is a local issue. It is a right and obligation of all citizens to be informed and encouraged to contribute to addressing a challenge that could potentially 
result in dire environmental consequences. Households need to make informed decisions about how to reduce energy and water consumption, improve thermal performance and effectively manage household waste. Good governance would build on the growing expertise regarding local projects that could contribute to carbon reduction such as community gardens, waste recycling, re-forestation and household energy audits. A model of community engagement identified as part of this project is the case of Sustainable Sydney 2030 (see Box 26).

\section{Box 26. A model of Community engagement - Sustainable Sydney 2030}

The City of Sydney's Sustainable Sydney 2030 presents a bold and compelling vision for how this centrally located area will tackle climate change, global competition, transportation congestion, and a half dozen other major challenges over the next 20 years. The vision is continuously articulated by the Sydney Lord Mayor Clover Moore MP. The process involves ongoing interaction, review and refinement with government, business and the community. Sustainable Sydney 2030 is driven by 10 targets that are ambitious but fulfil the principles of SMART goal-setting they are specific, measurable, attainable, realistic and timely. The targets reinforce each other and are underpinned by "5 Big Moves" aimed at remaking the City "into one that is green, global and connected." The strategy commits the city to reducing greenhouse gas emissions by $70 \%$ by 2030 .

A central feature of Sustainable Sydney 2030 is the model of community engagement. The importance of this model is the recognition of deepening democratic engagement and utilising the multiple talents and enterprises, households and different social groups. The vision was developed through lengthy and extensive community engagement. Some 12,000 people were consulted directly over 18 months via 30 community forums. Thousands of others attended City Talks or briefings, visited the six week Vision exhibition at the Customs House or engaged via the Vision website. This level of community engagement was critical because the policy shifts and resource allocation necessary to implement the vision require broad, deep and sustained public support.

Source : Miranda, G., et al. (2011c), "Climate Change, Employment and Local Development in Sydney, Australia", OECD Local Economic and Employment Development (LEED) Working Papers, No. 2011/14, OECD Publishing.

\section{Employment policies and actors}

As it has been argued, the impact of the transition to a green economy on job creation and the labour market will depend on a mix of conditions and actions that will vary from one place to another. Nonetheless, employment policies are at the core of these conditions as the quality and effectiveness of these policies will result in a more or less favourable situation. Labour market institutions have an essential role to play in ensuring that the policies and actions towards supporting job creation in the green economy are tailored to the local conditions, guarantee good quality jobs, and are inclusive. Trade unions and other social and employment agents that work in close relation with the businesses and workers should be placed at the centred of the discussions of priorities, the definition of actions and the implementation.

\section{Capacity building to address climate change}

The transition to a low-carbon economy will require changes in the way individuals and organisations function. Attention needs to be given to cost-effective ways to support capacity building, not only to meet immediate priorities, but also to underpin longer term norms and values that will deliver low-carbon growth. In a relevant report on capacity building for sustainable development ${ }^{55}$, the United Nations state that capacity building involves strengthening the processes, systems and rules that influence collective and individual behaviour and performance in all development endeavours, as well as enhancing people's technical ability and willingness to play new developmental roles and adapt to new demands and situations. As an overall conclusion from this OECD project, and in line with the UN report's findings, capacity building for the low-carbon economy at the local level should include: 
- Supporting sustainability, and in particular low-carbon, institution building at all levels of government, national, sub-national and local levels, and to support implementation at the local level.

- Strengthening vertical and horizontal collaboration and integrated systems and procedures across all tiers of governance to support local carbon adaptation and mitigation measures.

- Promoting awareness and knowledge and encouraging democratic community engagement in all aspects of the low-carbon and sustainability economies.

- Developing methodologies and instruments that can measure local carbon intensity, economic and social impacts and monitor and evaluate outcomes from low-carbon initiatives.

Many of the local institutions analysed as part of this project, including councils, local development agencies, education and training centres, and employment service providers, do not have the capacity nor the trained staff to advise firms on low-carbon and sustainability opportunities as well as emerging green skills and training. Many public institutions lack capacity to audit current business practices, advise on low-carbon options, and hence are not in a position to play a significant role in meeting business needs to prepare for the low-carbon economy. Overall, many public institutions do not seem to have the capacity to respond to the new demands of the businesses and provide quality advice to promote the green economy.

Evidence from this project suggests that, in building new skills for the green economy, many skills can be acquired not just through formal accredited and specialised courses, but through innovative ways to encourage "learning by doing" 56 . The options include:

- bringing in experts to the workplace to work on solutions to meet specific challenges,

- bringing groups together to undertake research that focuses on practical outcomes within and between organisations,

- mentoring programmes,

- validating informally acquired skills,

- development of continuous professional development courses (CPD) with an emphasis on lowcarbon options, and

- use of e-learning to expose organisations and businesses to best practice learning models that could be potentially adapted to meet local needs.

As shown in the previous analysis, investing in capacity building between businesses and organisations is closely related to improving governance. This involves putting more emphasis on how to join-up and on network groups in localities. One option is to train local agents and to foster much greater linking/networking between economic agencies to environmental experts. This might include employing "sustainability advisers" to work across the different administrative offices and to provide advice to the private sector and entrepreneurs on emerging low-carbon and other sustainability opportunities, as well as make assessments of emerging labour market opportunities. These "sustainability advisers" could also advise public institutions on how to make greener processes and methods within the public sector (for instance, green procurement). 


\section{Financing green growth}

The transition to a low-carbon economy requires major investments in infrastructure, plant and equipment, technology and skilling people. The economic as well as environmental benefits are becoming clearer, but there are many financial barriers, many of them at the local level, that slow down the transition. Some of the resources can be provided through public revenues such as a carbon tax or through direct grants from consolidated revenue. However, the continuing global financial and fiscal crises, the associated economic turbulence and slow growth may make it more difficult for governments to support the transition as a consequence of larger public sector deficits. Government support for the transition to a low-carbon economy cannot be short term.

Evidence from this project confirms that one of the challenges at the local level is how to evaluate and assess the risks associated with emerging low-carbon technologies and projects ${ }^{57}$. More emphasis needs to be put on investing in skills in the area of financial evaluation of environmental projects, risk assessment and climate change. Even in global financial centres such as London and Sydney, sustainability is not fully integrated into the formal education of financial graduates. Venture capital markets are underdeveloped in many localities. Many promising low-carbon projects have more difficulty in attracting seed funding and venture capital, compared to more established venture capital specialists that support bio-technology startups. Further, financial institutions may limit lending support for low-carbon innovation due to a focus on short-term financial returns and/or restrictions associated with banking targets during an era of economic uncertainty.

A classic dilemma involving investment decisions regarding improvements in energy-efficiency and carbon reduction is the split incentive that sometimes exists between investors (such as a property owner) and a beneficiary (such as a tenant), where the investor pays the higher upfront cost but the energy savings flow to the beneficiary. Local authorities, including local government and energy retailers with green agendas, can assist by providing better information about rational choices and incentives to better align upfront capital costs and life cycle benefits, particularly energy savings. Salix Finance (see Box 27) is a good example of how a public sponsored agency can create financial incentives for other agencies to adopt energy efficiency measures. An emerging opportunity exists for public authorities to work with financial institutions to design financial instruments to support upfront purchase/lease of energy-efficient improvements and to recover costs from energy savings over a specified period of time.

\section{Box 27. Salix Finance, UK}

Salix Finance is a government-sponsored agency which provides finance for investment in energy efficiency by other public bodies through an innovative 'revolving fund' model. The objective of the organisation is to boost investment in energy efficiency, resulting in cost savings, $\mathrm{CO}_{2}$ savings, and supply chain opportunities for firms in the energy efficiency sector.

Salix Finance works with a number of clients across the UK - such as local authorities, universities, hospital trusts, and other public bodies. It provides an initial allocation of funding (typically $£ 500000$ ), which is matched by the recipient public body into a funding pool for use by the public body (i.e. total of $£ 1$ million). The recipient public body identifies a list of potential energy saving projects, the most cost-effective of which are then implemented by the fund. The public body must then agree to pay back the investment to the fund out of the money they save on energy bills. Due to the focus on high-impact, cost effective project investments, the payback is usually 5 years. As the public body repays the investment, the fund can then implement the next phase of investments, and so on. The public bodies involved benefit through energy savings and reduced energy bills. Overall, this model ensures that the public body achieves energy savings, and results in the greatest impact from the initial investment by Salix Finance.

Source : Miranda, G., et al. (2011a), "Climate Change, Employment and Local Development in Extremadura, Spain", OECD Local Economic and Employment Development (LEED) Working Papers, No. 2011/04, OECD Publishing. 
An important issue for all localities is how to strengthen entrepreneurial capabilities to identify projects, coordinate partners and to develop a business case for financial institutions to provide finance for these opportunities. Driven by market forces and a supportive policy environment, there are many opportunities for new firms in high growth low-carbon markets such as energy service companies, lowcarbon assessment software and monitoring devices, and specialised financial institutions that can package low-carbon purchases for consumers such as co-generation/tri-generation systems. Despite gaps in the market, the rate of business formation in low-carbon markets and entrepreneurial capacity remains low ${ }^{58}$.

\section{Conclusion}

This chapter has outlined seven enablers of low-carbon or green growth at the local level. All are important if local authorities are to assist their local areas to shift onto sustainable development paths, characterised by growth of jobs, social cohesion and significant reductions in carbon intensity, as well as broader environmental health. Action around all enablers needs to be tailored to meet the specific circumstances of different localities. All local authorities need to aim to align local initiatives with global and national frameworks and policies. There are significant risks if local authorities seek to go it alone.

They all require strong local leadership. Some of the enablers will require local government to play a leadership role, such as the formulation of a local sustainable economic development framework. This is an important pre-requisite for strengthening local foundations for green growth, as there needs to be consensus among major parties that are well-thought out strategic opportunities with the ability to integrate local economic and employment growth with carbon reduction. If communities remain divided over the relationship between economic growth and carbon reduction, based on lack of awareness and careful analysis, then it will be difficult for localities to make significant shifts.

Some enablers require close collaboration between local government and sub-national tiers of government, and private and public sector infrastructure agencies, such as local planning and sustainable infrastructure. Other enablers, such as financing green growth, should be led by the private sector. An underling feature is that all enablers require the development and implementation of new learning models based on effective partnerships and networks. This is made explicit in the case of local governance and green growth, which outlines three importance principles of local governance and the green economy leadership, building partnerships and community engagement.

The importance of what drives low-carbon or eco-innovation at the local level needs to be understood. Not all localities will be leaders in breakthrough green technologies, as these are usually, but not always, concentrated in metropolitan regions characterised by research and other knowledge institutions, globally competitive firms and government leadership. Expanding innovative capacity in firms, particular SMEs, to take-up and adapt to low-carbon and green technologies, may be just as important as major scientific and technological innovation. All localities can pursue opportunities to improve entrepreneurial skills, improve information and training opportunities, and in some cases, establish green incubators. A commitment to building capacity within organisations and between organisations to manage such an important shift in local economic and environmental management is a cost effective way of growing individual and institutional awareness, commitment, and of managing the transition to a low-carbon economy.

\section{ENDNOTES}


See: Cecilia V. Estolano (2011), "Enabling Green Growth in Sydney”, in Miranda, G., et al. (2011c), Climate Change, Employment and Local Development in Sydney, Australia, OECD Local Economic and Employment Development (LEED) Working Papers, No. 2011/14, OECD Publishing. Page 81.

See: Eberts, R. W. (2011), "Framework and Tools for Assessing and Understanding the Green Economy at the Local Level", OECD Local Economic and Employment Development (LEED) Working Papers, No. 2011/08, OECD Publishing.

See: Miranda, G., et al. (2011a), Climate Change, Employment and Local Development in Extremadura, Spain, LEED Working Papers, No. 2011/04, OECD Publishing.

London Energy Partnership (2008), Low Carbon Zones Workshop, London Energy Partnership Annual Forum.

UNEP (2002), Capacity Building for Sustainable Development: An overview of UNEP environmental capacity development initiatives, UNEP.

See Miranda, G., et al. (2011b), Climate Change, Employment and Local Development in London, UK, OECD Local Economic and Employment Development (LEED) Working Papers, No. 2011/05, OECD Publishing. Pages 81-82

See: Miranda, G., et al. (2011c), Climate Change, Employment and Local Development in Sydney, Australia, OECD Local Economic and Employment Development (LEED) Working Papers, No. 2011/14, OECD Publishing. Page 87

Miranda, G., et al. (2011b), Climate Change, Employment and Local Development in London, UK, OECD Local Economic and Employment Development (LEED) Working Papers, No. 2011/05, OECD Publishing. 


\section{ANNEX A: METHODOLOGY AND SURVEY}

\section{Methodology}

The OECD LEED project on "Climate Change, Employment and Local Development" reviewed national and local strategies and initiatives on employment, economic and workforce development, and explores how local economies can best harness the opportunities open to them in the context of the transition to a green economy, in order to generate greater productivity and sustainability in the labour markets at the national and local levels.

The project involved four full case study visits to: Extremadura in Spain (21-25 June 2010), London in the United Kingdom (13-15 September 2010), Sydney in Australia (29 Nov. - 3 Dec. 2010), and Podlaskie/ Pomorskie in Poland (27 Mar. $-1^{\text {st }}$ Apr. 2011). Two additional study visits were hosted by Styria, Austria (11-13 October 2010) and Trento, Italy (9-11 June 2010) which allowed for further field research. Various OECD seminars and conferences were organised as part of this project, which allowed for further discussion. The European Commission, DG Employment, Social Affairs and Equal Opportunities, participated in this project and provided a financial contribution towards its completion.

It is important to highlight that the present LEED project seeks to reflect a broader illustration of the transition to the green agenda, while complementing the work that each of the participants is undertaking locally. Each of the country reviews was therefore adjusted to the participants' own agendas to ensure that the final outcome was relevant to the different approaches pursued by mentor governments.

The project consisted in the following steps:

\section{1) Survey}

An electronic survey was prepared and distributed to firms in the areas studied by the project. In addition, a set of questions related to climate change were included in surveys performed as part of the OECD LEED project on Leveraging Training and Skills Development in SMEs. The surveys will seek to generate evidence on the impacts on job profiles and skills requirements on the work place from climate change (both through policy and regulation). Further detail of the survey is provided further below.

A second electronic survey was prepared and distributed to public labour market institutions. This survey aimed at understanding the barriers faced by public sector agencies to adjust and deliver appropriate services to the private sector to facilitate the transition to a greener economy. This survey did not receive enough responses to allow for analysis and was therefore not referred to in this report.

\section{2) Diagnostic report}

Participating countries were asked to provide background material and documents to prepare an initial diagnostic paper in collaboration with a local expert. Based on this background, key sectors for transformation or emergence were identified prior to the country study visit to target the public initiatives that could support the adaptation of the business community to the green economy. This diagnostic report was included in the country reports as Chapter 1. 


\section{3) Study visit}

A one-week study visit to participating countries took place by an international expert team led by the OECD Secretariat. These study visits included the organisation of small workshops with public and private actors involved in workforce and economic development, the organisation of face-to-face interviews with representatives of the public sector (employment offices, training providers, etc.) and industry, as well as visiting various relevant initiatives that were identified as learning models for the project. This study visit aimed at deepening the understanding of the challenges and opportunities that are arising for the work of public services and provide more opportunities for learning on mechanisms and practices used to facilitate transformation and adaptation to greener demands of labour markets locally.

\section{4) Learning models}

A call for papers was issued to identify cases where innovative policies and practices have been observed. The learning models identified challenges and opportunities arising for the work of public services and other stakeholders in the relevant policy areas, and mechanisms and practices that have been put in place as a result to facilitate adaptation to greener demands of labour markets locally. These new practices may have led to:

- Transformation of traditional jobs into "green jobs" or the creation of new "green jobs".

- New/adapted training programmes as a response to new skill needs in businesses and/or public organisations or to green demands and regulations.

Three case studies were commissioned as part of this call for paper: Landcom (Australia), Eolicas (Portugal) and Virginia (USA). Other learning models were identified by the international experts that formed part of the review panels for the different study visits. All of the learning models are summarised in a Table in Annex B.

\section{5) Analysis}

Based on the responses from the surveys, the learning models and the peer review examinations, a country report for each participating region was prepared by the OECD Secretariat and presented at the LEED Directing Committee meetings. Each of these reports includes the analysis of the country/region and concludes with a set of policy recommendations on how best to adapt the labour markets to greener demands and on how labour market institutions can support the transition to a cleaner and fairer economy. The country reports have been published by the OECD as working papers and are available free of charge at www.oecd.org/cfe/LEED. This work has been disseminated in international conferences, country seminars, and in the global launch of the project's report in Sydney on 5-6 December 2011.

The present is the synthesis report, summarising the analysis and findings of the entirety of this work.

\section{Survey description}

As discussed above, this OECD project involved the preparation of a survey aimed at identifying the impact of climate change on businesses and the changes in firms (due to climate change impacts on their processes and methods), in terms of the creation, transformation or suppression of jobs, as well as in terms of training and skills needs. Extremadura, London and Sydney participated in this survey - Poland decided not to be enrolled as it had just sent out a survey in the context of another OECD LEED Project on Leveraging Training and Skills Development in SMEs. 
In terms of the survey, the valid responses collected were 64 for Extremadura, 200 for London and 78 for Sydney. It is important to highlight that the OECD survey results complement and confirm the findings from the study visits to these regions. However, these surveys cover a small sample of the firms and are therefore not necessarily representative of the firms’ population in the countries.

The features of the firms surveyed vary significantly across countries in terms of sector, size and their approach to green skills development. General information on the surveyed firms is presented in this Annex, and specific information on training, skills needs and labour market characteristics are analysed in Chapter 2.

In Extremadura, the surveyed was translated into Spanish and applied in person by a representative of some of the 210 Employment and Local Development Agencies in the region. The Extremadura firms surveyed belong to various sectors relevant to the overall regional economy and about half of the sample operates in the services sector. The rest of the firms are equally distributed in the primary and secondary sectors.

In Sydney, the survey was created on line and it was sent out directly with the Regional Development Agency Sydney to its partner enterprises. The Council of the City of Sydney also sent out the link to its own database of businesses in metropolitan Sydney. Nearly two thirds of the surveyed firms operate in the services sector, $30 \%$ in the secondary sector and just a very small percentage in the primary sector.

Table 5. Extremadura and Sydney: surveyed enterprises by sector

\begin{tabular}{|l|l|l|l|}
\hline & Primary & Secondary & Services \\
\hline Extremadura & $26.2 \%$ & $23 \%$ & $50.8 \%$ \\
\hline Sydney & $3.8 \%$ & $30.8 \%$ & $65.4 \%$ \\
\hline
\end{tabular}

Note: Primary (agriculture, fishing, mining - ISIC categories A, B, C), Manufacturing and Construction (ISIC categories D, E and F) and Services (ISIC categories G to Q)

In London, the enterprises surveyed belong to the 'low-carbon' sector as defined by the London Development Agency (LDA). The 'low-carbon' sector in London includes those sub-sectors that are related to the carbon reduction programme and LDA intervention. This definition is more closely tailored to the needs of the low carbon initiatives of the LDA and is narrower than the broad definition used in the study "Low Carbon and Environmental Goods and Services” report (DTZ, 2010, page 6). A selection of relevant questions of the OECD survey was sent out electronically to the enterprises being surveyed by DTZ as part of a project on Skills for a Low Carbon London commissioned at the same time by the LDA.

Table 6. London: surveyed enterprises by sector

\begin{tabular}{|l|l|}
\hline Energy Efficient - Building Technologies & $24.5 \%$ \\
\hline Energy Efficient - Energy Management & $11.5 \%$ \\
\hline Energy Supply + Renewable Energy & $5.5 \%$ \\
\hline Waste and waste to energy & $27.0 \%$ \\
\hline More than one sector (specialty) & $31.5 \%$ \\
\hline
\end{tabular}


As shown in Table 7, the size of the firms surveyed were representative of the enterprises in each place $^{59}$. In Extremadura, the majority of firms are located in rural areas and are family businesses. In Extremadura, only $2 \%$ of the enterprises are larger than 50 employees. Also, in London the majority of the firms are micro (1-9 employees) but there was a significant participation in the survey of larger firms, including 4\% of firms larger than 1000 employees. Finally, in Sydney, the firms surveyed are more varied in size. In comparison to the other two countries, the percentage of micro firms is very small (21\%) and one in 5 enterprises employs more than 1000 people.

Table 7. Surveyed firms by size

\begin{tabular}{|c|c|c|c|c|c|c|c|}
\hline & $\mathbf{1 - 9}$ & $\mathbf{1 0 - 1 9}$ & $\mathbf{2 0 - 4 9}$ & $\mathbf{5 0 - 2 4 9}$ & $\mathbf{2 5 0 - 4 9 9}$ & $\mathbf{5 0 0 - 9 9 9}$ & $\mathbf{> 1 0 0 0}$ \\
\hline Extremadura & $83 \%$ & $9 \%$ & $6 \%$ & $2 \%$ & $0 \%$ & $0 \%$ & $0 \%$ \\
\hline London & $61 \%$ & $13 \%$ & $8 \%$ & $7 \%$ & $4 \%$ & $3 \%$ & $4 \%$ \\
\hline Sydney & $21 \%$ & $12 \%$ & $14 \%$ & $21 \%$ & $6 \%$ & $6 \%$ & $21 \%$ \\
\hline
\end{tabular}

\section{ENDNOTES}

Indeed, the surveys were sent to a wide variety of enterprises in each country. The profile of the enterprises reflects the population of the business sector. For instance, in Extremadura there were a vast majority of micro and small enterprises, while in London there were a mix of small and medium (and some large) companies, as well as in Sydney. 


\section{ANNEX B: LEARNING MODELS}

This section provides a table which summarises the most relevant practical examples (learning models) to illustrate some of the approaches and recommendations suggested in this report. These models cannot necessarily be replicated elsewhere as the local context needs to be taken into consideration. However, these models do intend to provide some guidance on how other cities and regions in the OECD and beyond have dealt with similar challenges. The full description of each of these learning models can be consulted in the country reports, available free of charge on the LEED online platform of working papers at www.oecd.org/cfe/LEED

Table 8. Synthesis of learning models

\begin{tabular}{|c|c|c|}
\hline Model & Region (country) & Recommendation/Approach \\
\hline \multicolumn{3}{|c|}{$\begin{array}{l}\text { Learning models in: Miranda, G., et al. (2011a), Climate Change, Employment and Local Development in } \\
\text { Extremadura, Spain, LEED Working Papers, No. 2011/04, OECD Publishing. }\end{array}$} \\
\hline $\begin{array}{l}\text { Clean Energy Economy } \\
\text { Programme }\end{array}$ & Colorado (USA) & $\begin{array}{l}\text { Support the attraction and development of } \\
\text { businesses in energy-related sectors }\end{array}$ \\
\hline $\begin{array}{l}\text { Gangwon Green Growth (3G) } \\
\text { Project }\end{array}$ & Gangwon (Korea) & $\begin{array}{l}\text { Attract investment and build up green } \\
\text { infrastructure }\end{array}$ \\
\hline Regen SW & South West of England (UK) & $\begin{array}{l}\text { Supply chain development to capture full } \\
\text { economic benefits of renewables. }\end{array}$ \\
\hline Belvedere SpA & Peccioli (Italy) & $\begin{array}{l}\text { Develop waste management framework } \\
\text { and support the emergence of a new green } \\
\text { sector }\end{array}$ \\
\hline Salix Finance & UK & $\begin{array}{l}\text { Public sector lead on energy efficiency } \\
\text { through 'invest to save' programme or } \\
\text { revolving fund }\end{array}$ \\
\hline $\mathrm{CO}_{2}$ Sense & $\begin{array}{l}\text { Yorkshire and Humberside } \\
\text { (UK) }\end{array}$ & $\begin{array}{l}\text { Promote energy efficiency improvements in } \\
\text { the private sector }\end{array}$ \\
\hline $\begin{array}{l}\text { Federazione Trentina della } \\
\text { Cooperazione }\end{array}$ & Trentino (Italy) & $\begin{array}{l}\text { Organise, simplify and rationalize training } \\
\text { infrastructures, by easing the collection and } \\
\text { analysis of skills needs and allowing a } \\
\text { smarter provision of skills development } \\
\text { services. }\end{array}$ \\
\hline SKILLS Programme & Europe & $\begin{array}{l}\text { Use an integrated approach to training for } \\
\text { local development in a context of SMEs and } \\
\text { by the need to share, rationalize and } \\
\text { efficiently use resources. }\end{array}$ \\
\hline $\begin{array}{l}\text { Centres de compétence du } \\
\text { Forem }\end{array}$ & Wallonia (Belgium) & $\begin{array}{l}\text { Recognition and validation of learning } \\
\text { outcomes for skills development. Also on } \\
\text { how to support this kind of initiatives } \\
\text { through a public-private partnership }\end{array}$ \\
\hline $\begin{array}{l}\text { South Styrian Cooperative for } \\
\text { Energy Production }\end{array}$ & Mureck (Austria) & $\begin{array}{l}\text { Partnerships for greening the economy and } \\
\text { human capital. Use of local farm products, } \\
\text { local waste and local resources. }\end{array}$ \\
\hline $\begin{array}{l}\text { Competitiveness Operational } \\
\text { Programme }\end{array}$ & East of England (UK) & $\begin{array}{l}\text { Develop institutional capacity for the green } \\
\text { economy }\end{array}$ \\
\hline $\begin{array}{l}\text { Eco-Innovation Support } \\
\text { through Clusters }\end{array}$ & Styria (Austria) & $\begin{array}{l}\text { Make the best use of clusters by having a } \\
\text { clearer focus upon the green economy } \\
\text { agenda and upon the benefits of investing } \\
\text { in eco-innovation }\end{array}$ \\
\hline
\end{tabular}




\begin{tabular}{|c|c|c|}
\hline Model & Region (country) & Recommendation/Approach \\
\hline $\begin{array}{l}\text { Green Public Procurement } \\
\text { Policy }\end{array}$ & London (UK) & $\begin{array}{l}\text { Coordinate efforts and initiatives towards } \\
\text { the green economy by 'leading by example', } \\
\text { notably by adopting green purchasing policy }\end{array}$ \\
\hline \multicolumn{3}{|c|}{$\begin{array}{l}\text { Learning models in: Miranda, G., et al. (2011b), Climate Change, Employment and Local Development in } \\
\text { London, UK, LEED Working Papers, No. 2011/05, OECD Publishing. }\end{array}$} \\
\hline ‘Cool City Sakai' Plan & Sakai (Japan) & $\begin{array}{l}\text { Strengthen collaboration with large } \\
\text { businesses. Involve HE and FE in larger } \\
\text { low-carbon projects. }\end{array}$ \\
\hline A ‘Demonstration' city & Baoding (China) & $\begin{array}{l}\text { Grow your market internationally in } \\
\text { collaboration with the private sector }\end{array}$ \\
\hline The Wise Group & Glasgow (UK) & $\begin{array}{l}\text { Support government actions through social } \\
\text { enterprises }\end{array}$ \\
\hline TransverS'AL & Alsace (France) & $\begin{array}{l}\text { Identify transferrable skills and make the } \\
\text { information available to a wide audience }\end{array}$ \\
\hline Green Public Procurement & Basque Country (Spain) & $\begin{array}{l}\text { Definition and implementation of common } \\
\text { GPP criteria in collaboration with the private } \\
\text { sector }\end{array}$ \\
\hline $\begin{array}{l}\text { Green Skills in Vocation } \\
\text { Education and Training, TAFE }\end{array}$ & New South Wales (Australia) & $\begin{array}{l}\text { Green training for private and public sector } \\
\text { actors }\end{array}$ \\
\hline EcoBuy & Vienna (Austria) & $\begin{array}{l}\text { Develop criteria for GPP and involve all of } \\
\text { the public sector in the process }\end{array}$ \\
\hline Eco-primes & Paris (France) & $\begin{array}{l}\text { Stimulate the use of RE:NEW programme } \\
\text { by home owners through incentives }\end{array}$ \\
\hline \multicolumn{3}{|c|}{$\begin{array}{l}\text { Learning models in: Miranda, G., et al. (2011c), Climate Change, Employment and Local Development in } \\
\text { Sydney, Australia, LEED Working Papers, No. 2011/14, OECD Publishing. }\end{array}$} \\
\hline $\begin{array}{l}\text { Retrofit Employer Accord Pilot } \\
\text { (REAP) }\end{array}$ & London (UK) & $\begin{array}{l}\text { A city-wide retrofitting programme to make } \\
\mathrm{CO}_{2} \text { emissions savings and open up job } \\
\text { opportunities. }\end{array}$ \\
\hline $\begin{array}{l}\text { Twin Cities Initiative on Green } \\
\text { Manufacturing }\end{array}$ & $\begin{array}{l}\text { Minneapolis / Saint Paul } \\
\text { (USA) }\end{array}$ & $\begin{array}{l}\text { Strategy to become a world leading city in a } \\
\text { specific area }\end{array}$ \\
\hline $\begin{array}{l}\text { Labour market analysis of } \\
\text { green jobs }\end{array}$ & London (UK) & $\begin{array}{l}\text { Decide the most appropriate way to define } \\
\text { green skills and determine the number of } \\
\text { green jobs and skills in the economy }\end{array}$ \\
\hline $\begin{array}{l}\text { The California WE\&T Needs } \\
\text { Assessment }\end{array}$ & California (USA) & $\begin{array}{l}\text { A state-of-the-art workforce education and } \\
\text { training assessment undertaken as part of a } \\
\text { wider strategy focusing on energy efficiency } \\
\text { goals. }\end{array}$ \\
\hline Local Enterprise Partnership & England (UK) & $\begin{array}{l}\text { Empower communities, connect people to } \\
\text { jobs and provide the skills needed to create } \\
\text { and shape a dynamic and entrepreneurial } \\
\text { local economy }\end{array}$ \\
\hline $\begin{array}{l}\text { Lindoe Offshore Renewables } \\
\text { Center }\end{array}$ & Syddanmark (Denmark) & $\begin{array}{l}\text { Develop physical and human assets into a } \\
\text { world-class facility in an emerging } \\
\text { technology for sustainability }\end{array}$ \\
\hline $\begin{array}{l}\text { Education Employment } \\
\text { Linkages Research Programme }\end{array}$ & New Zealand & $\begin{array}{l}\text { Education systems help young people } \\
\text { prepare themselves for new opportunities } \\
\text { being created in the green economy. }\end{array}$ \\
\hline CleanTECH San Diego & San Diego (USA) & $\begin{array}{l}\text { An organisation with major stakeholders to } \\
\text { accelerate green business formation, } \\
\text { leverage intellectual property, promote } \\
\text { networking in the green economy }\end{array}$ \\
\hline The Pecan Street Project & Austin (USA) & $\begin{array}{l}\text { A collaborative project among a city, a } \\
\text { public utility, a university, businesses and } \\
\text { an environmental organisation to leverage } \\
\text { the public utilities for broader green growth } \\
\text { purposes }\end{array}$ \\
\hline Regional Growth Strategy & Vancouver (Canada) & Shared governance around planning and \\
\hline
\end{tabular}




\begin{tabular}{|c|c|c|}
\hline Model & Region (country) & Recommendation/Approach \\
\hline & & infrastructure \\
\hline \multicolumn{3}{|c|}{$\begin{array}{l}\text { Learning models in: Miranda, G., et al. (2011d), Climate Change, Employment and Local Development in } \\
\text { Poland, LEED Working Papers, No. 2011/22, OECD Publishing. }\end{array}$} \\
\hline $\begin{array}{l}\text { CENIFER foundation for } \\
\text { renewable energies }\end{array}$ & Navarra (Spain) & $\begin{array}{l}\text { Anticipating skills needs for renewable } \\
\text { energies and ensure skills availability in } \\
\text { renewables }\end{array}$ \\
\hline FONAMA training programme & Extremadura (Spain) & $\begin{array}{l}\text { Provision of training adapted to 'green' skills } \\
\text { needs and enhance the capacity of labour } \\
\text { market institutions }\end{array}$ \\
\hline Development of rural tourism & Castille and Leon (Spain) & $\begin{array}{l}\text { Develop a tourism sector in rural areas, } \\
\text { either related to culture, nature or } \\
\text { agriculture. }\end{array}$ \\
\hline GreenEvo & Various regions (Poland) & $\begin{array}{l}\text { Support access to global markets and } \\
\text { strengthen internal capacities of businesses } \\
\text { in green sectors }\end{array}$ \\
\hline Green Technologies Centre & Podlaskie (Poland) & $\begin{array}{l}\text { Support the transformation of businesses in } \\
\text { traditional sectors (notably agriculture) } \\
\text { towards green activities. Identify niche } \\
\text { markets and train business owners. }\end{array}$ \\
\hline Bartosz company & Podlaskie (Poland) & $\begin{array}{l}\text { On-the-job training provision for workers in } \\
\text { green skills }\end{array}$ \\
\hline Shipbuilding to wind turbines & Belfast (UK) & $\begin{array}{l}\text { Identify transferable skills from a shrinking } \\
\text { industry (shipbuilding) to a green industry } \\
\text { (wind turbines) }\end{array}$ \\
\hline Shipbuilding to wind turbines & Gdansk (Poland) & $\begin{array}{l}\text { Support the transformation of a declining } \\
\text { industry (shipbuilding) to new green } \\
\text { activities (wind turbines) }\end{array}$ \\
\hline $\begin{array}{l}\text { Institute for the Diversification } \\
\text { and Energy Saving (IDEA) }\end{array}$ & Spain & $\begin{array}{l}\text { Free and applied training courses for the } \\
\text { 'greening of the agriculture' }\end{array}$ \\
\hline $\begin{array}{l}\text { Siemens Wind Power Training } \\
\text { Centre }\end{array}$ & Bremen (Germany) & $\begin{array}{l}\text { Up-to-date and appropriate specific training } \\
\text { for employees within the wind power sector }\end{array}$ \\
\hline Biogas in Kristianstad & Kristianstad (Sweden) & $\begin{array}{l}\text { Production of biogas from landfill and other } \\
\text { agricultural waste }\end{array}$ \\
\hline $\begin{array}{l}\text { Emprendeverde - Green } \\
\text { Entrepreneurship Network }\end{array}$ & Spain & $\begin{array}{l}\text { Promote green entrepreneurship with } \\
\text { support of ESF. }\end{array}$ \\
\hline $\begin{array}{l}\text { Programma Operativo } \\
\text { Interregionale }\end{array}$ & Puglia (Italy) & $\begin{array}{l}\text { Overcome the issue of lack of coordination } \\
\text { of different policies around the topic of } \\
\text { renewable energies in rural areas }\end{array}$ \\
\hline $\begin{array}{l}\text { Fund for Electric Energy Saving } \\
\text { (FIDE) }\end{array}$ & Various regions (Mexico) & $\begin{array}{l}\text { Train energy specialists, households and } \\
\text { children on energy saving approaches. }\end{array}$ \\
\hline $\begin{array}{l}\text { Converting the Rust Belt to the } \\
\text { Wind Belt }\end{array}$ & Lackawanna (USA) & $\begin{array}{l}\text { Make use of skills available from one sector } \\
\text { to a green sector. Transform the highly } \\
\text { contaminated Superfund sites into a } \\
\text { useable brownfields while creating jobs }\end{array}$ \\
\hline $\begin{array}{l}\text { Seeing innovation in regional } \\
\text { green manufacturing }\end{array}$ & New Mexico (USA) & $\begin{array}{l}\text { Provide a nurturing environment for green } \\
\text { businesses and engage universities in } \\
\text { promoting innovation, commercializing } \\
\text { ideas, and training students effectively }\end{array}$ \\
\hline
\end{tabular}





\section{GLOSSARY}

The OECD LEED Programme has prepared the following glossary for the purposes of this project. The definitions below do not necessarily reflect the definition of member countries or of the Organisation as a whole. However, this glossary aims to clarify some of the most frequently used terms in the context of this work. Most of the terms presented below are taken from the OECD LEED working paper "Greening Jobs and Skills: Labour Market Implications of Addressing Climate Change” which was prepared in 2010 as a conceptual framework for this project.

Carbon leakage. Carbon leakage refers to "the ratio of carbon emissions increase from a specific sector outside the country (as a result of a policy affecting that sector in the country) over the carbon emission reductions in the sector (again, as a result of the environmental policy)" (IEA, 2008, p. 3). In other words, carbon leakage occurs when economic activity migrates from one country with strict environmental regulation to another country with more flexible or reduced environmental regulation frameworks. The impact on employment is quite obvious: jobs migrate and usually do so at the expense of job quality (decreased wages and working conditions) in the new host country. Low skilled workers tend to be the hardest hit by this phenomenon because while production relocates, the high added-value occupations (design, management, etc.) in these firms usually remain in the country of origin (IEA, 2008).

Carbon pricing. The two main economic instruments used to reduce Greenhouse Gas (GHG) emissions are carbon taxes and cap-and-trade schemes (also known as emissions trading systems). Carbon taxes involve governments imposing a tax on the amount of emissions produced. These taxes increase the price of using emissions intensive products and thus contribute to the reduction of GHG pollution. Capand-trade schemes on the other hand require all emitters to acquire permits for their planned emissions. The government or international institution implementing the scheme establishes an overall target for emissions and then issues a certain number of emission permits according to the target. Permit holders can trade them among themselves and as a result, prices are established through a mechanism of supply and demand (rather than a fixed rate as in carbon taxes) as well as through the tightness of the target established at the outset. Both instruments generate prices for GHG emissions, but do so in different ways. Currently cap-and-trade systems are increasingly the focus of interest in most countries or regions considering market based approaches to reducing GHG emissions (OECD, 2008).

Circular economy. Also known as loop economy, is an economy that does not produce any emissions of GHGs and has no environmental footprint. It can be achieved through a process allowing industries to complement and take advantage of each other's production cycles, waste and technological development.

Clean economy. The clean economy is economic activity - measured in terms of establishments and the jobs associated with them - that produces goods and services with an environmental benefit or adds value to such products using skills or technologies that are uniquely applied to those products (Brookings Institute, 2011).

Decent work. The ILO defines decent work as work that takes place "under conditions of freedom, equity, security and dignity, in which rights are protected and adequate remuneration and social coverage is provided". Decent work has four pillars: Employment, Social Protection, Rights, and Social Dialogue. Gender equality is an integral cross-cutting theme in the decent work agenda, with particular focus on the 
process of creating equal opportunities for women, enhancing their social protection, ensuring that the human rights of women are addressed, and enabling them to participate in social dialogue. (UNEP, ILO, ITUC, IOE, 2008a, p. 278).

Eco-innovation. This term refers to the implementation of new, or significantly improved, products (goods and services), processes, marketing methods, organisational structures and institutional arrangements which, with or without intent, lead to environmental improvements compared to relevant alternatives (OECD, 2009)

Energy efficient. It is the ratio between an output of performance, service, goods or energy, and an input of energy (Directive 2006/32/EC of the European Parliament and of the Council of 5 April 2006)

Environmental Goods and Services Industry (EGS). All activities which produce goods and services to measure, prevent, limit, minimise or correct environmental damage to water, air and soil, as well as problems related to waste, noise and eco-systems. This includes technologies, products and services that reduce environmental risk and minimise pollution resources (OECD/EUROSTAT, 1999).

Green economy. The one that results in improved human well-being and social equity, while significantly reducing environmental risks and ecological scarcities. In its simplest expression, a green economy can be thought of as one which is low-carbon, resource efficient and socially inclusive (UNEP, 2011, Towards a Green Economy: Pathways to Sustainable Development and Poverty Eradication - A Synthesis for Policy Makers, www.unep.org/greeneconomy)

Green entrepreneurship. Synonyms to green entrepreneurship include ecoentrepreneurship, ecopreneurship, environmental entrepreneurship, sustainable entrepreneurship, ecological entrepreneurship, enviro-preneurship or sustainopreneurship. This term refers to the entrepreneurial activity in making less use of resources, reducing carbon emissions and integrating the sustainability component. Green entrepreneurship can take place in sectors aiming at either improving the environment (mitigating) or in sectors aiming at adapting to environmental changes (adaptation) (OECD, 2011).

Green growth. Means the way in which the current economy can make the transition to a sustainable economy. It involves promoting growth and development while reducing pollution and greenhouse gas emissions, minimising waste and inefficient use of natural resources, maintaining biodiversity, and strengthening energy security. It requires further "decoupling" of environmental impacts from economic growth, and greening of consumption and production patters, while reducing poverty and improving health and job prospects. Green growth means making investment in the environment a new source of economic growth (OECD Green Growth Strategy 2009).

Green innovation. Green innovation relates to innovative activities undertaken as part of climate change adaptation or mitigation; either as a direct consequence of climate change, or more likely, as a way to identify new business opportunities as a result of the demand for climate change adaptation or mitigation (CFE/LEED (2010)14)

Green jobs. For the sole purposes of this project, the OECD LEED Programme define green jobs as those that contribute to protecting the environment and reducing the harmful effects human activity has on it (mitigation) or to helping to better cope with current climate change conditions (adaptation).

Greener jobs. This term is more frequently used throughout this report as it refers to any job that has been transformed or adjusted to reduce its environmental impact. For the purposes of this project, it is assumed that any job can be greener, regardless of the sector, the outputs or the skills required. 
Green skills. Specific skills required to tailor products, services, processes or operations due to climate change/low-carbon adjustments, mitigation, requirements or regulations (e.g. water purification and site remediation planning/engineering in mining, solar panels installation, wind turbines design, green management, carbon capture and storage techniques).

Green tax. A tax intended to make the choices and activities of producers and/or consumers more environmentally sound by internalising some of the cost of environmental impacts which are not conventionally accounted for in the market price (OECD, 2009e).

Green washing. The term "green washing" refers to false claims of environmental virtues by companies, training providers, policy makers or NGOs, aiming at the creation of a positive image of their goods or services, which look more environmentally-friendly than they really are. See Miranda, G., et al. (2011a), Climate Change, Employment and Local Development in Extremadura, Spain, OECD Local Economic and Employment Development (LEED) Working Papers, No. 2011/04, OECD Publishing.

Labour markets. Places where labour supply is exchanged for a wage. Labour markets can be identified by a combination of such factors as geography (local, regional, national, international), industry, education, licensing or certification, and occupation. More generally, labour market can refer to the processes by which workers and employers are brought into contact, and wages and conditions of work are decided. Some of these involve formal institutions: contacts between workers and employers may be arranged by employment exchanges or agencies, either public or private (Black et al., 2009). In addition, labour market institutions are the organisations and procedures through which workers, firms, and government affect wages, employment and working conditions. These vary widely across countries and among firms and industries within a country (Durlauf et al., 2008).

Low-carbon economy. Low-carbon economy implies an economy that is more sober in carbon emissions. In this report, this term is used as synonym to green economy.

Performance-based standard. An environmental policy measure which sets a minimum level of performance or maximum level of emissions (e.g. g/km for vehicle emission) (OECD, 2007b).

Skills. The meaning of skills refers to the abilities and capacities people have to perform tasks that are in demand in the workforce. These skills can be generic or specific regarding functions at work such as managing people, computing, collaborating or dealing with risk and uncertainty or developing a new product or service (Tether et al., 2005).

Sustainable development. Sustainable development is defined as a development that meets the needs of the present without compromising the ability of future generations to meet their own needs (World Commission on Environment and Development, 1987).

Technology-based standard. An environmental policy measure which prescribes the technologies which are authorized for use (e.g. catalytic converters) (OECD, 2007b). 



\section{BIBLIOGRAPHY}

Apollo Alliance et al. (2008), Green-Collar Jobs in America’s Cities, United States.

Babiker M. \& R.S. Eckaus (2006), Unemployment Effects of Climate Policy, MIT Joint Programme on the Sciences and Policy of Global Change, Report No. 137, MIT, Cambridge.

Barrett J. et al. (2002), Clean Energy and Jobs, Economic Policy Institute and Centre for Sustainable Economy, United States.

Beaudet, M.B. (2009), "Doutes sur la création des 600000 emplois verts", Le Monde, 30 July.

Bell R. (2009), available at http://robertibell.com/thegreenbubble.html, accessed 15 August 2009.

Bettencourt et al. (2006), Not if But When, Adapting to Natural Hazards in the Pacific Islands Region, World Bank, East Asia and Pacific Region, Pacific Islands Management Unit.

Black, J., N. Hashimzade and G. Myles (2009), "A Dictionary of Economics", Oxford Reference Online, Oxford University Press, Bibliothèque Sciences Po, https://acces-distant.sciences-

po.fr:443/http/www.oxfordreference.com/views/ENTRY.html?subview=Main\&entry=t19.e1748, accessed 5 January 2010.

Boettcher M. et al. (2008), Employment Opportunities and Challenges in the Context of Rapid Industry Growth, BWEA, www.bwea.com/pdf/publications/Bain\%20Brief_Wind\%20Energy\%202008_FINAL.pdf.

Briggs C., et al. (2007), Going with the Grain? Skills and Sustainable Business Development: Project Report, Workplace Research Centre, University of Sydney, Australia.

BWEA (2008), Today's Investment - Tomorrows Asset: Skills and Employment in Wind, Wave and Tidal Sectors, SQW Energy, www.bwea.com/pdf/publications/BWEA\%20Skills\%20Report\%20FINAL\%2016oct.pdf.

BMU (2006), Erneuerbare Energien: Arbeitsplatzeffekte, Berlin.

Connection Research (2009), "Who are the Green Collar Workers?", Department of Environment and Climate Change NSW and the Environment Institute of Australia and New Zealand, Australia, available at:

www.eianz.org/sb/modules/news/attachments/71/Green\%20Collar\%20Worker\%20report\%20Final. pdf, accessed 26 October 2009.

Delai N. (2009), Rifiuti \& sviluppo. Il caso virtuoso del sistema Peccioli, Franco Angeli, Italy

DELEG (Department of Energy, Labour and Economic Growth) (2009), Michigan Green Jobs Report 2009, Michigan, available at: 
www.michigan.gov/documents/nwlb/GJC_GreenReport_Print_277833_7.pdf, accessed 2 October 2009.

Docquiert, J. (2009), "45\% des Français favorables à une taxe carbone", Les Echos, 31 July 2009.

DTZ (2010), Skills for Low Carbon London, London

Dupont, G. (2009), "Les infractions à l'environnement restent peu sanctionnées", Le Monde, 5 August 2009.

Durlauf, S. and L. E. Blume (2008), "The New Palgrave Dictionary of Economics", Second Edition.

Eberts, R. W. (2011), "Framework and Tools for Assessing and Understanding the Green Economy at the Local Level", OECD Local Economic and Employment Development (LEED) Working Papers, No. 2011/08, OECD Publishing.

ECORYS (2008), "Environment and Labour Force Skills: Overview of the Links between the Skills Profile of the Labour Force and Environmental Factors", Report for the European Commission DG Environment, Rotterdam.

EEA (2009a), "Urban Frontrunners - Cities in the Fight against Global Warming", June, available at: www.eea.europa.eu/articles/urban-frontrunners-2013-cities-and-the-fight-against-global-warming, accessed 10 October 2009.

EEA (2009b), "Cities of the Future - How will European Cities Adapt to New Climate Conditions?", June, available at: www.eea.europa.eu/articles/cities-of-the-future-2013-how-will-european-cities-adaptto-new-climate-conditions, accessed 10 October 2009.

ESCAP (2000), Ministerial Conference on Environment and Development in Asia and the Pacific 2000, available at: www.unescap.org/mced2000/, accessed 20/08/2009.

Esty D. and A. Winston (2006), Green to Gold: How Smart Companies use Environmental Strategy to Innovate, Create Value and Build Competitive Advantage, Yale University Press.

ETUC (2006), "Climate Change and Employment: Impact on Employment in the European Union-25 of Climate Change and $\mathrm{CO}_{2}$ Emission Reduction Measures by 2030", available at: www.tradeunionpress.eu/Web/EN/Activities/Environment/Studyclimatechange/rapport.pdf, accessed

ETUC (2007), The Impact on Employment in the EU-25 of Climate Change and $\mathrm{CO}_{2}$ Emission Reduction Measures by 2030, Brussels, www.tradeunionpress.eu/Web/EN/Activities/Environment/Studyclimatechange/rapport.pdf.

Fankhauser, S., F. Seheiler and N. Stern (2008), "Climate Change, Innovation and Jobs", Climate Policy, Vol. 8, pp. $421-429$.

Froy, F. and S. Giguere (2009), Putting in Place Jobs which Last, A Guide to Re-Building Sustainable Employment at the Local Level, OECD LEED programme, OECD.

GHK (2009a), "The Impacts of Climate Change on European Employment and Skills in the Short to Medium-Term: Company Case Studies", Final Report, Vol. 1, May 2009, London. 
GHK (2009b), "The Impacts of Climate Change on European Employment and Skills in the Short to Medium-Term: A Review of the Literature", Final Report, Vol. 2, May 2009, London.

Global CCS Institute (2009), "Strategic Analysis of the Global Status of Carbon Capture and Storage, Report 1: Status of Carbon Capture and Storage Projects Globally", Canberra, available at: www.globalccsinstitute.com/downloads/Reports/2009/worley/Foundation-Report-1-rev0.pdf, accessed 5 January 2010.

Green Jobs Act (2007), Washington D.C., United States Congress.

Grimshaw, G. (2009), "The Proposed Carbon Pollution Reduction Scheme: How does it Work and What are the Possible Implications?" New Planner, No. 80, September, pp. 14-15.

IEA (2008), "Issues behind Competitiveness and Carbon Leakage, Focus on Heavy Industry", IEA Information paper, October 2008, Paris.

IEA (2009), "Ensuring Green Growth in a Time of Crisis; The Role of Energy Technology", available at: www.iea.org/Papers/2009/ensuring_green_growth.pdf, accessed 5 November 2009.

IEA (2010), "Climate Change Policies and Measures Database", available at: www.iea.org/textbase/pm/index_clim.html, accessed on 6 Jan 2010.

ILO (2007), "Decent Work for Sustainable Development - The Challenge for Climate Change", Working Party on the Social Dimension of Globalization, November 2007, Geneva.

ILO (2008), "Global Challenges for Sustainable Development: Strategies for Green Jobs", ILO Background note for the G8 Labour and Employment Ministers Conference, May 2008, Japan.

ILO (2011), Skills for Green Jobs, A Global View, Geneva

ILO and EC (2011a), Skills and Occupational Needs in Renewable Energy, ILO Skills and Employability Department, Geneva

ILO and EC (2011b), Skills and Occupational Needs in Green Building, ILO Skills and Employability Department, Geneva

ILO and EC (2011c), Comparative Analysis of Methods of Identification of Skill Needs on the Labour Market in Transition to the Low Carbon Economy, ILO Skills and Employability Department, Geneva

IPCC (1995), "Climate Change: A Glossary by the Intergovernmental Panel on Climate Change", available at: www.ipcc.ch/pdf/glossary/ipcc-glossary.pdf, accessed 6 January 2010.

IPCC (2007), “Climate Change: Synthesis Report”, Fourth Assessment Report (AR4), IPCC, Geneva.

ITUC CSI IGB (2008), Trade Unions and Climate Change: Equity, Justice \& Solidarity in the Fight against Climate Change, Brussels.

ITUC (2009a), “Equity, Justice and Solidarity in the Fight against Climate Change”, series Trade Unions and Climate Change, Trade Union Statement to COP15, Brussels, December 2009. 
ITUC (2009b), “A Just Transition: A Fair Pathway to Protect the Climate”, series Trade Unions and Climate Change, available at: http://climate.ituc-csi.org.

Joint Venture Silicon Valley Network (2009), Climate Prosperity: A Greenprint for Silicon Valley, United States.

Kammen D., K. Kapadia and M. Fripp (2004), "Putting Renewables to Work: How many Jobs can the Clean Energy Industry Generate?", Energy Resources Group, Goldman School of Public Policy, University of California, Berkley.

Larcombe, G. (2010), Climate Change, Employment and Local Development: The Case of Landcom, NSW, for OECD LEED

Leiva Gea, A. (2009), El medio ambiente emplea, in Ambienta: La revista del Ministerio de Medio Ambiente $\mathrm{N}^{\circ}$. 84, Spain, in www.mma.es/secciones/biblioteca_publicacion/publicaciones/revista_ambienta/n84/pdf/36fundacio nbiodiv842009.pdf.

Local Government Denmark (2009), Session Summaries from Local Government Climate Change Leadership Summit, 2-4 June 2009, Copenhagen, Denmark.

Martinez-Fernandez, C. (2010), Skills and Employment Strategies in Resource-Intensive Cities: A Global Perspective, in O. Hamm and C. Gräwe (eds.), Bergbau Folge Landschaft/Post Mining Landscapes, Jovis-Verlag: Berlin.

Martinez-Fernandez, C., Hinojosa, C., Miranda, G., "Greening Jobs and Skills: Labour Market Implications of Addressing Climate Change", OECD Local Economic and Employment Development (LEED) Working Papers, No. 2010/02, OECD Publishing.

Michaels, R. and R. Murphy (2009), Green Jobs Fact or Fiction? An Assessment of the Literature, January 2009, Institute for Energy Research.

Miranda, G., et al. (2011a), Climate Change, Employment and Local Development in Extremadura, Spain, OECD Local Economic and Employment Development (LEED) Working Papers, No. 2011/04, OECD Publishing.

Miranda, G., et al. (2011b), Climate Change, Employment and Local Development in London, UK, OECD Local Economic and Employment Development (LEED) Working Papers, No. 2011/05, OECD Publishing.

Miranda, G., et al. (2011c), Climate Change, Employment and Local Development in Sydney, Australia, OECD Local Economic and Employment Development (LEED) Working Papers, No. 2011/14, OECD Publishing.

Miranda, G., et al. (2011d), Climate Change, Employment and Local Development in Poland, OECD Local Economic and Employment Development (LEED) Working Papers, No. 2011/22, OECD Publishing.

New Economics Foundation (2008), A Green New Deal, UK.

OECD (1982), Product Durability and Product Life Extension, OECD Paris 
OECD (1997), Environmental Policies and Employment, Paris.

OECD (1998), Women Entrepreneurs in Small and Medium Enterprises, OECD Paris

OECD/EUROSTAT (1999), The Environmental Goods \& Services Industry: Manual for Data Collection and Analysis, OECD, Paris.

OECD (2003), The Non-profit Sector in a Changing Economy, Paris.

OECD (2004), Environment and Employment: An Assessment, Working Party on National Environmental Policy, Environment Policy Committee, May 2004, OECD, Paris.

OECD (2007a), Climate Change in the European Alps - Adapting Winter Tourism and Hazards Management, Paris.

OECD (2007b), Business and the Environment: Policy Incentives and Corporate Responses, OECD, Paris.

OECD (2008a), Climate Change Mitigation: What do we do?, Paris.

OECD (2008b), Economic Aspects of Adaptation to Climate Change, Paris.

OECD (2008c), Reconciling Development and Environmental Goals, Paris.

OECD (2008d), Venice Action Statement on Enhancing Flexibility in the Management of Labour Market Policy, OECD CFE/LEED (2008)7.

OECD (2008e), More than Just Jobs: Workforce Development in a Skills-Based Economy, Paris.

OECD (2008f), Climate Change, Employment and Local Development, OECD CFE/LEED(2008)15.

OECD (2009a), Integrating Employment, Skills and Economic Development, Paris.

OECD (2009b), Conclusions and Green Growth Declaration, adopted by the Council at Ministerial Level, 25 June 2009, OECD, Paris.

OECD (2009c), The Green Growth Race, OECD Observer, No. 273, June 2009, pp. 47 - 49.

OECD (2009d), "Policy Brief", August 2009, available at: www.oecd.org/dataoecd/1/40/43656443.pdf, accessed 28 August 2009.

OECD (2009e), Eco-Innovation in Industry: Enabling Green Growth, Paris

OECD (2010a), Interim report of the Green Growth Strategy: Implementing our Commitment for a Sustainable Strategy, C(2010)48/REV1, 19 April 2010, OECD internal document.

OECD (2010b), SMEs and Green Growth, Issues Paper for the "BOLOGNA +10” High-level meeting on SMEs and Entrepreneurship: lessons from the global crisis and the way forward to job creation and growth, CFE/SME(2010)9, Paris.

OECD (2010c), Leveraging training and skill development activities in SMEs - Cross-country analysis of the TSME survey, CFE/LEED (2010)14, Paris. 
OECD (2010d), Climate Change, Employment and Local Development: Preliminary Findings, CFE/LEED(2010)15, Paris.

OECD (2010e), Entrepreneurship, SMEs and Innovation, OECD, Paris.

OECD (2011a), Market Development for Green Cars, DSTI/IND(2011)20, Paris.

OECD (2011b), Entrepreneurship at a Glance 2011, Paris

OECD (2011c), Towards Green Growth, Paris

OECD (2011d), Invention and Transfer of Environmental Technologies, Paris

Patt, A., et al. (2010), What Can Social Science tell us about Meeting the Challenge of Climate Change? Five Insights from Five Years that Might Make a Difference, in M. Hulme and H. Neufeldt (eds.), Making Climate Change Work for Us - European Perspectives on Adaptation and Mitigation Strategies, Cambridge University Press Cambridge, pp. 369-388.

Pearce, A. and F. Stilwel (2008), "Green-Collar Jobs: Employment Impacts of Climate Change Policies", Journal of Australian Political Economy, December, No. 62, pp. 120-138.

Pollan Michael (2008), Farmer in Chief, The Food Issue, United States.

Pollin, R. and J. Wicks-Lim (2008), "Job Opportunities for the Green Economy: a State-by-State Picture of Occupations that Gain from Green Investments", Political Economy Research Institute, University of Massachusetts, Amherst.

Pope, A. (1720), "Translation of the Iliad of Homer", Web Editions, Adelaide.

Potts, T. (2010), "The New Green Deal and Knowledge Intensive Service Activities: A Global and Australian Perspective", in C. Martinez-Fernandez and I. Miles (eds.), The Knowledge Economy at Work: Skills and Innovation in Knowledge Intensive Service Activities, Edward Elgar Publishing, UK.

Potts, T. (2010), "The Natural Advantage of Regions: Linking Sustainability, Innovation, and Regional Development in Australia", Journal of Cleaner Production, available at: http://dx.doi.org/10.1016/j.jclepro.2010.01.008.

Prata Dias, G. and T. B. Ramos (2010), Climate Change, Employment and Local Development: The Case of ENEOP Portugal. LEED Working Papers Series, OECD

Présidence de la République (2009), Déclaration de M. le Président de la République devant le Parlement Réuni en Congres à Versailles, 22 June 2009, available at:

www.elysee.fr/documents/index.php?mode $=$ cview\&press_id=2723\&cat_id=7\&lang=fr, accessed 5 January 2010.

Reckien, D., T. Grothmann and T. Egli (2009), "Klimafolgen und Anpassungsmaßnahmen in Verkehr und Mobilität", in: T. Grothmann, D. Krömker, A. Hornburg, and B. Siebenhüner (eds.), KyotoPlusNavigator - Praxisleitfaden zur Förderung von Klimaschutz und Anpassung an den Klimawandel Erfolgsfaktoren, Instrumente, Strategie, pp. 283-334, available at: www.erklim.de, accessed April 2009. 
Renner, M., M. Ghani-Eneland, and A. Chawla (2009), Low-Carbon Jobs for Europe: Current Opportunities and Future Prospects, June 2009, World Wide Fund for Nature, Brussels.

Schofield, C. and T. Potts (2009), "Across the Top of the World? Emerging Arctic Navigational Opportunities and Arctic Governance". Carbon and Climate Law Review, No. 4, pp. 472-482.

Selwyn, J. and B. Leveret (2006), Emerging Markets in the Environmental Industries Sector, CEED, UK.

Stern, Nicholas (2006), The Economics of Climate Change, The Stern Review, Cambridge University Press.

Stiglitz, J. (2009), "Regulation and Failure", in D. Moss and J. Cisternino (eds.), New Perspectives on Regulation, available at: www.tobinproject.org/twobooks/, accessed 15 August 2009.

Tether, B., Mina, A., Consoli, D. and Gagliardi, D. (2005), A Literature Review on Skills and Innovation. How Does Successful Innovation Impact on the Demand for Skills and How Do Skills Drive Innovation? ESRC Centre on Innovation and Competition, University of Manchester.

TUAC (2008), Outreach, Reform and the Economics of Climate Change, Paris.

TUC (2009), Unlocking Green Enterprise: A Low-Carbon Strategy for the UK Economy, Pamphlet 5, UK.

TUAC (2009), "Trade Unions Statement to the Pittsburgh G20 Summit: Global Unions Pittsburgh Declaration", available at: www.tuac.org/fr/public/e-docs/00/00/05/57/document_doc.phtml, accessed 20 October 2011.

UNECE, OECD, Eurostat (2009), Measuring Sustainable Development, available at www.unece.org/stats/archive/03.03f.e.htm.

United States Department of Labour (2009), A Woman's Guide to Green Jobs, Washington.

UNDP/UNEP (2008), Making the Economic Case - a Review of Approaches for Improving the Economic Analysis of Environment and Natural Resources in National Development Planning, Nairobi.

UNEP, ILO, IOE, ITUC (2008a), Green Jobs - Towards Decent Work in a Sustainable, Low-Carbon World, report produced by Worldwatch Institute and commissioned by UNEP, ILO, IOE, ITUC, Nairobi.

UNEP (2008b), Background Paper on Green Jobs, Nairobi.

UNEP (2008), Global Trends in Sustainable Energy Investment 2008, UNEP.

Vogel, D. (2003), The Hare and the Tortoise Revisited: The New Politics of Consumer and Environmental Regulation in Europe, British Journal of Political Science, Vol. 33, No. 4, October 2003, pp. 557580, Cambridge University Press.

Wiener, J. (1999), "Global Environmental Regulation: Instrument Choice in Legal Context", The Yale Law Journal Company, Inc., January, Vol. 108, No. 4, pp. 677-800.

Wider Opportunities for Women-WOW (2008), Fact Sheet: The Green Jobs Act of 2007, USA. www.WOWonline.org 
Wider Opportunities for Women-WOW (2009), Women and the Green Economy, An Opportunity for Economic Security, USA. www.WOWonline.org

Woodward, A., S. Hales and P. Weinstein (1998), Climate Change and Human Health in the Asia Pacific Region: Who Will be Most Vulnerable?, Department of Public Health, Wellington School of Medicine, University of Otago, New Zealand.

World Commission on Environment and Development (1987), Our common future, Oxford University Press, Oxford. www.worldinbalance.net/pdf/1987-brundtland.pdf

World Watch Institute (2008), Green Jobs - Towards Decent Work in a Sustainable, Low-Carbon World, UNEP and ILO.

\section{Press references}

CNN.com, French Toxic Ship Ends Global Odyssey, February $8^{\text {th }} 2009$.

Financial Times, Eco-groups Fear an Opportunity Lost, March $4^{\text {th }} 2009$.

Le Monde, L'économie verte promet des millions d'emplois, September 26 2008.

Stiglitz J. and Stern N., Obama's Chance to Lead the Green Recovery, in Financial Times, $3^{\text {rd }}$ March 2009.

The Economist, The Green Pound, November $15^{\text {th }} 2008$.

The Economist, The People Puzzle, January $3^{\text {rd }} 2009$.

The Guardian (2009), "Boris Johnson Announces London's 10 'Low-Carbon Zones'", 3 September 2009, available at: www.guardian.co.uk/environment/2009/sep/03/london-low-carbon-zones, accessed 10 October 2009. 



\section{For more information, see www.oecd.org/greengrowth}

\section{GREEN GROWTH STRATEGY}

\section{STRATÉGIE POUR UNE CROISSANCE VERTE}

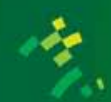

.

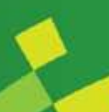

(4)

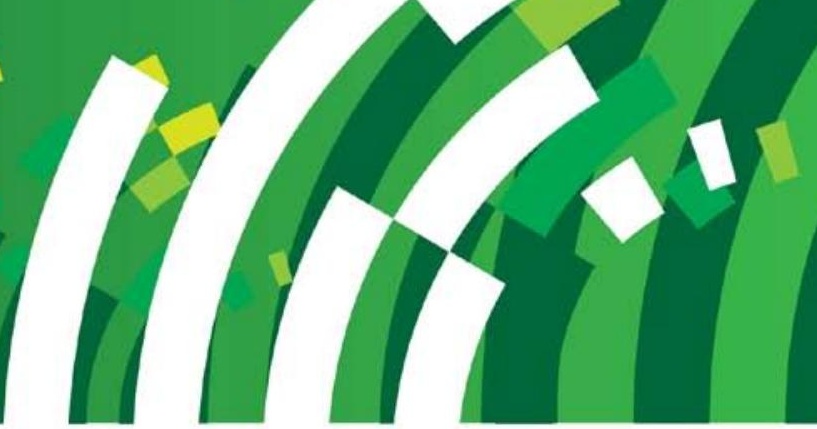

This report has been prepared with the support of the European Commission, DG Employment, Social Affairs and Equal Opportunity.

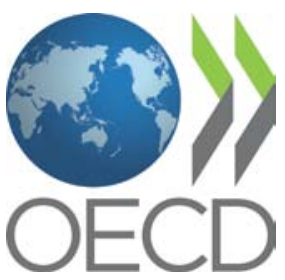

